Influencia de las expectativas y la calidad de vida en el estado de ánimo durante la transición menopáusica 


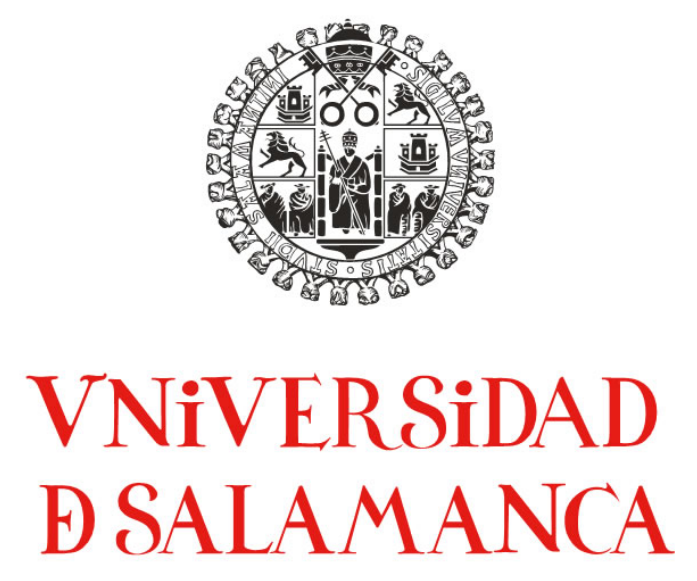

\section{Influencia de las expectativas y la calidad de vida en el estado de ánimo durante la transición menopáusica}

Salamanca, 2008 


\section{UNIVERSIDAD DE SALAMANCA}

\section{FACULTAD DE MEDICINA}

Departamento de Psiquiatría y Psicología Médica, Medicina

Legal e Historia de la Ciencia

\section{Influencia de las expectativas y la calidad de vida en el estado de ánimo durante la transición menopáusica}

Autor:

Jesús Sánchez Hernández

Directores:

Dra. Ma Ángeles Díez Sánchez

Dr. Jesús J. de la Gándara Martín 
Ma ÁNGELES DÍEZ SÁNCHEZ, PROFESORA TITULAR DEL ÁREA

DE PSIQUIATRÍA DE LA FACULTAD DE MEDICINA DE LA UNIVERSIDAD DE SALAMANCA y JESÚS J. DE LA GÁNDARA MARTÍN JEFE DEL SERVICIO DE PSIQUIATRÍA DEL COMPLEJO ASISTENCIAL DE BURGOS

\section{CERTIFICAN:}

Que el presente trabajo de Tesis Doctoral titulado "Influencia de las expectativas y la calidad de vida en el estado de ánimo durante la transición menopáusica" y realizado por D. Jesús Sánchez Hernández, licenciado en Psicología, reúne a nuestro criterio, méritos suficientes de originalidad, rigor y erudición científica para que su autor pueda optar con él al Grado de Doctor.

En Salamanca, a 31 de marzo de 2008 
A Vega

A mis padres 


\section{AGRADECIMIENTOS}

La realización de cualquier trabajo de investigación requiere la colaboración, implicación y motivación de bastantes personas, sin todas ellas no hubiera podido finalizar este estudio, ni superar los momentos de dificultades y silencios.

En primer lugar, tengo dificultad para describir lo que ha supuesto, tanto a nivel personal como profesional, la Profesora $\mathrm{M}^{\mathrm{a}}$ Ángeles Díez en mi formación, en mi interés por la Psicología y por la investigación clínica. Gracias por transmitirme tu humanidad como herramienta imprescindible, y por tus consejos ante las disyuntivas que han surgido en mí todavía incipiente carrera profesional.

De igual modo, agradezco a mi codirector, el Dr. Jesús De la Gándara, por su motivación constante, por transmitirme el concepto de salud mental relacionada con la mujer como un campo apasionante, y por orientarme siempre hacia objetivos precisos.

La aceptación de los Dres. Arnaiz y Aragón para participar en este estudio ha sido fundamental en la recogida de muestra y también debo destacar la importancia del Dr. Hernández en sus aclaraciones estadísticas, cuando más perdido estaba y las dudas eran mayores que las intenciones. De igual modo, agradezco a la Unidad de Investigación del Hospital General Yagüe y, en especial a su directora la Dra. M $^{\mathrm{a}}$ Jesús Coma, por su motivación para fomentar la investigación y las facilidades ofrecidas.

A mis compañeros del $2^{\circ}$ Distrito de Salud Mental, a los que les debo su interés, comprensión y cariño, que me demuestran en nuestra rutina diaria.

Sin duda, este trabajo se debe a la incondicionalidad de mi mujer y a la valoración del esfuerzo que siempre me ha transmitido mi familia. Gracias Eva, por tú tiempo y tú 
entusiasmo ante cualquier reto y cualquier circunstancia, gracias por compartir conmigo cada instante de cada ilusión. A mis padres, por su sacrificio y por anteponer mi formación a cualquier aspecto de sus vidas. Gracias por enseñarme a encontrar luces en momentos de sombras. A mis hermanos, por su apoyo y cariño desde la distancia, que siempre se acorta al tenernos tan presentes.

Por último, a las mujeres participantes en este estudio por permitirme conocer sus sentimientos y emociones en una etapa importante de sus vidas. 
Este proyecto ha contado para su desarrollo con el apoyo del Fondo Caja de Burgos de Investigación Clínica y de la Dirección General de la Mujer de la Junta de Castilla y León. 


\section{INDICE:}

1.JUSTIFICACIÓN................................................ 12

2.-ASPECTOSCONCEPTUALES............................... 16

2.1. Envejecimiento ..................................... 17

2.1.1.Evolución histórica...............................

2.1.2. Conceptualización y condicionantes ........... 26

2.1.3.Envejecimiento femenino...................... 32

2.2. Climaterio y menopausia.................................. 38

2.2.1. Evolución histórica............................. 38

2.2.2. Concepto, sintomatología y condicionantes ....... 43

2.2.3. La menopausia como indicador del envejecimiento... 68

3.-VARIABLES PSICOLÓGICAS Y MENOPAUSIA.............. 71

3.1. Expectativas y menopausia $\ldots \ldots \ldots \ldots \ldots \ldots \ldots \ldots \ldots \ldots . \ldots \ldots$

3.2. Calidad de vida en la menopausia ................... 92

3.3. Estado e ánimo y menopausia ...................... 109

4.- OBJETIVOS E HIPÓTESIS....................................... 127

5.-METODOLOGIA ............................................... 129

5.1. Muestra ........................................... $\quad 130$

5.2. Batería de instrumentos........................... 134

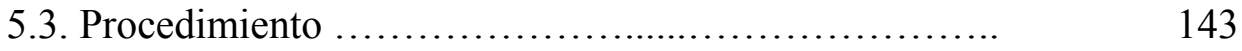


5.4. Análisis de datos

6.- RESULTADOS Y DISCUSIÓN

6.1. Resultados descriptivos

6.2. Resultados inferenciales

7.- CONCLUSIONES.

8.- REFERENCIAS BIBLIOGRÁFICAS............................ 
Justificación 


\section{1.- JUSTIFICACIÓN}

El Consejo Económico y Social perteneciente a la Comisión Económica de la Unión Europea ha publicado recientemente las conclusiones de la Conferencia de la ONU sobre Envejecimiento de la Región Europea de la Organización de Naciones Unidas celebrada en nuestro país, en la ciudad de León en Noviembre de 2007. Esta Conferencia finalizó con una Declaración Ministerial titulada: “Una sociedad para todas las edades: retos y oportunidades" de 2008, en que se determinan conclusiones y proyectos de actuación en el futuro. Una de estas conclusiones incide en la necesidad de una mayor implicación de la sociedad con las personas mayores y necesidad de lograr una integración de los programas dirigidos a este grupo de edad dentro de las acciones comunitarias. De forma específica, se determina que es necesario impulsar el papel de las mujeres en todas las políticas destinadas a personas mayores, aún más teniendo en cuenta que son mayoría entre las personas de edad.

El informe de la II Asamblea Mundial sobre Envejecimiento celebrada en Madrid (2002) predice que en el año 2020, nuestro país será uno de los más envejecido de todo el planeta. El envejecimiento es el principal problema con el que se enfrenta la sociedad y, concretamente, las instituciones sanitarias y sociales. Las características sociodemográficas indican un aumento significativo mayor en la esperanza de vida de las mujeres, principalmente en países desarrollados, siendo las mujeres mayores las mayores demandantes de atención sanitaria.

Sin duda, el climaterio supone la evidencia más determinante del envejecimiento femenino y, de forma más concreta, la menopausia. Este momento evolutivo, supone la ruptura con algunas de las características definitorias de la mujer (capacidad reproductora, rol maternal, esplendor físico, etc.), y deben recomponer el 
papel a desempeñar en las principales áreas vitales. Pero esta reconstrucción es un proceso que puede no ser fácil y estar condicionada por factores que provoquen desadaptacion (desocupación laboral, escasas relaciones interpersonales, relación de pareja escasamente armónica, etc.) o por síntomas propios de la transición menopáusica.

Consideramos que es necesario intentar especificar qué variables pueden ayudarnos a predecir si la mujer va a aprovechar esta transición fisiológica para establecer nuevas estrategias y objetivos vitales, que conlleven aun envejecimiento saludable, mediante unas expectativas adecuadas y adaptativas. Esta afirmación está confirmada en la literatura especializada por diversos estudios, entre ellos, el desarrollado en Dinamarca (2006) por Hvas, quien concluye que no puede haber discusión en el papel fundamental que juegan las expectativas de las mujeres en relación con su envejecimiento y con la menopausia, en suma, en el afrontamiento de esta etapa de su vida. En este sentido, una investigación americana liderada por Leggetts (2007), reitera la necesidad de convencer a las mujeres de mediana edad mediante información objetiva, que se encuentran en una etapa de grandes oportunidades.

También es de gran interés la percepción subjetiva de calidad de vida que tienen las mujeres en esta etapa de su vida. Existe una opinión a nivel social, casi generalizada, según la cual el descenso en la percepción de la calidad de vida está asociado a la transición menopáusica. Las investigaciones científicas en cambio, muestran un amplio espectro de opiniones entre los profesionales unos opinan que sí existe un decrecimiento en el bienestar de la mujer y otros consideran que se trata de una etapa más en la vida femenina y su calidad de vida dependerá de su historia vital 
y de los recursos personales para afrontar sus vivencias. Entre los autores que adoptan la primera postura cabe destacar a Lain (2006), en cambio las investigaciones más recientes muestran una tendencia a considerar la menopausia un continuo en la vida de cada mujer, no un estadío con características peculiares que potencian una peor percepción de la calidad de vida (Chen, 2007; Lindh-Astrand, 2007).

De igual modo, existe otra variable que presenta controversia de forma recurrente, en la investigación científica sobre menopausia, es el estado de ánimo y qué variables pueden predecir o explicar esa afectación del humor. En este sentido, el posicionamiento bipolar en las distintas investigaciones es todavía más acentuado, desde las que consideran que la menopausia conlleva un estado de ánimo depresivo (Tatebayashi, 2007; Freeman, 2007), y las que tienen en cuenta las diferencias individuales para explicar cualquier alteración del humor durante esta etapa (Rohde, 2007; Callegari, 2007).

Por todo ello, nos proponemos investigar si las mujeres en la transición menopáusica presentan alteraciones del humor y con qué intensidad, determinando qué factores influyen en el estado de ánimo evaluando qué relación existe entre la intensidad de la sintomatología depresiva, la percepción de calidad de vida relacionada con la salud y los síntomas climatéricos.

Siendo el objetivo general del estudio:

Estudiar qué tipo de variables personales, como las expectativas y la calidad de vida percibida, podrían explicar el estado de ánimo de la mujer en la transición menopáusica. 
Influencia de las expectativas y la calidad de vida en el estado de ánimo durante la transición menopáusica 


\section{Aspectos conceptuales}




\section{2.- ASPECTOS CONCEPTUALES}

\subsection{Envejecimiento}

\subsection{1- Evolución histórica}

Los sinónimos de la palabra viejo son veintidós y para el vocablo anciano treinta y tres, (Ribera, 1995), pero quizás sean más y la mayor parte de ellos son utilizados como expresiones peyorativas.

Cuando una palabra, en este caso "viejo", posee tan variados sinónimos significa que el objeto es de larga historia. En este sentido, uno de los textos más antiguo conocido es el de un anciano autoanalizándose. Se trata de un escriba egipcio, Ptah-Hotep, visir del faraón Tzezi de la V dinastía, por tanto redactado hacia el año 2450 A.C., que dice: "¿Qué penoso es el fin de un viejo! Se va debilitando cada día; su vista disminuye, sus oídos se vuelven sordos; su fuerza declina, su corazón ya no descansa; su boca se vuelve silenciosa y no habla. Sus facultades intelectuales disminuyen y le resulta imposible acordarse hoy de lo que sucedió ayer. Todos los huesos están doloridos. Las ocupaciones a las que se abandonaba no hace mucho con placer, sólo las realiza con dificultad, y el sentido del gusto desaparece. La vejez es la peor de las desgracias que puede afligir a un hombre"( Debray; 1995).

Sin embargo, aunque los ancianos prehistóricos no dejaron, por supuesto, registro de sus actividades o pensamientos, podemos imaginar con cierta seguridad cuál fue su condición al comprobar que todas las culturas ágrafas que conocemos tienen una consideración parecida hacia sus senectos. Su longevidad es motivo de orgullo para el clan, por cuanto eran los depositarios del saber, la memoria que los contactaba con los antepasados. Muchos de ellos se constituían en verdaderos intermediarios entre el presente y el más allá. No es de extrañar que los brujos y 
chamanes fuesen hombres mayores. Ejercían también labores de sanación, de jueces y de educadores. En aquellas sociedades, y ajeno a su edad, no era infrecuente que denominaren "ancianos" a quienes ejercían labores importantes. En otras palabras la vejez representaba la sabiduría, el archivo histórico de la comunidad (Trejo, 2001).

La Grecia antigua cuna de la civilización occidental, dio en herencia nuestra concepción del mundo. Para esos griegos adoradores de la belleza, la vejez, con su deterioro inevitable, no podía menos que significar una ofensa al espíritu, motivo de mofa en sus comedias. Las numerosas leyes atenienses que insisten en el respeto a los padres ancianos nos hacen suponer que no eran muy acatadas. La vejez fue considerada en sí misma una tara. Platón relaciona la vejez feliz a la virtud, cuando dicen en La República: pero aquel que nada tiene que reprocharse abriga siempre una dulce esperanza, bienhechora, nodriza de la vejez. (Lledó, 1988).

El reverso lo constituye el hecho que es en Grecia donde por primera vez se crean instituciones de caridad preocupadas del cuidado de los ancianos necesitados. Vitruvio relata sobre la casa de Creso, destinada por los sardianos a los habitantes de la ciudad que, por su edad avanzada, han adquirido el privilegio de vivir en paz en una comunidad de ancianos a los que llaman Gerusía (Platón, 1974).

La otra gran fuente cultural de nuestra civilización occidental proviene de la tradición hebreo-cristiana. Sin lugar a dudas, el mejor lugar para descubrir la historia de este pueblo semita la encontramos en las cuarenta y cinco obras del Antiguo Testamento, que abarcan aproximadamente un milenio de acontecimientos. El relato de sus avatares desde el siglo IX al I A.C. permite comprender que los ancianos ocuparon un lugar privilegiado. En su período de nomadismo cumplieron una función importante en la conducción de su pueblo (Ex 3:16). 
En el Libro de los Números encontramos la descripción de la creación del Consejo de Ancianos como una iniciativa Divina: "Entonces dijo Yahvé a Moisés: Elígeme a setenta varones de los que tú sabes que son ancianos del pueblo y de sus principales, y tráelos a la puerta del tabernáculo... para que te ayuden a llevar la carga y no la lleves tú solo" (Nm 11:16 y 17).

Otra fuente importantísima de nuestra civilización occidental proviene de la cultura romana. El notable nivel alcanzado por el Derecho contribuyó a preocuparse por la duración de la vida humana. La Tabla de Ulpiano tenía por objeto evaluar la importancia de las rentas vitalicias asignadas por legados según la edad del beneficiario. De esta tabla, basada en observaciones empíricas, podemos hacernos una idea verosímil de la esperanza de vida de los romanos para cada edad. Se establece que existía un mayor número de ancianos varones que de ancianas, situación inversa a la actual, la causa, posiblemente se debía a las muertes maternas post parto. Las consecuencias de este perfil demográfico se manifestó en matrimonios frecuentes de viejos con jóvenes.

El mundo romano evidenció un envejecimiento a partir del siglo II, en particular en Italia. El Derecho Romano tipificaba la figura jurídica del "pater familia" que concedía a los ancianos un gran poder, que además era vitalicio y su autoridad ilimitada, pudiendo incluso disponer de la vida de un integrante de su familia. La "mater familia" jugaba un papel secundario pero, en general, gozaba de la simpatía y connivencia de la prole.

El Cristianismo naciente vivía sus dificultades por sobrevivir en un ambiente difícil y urgidos por evangelizar. Los ancianos no fueron de interés para los escritores de la Iglesia, la gran excepción fue San Gregorio Magno. Las reglas monásticas 
tampoco les concedieron privilegios, pues concebían la idea que la vejez verdadera era la sabiduría. La iglesia desde sus inicios se preocupaba de los desheredados y pobres, entre los cuales, los ancianos abundaban. A partir del siglo III los hospitales cristianos empezaron a ocuparse de ellos.

La denominada "Edad Oscura" o "Alta Edad Media", del siglo V al X, es la época de la brutalidad y del predominio de la fuerza. En semejante ámbito cultural, no es difícil imaginar el destino de los débiles, lugar que les corresponde a los ancianos. Serán acogidos temporalmente en los hospitales y monasterios, para luego reencontrarse con la persistente realidad de sus miserias.

Su nueva convicción les hacía revelarse frente a los incrédulos, donde frecuentemente estaban sus viejos padres. El respeto a la obediencia de sus progenitores se impuso cuando la sociedad europea estuvo cristianizada en su mayoría. Hoy casi no podemos imaginar que desde el siglo VI la Iglesia será la principal, casi la única, institución de unión de una Europa Occidental. Época de contrastes y confusión, de yuxtaposición de costumbres bárbaras y romanas. Primó la ley del más fuerte, por tanto, los ancianos estaban desfavorecidos.

La Iglesia se pronuncia en las reglas monásticas, la más influyente, la de San Benito, que considera el trato hacia los ancianos equivalente al de los niños. La "Regla del Maestro", conjunto de reglas monásticas del siglo IX, desplaza a los ancianos a labores de portero o pequeños trabajos manuales (Gafo, 1995).

Los siglos XI al XIII tuvieron un florecimiento económico y estabilidad social. Nunca Europa estuvo más unida. A partir del siglo XIII, debido al desarrollo material, se fortalecieron los Estados y se multiplicaron las guerras. Los ancianos 
tuvieron una nueva oportunidad en el mundo de los negocios. Su actividad dependía sólo de su capacidad física, no siendo, en general, segregados por su condición etaria.

Las pulgas, portadoras de la Yersinia pestis, no incidieron en los ancianos, sino preferentemente en niños y jóvenes. Más tarde, en el siglo XV, sucedió lo mismo con la viruela. Dicho de otra manera, se produjo un fuerte incremento de ancianos entre 1350 y 1450. La desintegración parcial de la familia provocada por la peste se tradujo en un reagrupamiento -familias extendidas. Los ancianos, en ocasiones, se convirtieron en patriarcas, la vinculación entre las generaciones se vio facilitada.

Durante el siglo XV las gentes se fueron entusiasmando con el descubrimiento de las bellezas escondidas del mundo romano que yacía sepultado. El hallazgo de cualquier manuscrito excitaba la imaginación y la admiración. Los humanistas ocuparon un lugar de respeto. Les atraían los griegos antiguos, cultivadores de la belleza, juventud y perfección, rechazando sin disimulo la vejez que representaba fealdad, decrepitud y decadencia. Fueron, quizás, los tiempos más agresivos contra los ancianos. Pero, más encono aun, contra las ancianas. Refleja este sentir el más grande humanista de le época, Erasmo, que en su Elogio a la locura nos dice: "Pero lo que verdaderamente resulta más divertido es ver a ciertas viejas, tan decrépitas y enfermizas como si se hubieran escapado de los infiernos, gritar a todas las horas "viva la vida""(Erasmo, 1993).

La menor violencia durante el siglo XVI permite a los varones llegar a edades más avanzadas. En los medios aristocráticos acontece lo mismo con las mujeres, rompiendo con lo que había sido la tradición a consecuencia de una mejor higiene en la atención de los partos en ese medio social. Es probable que la actitud de cortesanos 
y humanistas respecto a la vejez era sólo una postura literaria, pues en la realidad cotidiana, la relación era más benevolente.

El pensamiento liberal y sus consecuencias políticas revolucionarias que derivan en la formación de repúblicas, significó no solamente un cambio de poder, sino también la aparición de un contingente nuevo de ciudadanos: los burócratas. El Estado moderno es impersonal, reglamentado y el poder se hace representativo, delegación del pueblo. En la actualidad, un hito muy significativo en la biografía de todo ciudadano trabajador, es la jubilación; palabra tomada del latín jubilare que significaba "lanzar gritos de júbilo"(Coralina, 1980).

Pretender efectuar una síntesis, sacar conclusiones de lo que ha sido el siglo veinte, resulta imposible, hasta ingenuo. Tres características relevantes se manifiestan hoy día: por una lado, la ya referida complejidad que hace inevitable el pluralismo. El abigarramiento en grandes megapolis en las cuales nunca antes cohabitaron tantas generaciones simultáneamente (subproducto del aumento de la esperanza de vida). De tal modo que ya no se comparten los mismos horizontes y el encuentro entre extraños culturales se hace usual. Y finalmente, el advenimiento de la tecnociencia, cuya preponderancia nos ha conducido a su veneración y también a su temor. Su poder ha sido tan avasallador que ha modificado todos los ámbitos de la vida humana, pero quizás esta cultura tecnocientífica, es la que más ha influido en la vida de los ancianos.

Las nuevas condiciones de vida creadas por la tecnociencia no sólo ha envejecido a los pueblos, sino que ahora el grupo de mayor velocidad de crecimiento entre las sociedades democráticas neotecnológicas lo constituye la población sobre 
los 85 años (Jecker, 1997). La más amplia proporción de viudas está en directa relación a la mayor expectativa de vida de las mujeres,

Otro impacto digno de mencionar se refiere a la llamada liberación femenina y al cambio de la consideración del cuerpo y de la sexualidad. La tecnociencia, asimismo, ha desempeñado una gran función, Karl Popper sostiene que la primera liberación femenina se produjo en 1913 con la invención del hornillo a gas (Popper; 1995) y, después, con toda la tecnología al servicio del hogar que permitió a las mujeres gozar de tiempo libre, que muchas dedicaron al estudio y al trabajo fuera de su morada y a optar por labores mejor remuneradas. Pero, además, salir de los límites, demasiado estrechos y fatigantes de su vivienda, para contactar horizontes más amplios.

La segunda etapa importante de liberación sucedió con el hallazgo de las drogas anticonceptivas que separó, conscientemente, la procreación de la sexualidad e hizo más evidente lo que es la sexualidad de los seres humanos. Finalmente, se llegó a una familia reducida, a una sexualidad sin procreación, a la convivencia en pareja y a una adolescencia prolongada.

El envejecimiento actual de la población se puede considerar como el mayor desafío sanitario en el inicio del siglo XXI ya que el aumento significativo de la esperanza de vida impondrá mayores exigencias económicas y sociales a todos los países. La humanidad está envejeciendo más rápido de lo previsto, tras dos milenios sin apenas variaciones, la esperanza de vida media ha experimentado durante el siglo XX un salto espectacular en la mayoría de los países desarrollados.

La ONU ha abordado el envejecimiento desde 1948, cuando la Asamblea General aprobó la resolución 213 (III) relativa al proyecto de declaración de 
Derechos de la Vejez. Desde entonces, el tema fue estudiado de forma indirecta por la Asamblea y por los organismos interesados en las cuestiones sociales. En 1977 el envejecimiento fue abordado de forma directa cuando se hizo énfasis en la necesidad de organizar una Asamblea Mundial sobre personas mayores y se acordó que esa conferencia tuviera lugar en 1982, en Viena. (NN.UU, 1994).

Desde entonces, Naciones Unidas han adoptado importantes medidas en relación con el envejecimiento y las personas mayores como el Plan de Acción Internacional sobre Envejecimiento, los Principios de las Naciones Unidas a favor de las personas de edad, la proclamación de 1999 como Año Internacional de las personas mayores bajo el lema "una sociedad para todas las edades" y, por último, el Plan de Acción Internacional de Madrid sobre el Envejecimiento 2002, adoptado en la Segunda Asamblea Mundial sobre el Envejecimiento (NN.UU., 2002).

Dentro de esta institución ha tomado un papel primordial en la comprensión, evaluación y desarrollo de programas sobre el envejecimiento ha sido la Organización Mundial de la Salud (OMS). En 1995, cuando la OMS cambió de nombre su "Programa de Salud de las Personas Mayores" por el de "Envejecimiento y Salud", marcó un importante cambio de orientación. (OMS, 1998). En vez de aislar en categorías a las personas mayores, el nuevo nombre consideraba una perspectiva de todo el curso vital: todos envejecemos y la mejor manera de asegurar una buena salud para las futuras generaciones de personas mayores es prevenir las enfermedades y promover la salud durante todo el ciclo vital. Por el contrario, sólo se entenderá la salud de aquellos que actualmente se encuentran en la vejez si se tiene en cuenta los acontecimientos de la vida por los que han pasado. 
El objetivo del Programa de Envejecimiento y Salud ha sido desarrollar políticas que aseguren "el logro de la mejor calidad de vida posible, para el mayor número de personas posible”. Este programa destaca la importancia de (OMS, 2002):

- Adoptar estrategias basadas en la comunidad, resaltando a ésta como el ámbito fundamental para las intervenciones.

- $\quad$ Respetar los contextos y las influencias culturales.

- Reconocer la importancia de las diferencias entre hombres y mujeres..

- Fortalecer vínculos entre generaciones.

- Respetar y conocer los problemas éticos relacionados con la salud y el bienestar en la vejez.

El “Año Internacional de las Personas de Edad” (1999) marcó un hito en la evolución del trabajo de la OMS sobre el envejecimiento y salud. Ese año, el tema del Día Mundial de la Salud fue "el envejecimiento activo marca la diferencia", poniéndose en marcha el Movimiento Global para el Envejecimiento Activo (OMS, 1999).

En el año 2000, el nombre del programa de la OMS se volvió a cambiar a "Envejecimiento y Ciclo Vital" para reflejar la importancia de una perspectiva que abarque todas las fases de la vida., manteniéndose el enfoque múltiple del programa anterior y el énfasis puesto en el desarrollo de actividades desde todos los sectores y disciplinas diferentes (OMS, 2000). 


\subsubsection{Conceptualización y condicionantes}

La definición más académica de envejecimiento indica que es “el conjunto de modificaciones morfológicas y fisiológicas que aparecen como consecuencia de la acción del tiempo sobre los seres vivos, que supone una disminución de la capacidad de adaptación en cada uno de los órganos, aparatos y sistemas, así como de la capacidad de respuesta a los agentes lesivos que inciden en el individuo” ( Binet y Bolurlieére, 1982 ). Otra conceptualización académica, es la que hace referencia a un "fenómeno normal, inevitable y biológico resultante de la involución heterocrónica del paso del tiempo, pero ordenada con cambios celulares y bioquímicos, morfológicos y psicológicos que se da en la raza humana y demás animales” ( Belsky, 1996).

Más concisa, desde el punto de vista gerontológico, es la que considera al envejecimiento como un proceso de deterioro progresivo del organismo que concluye con alteraciones funcionales irreversibles. Los cambios se producen a nivel morfológico, psicológico, bioquímico y funcional ( Buendía, 1994 ).

Desde un punto de vista gerontológico, el envejecimiento puede definirse como la suma de todas las alteraciones que se producen en un organismo con el paso del tiempo y que conducen a pérdidas funcionales y a la muerte. Puede afirmarse que se inicia cuando finaliza el desarrollo. No obstante es un parámetro relativo pues algunos autores consideran que el envejecimiento se manifiesta a partir del momento de la máxima vitalidad (alrededor de los 30 años en el hombre). Sin embargo, no todos los individuos envejecen al mismo tiempo, ni todos los órganos, ni todos los sistemas del mismo individuo lo hacen a la vez. Existe, pues, un envejecimiento 
diferencial entre individuos de la misma especie y entre órganos del mismo individuo (Lanussa, 2000).

El envejecimiento es una más de las etapas del ciclo vital, junto a la infancia, la adolescencia y la edad adulta. Y, en esta etapa, al igual que en las anteriores se producen una serie de cambios físicos, psicológicos y sociales, si bien no se producen en el mismo momento y grado en todas las personas, ya que se trata de un proceso dinámico, de tal forma que el envejecer tiene diversas trayectorias junto con la variabilidad interindividual (Muñoz, 2002). En esta etapa no sólo se producen pérdidas, sino que hay funciones o capacidades que mantienen su actividad o incluso pueden llegar a mejorar.

En este sentido, se deben diferenciar tres términos ya que suponen tres tipos de envejecimiento (Laforest, 1991):

\section{a) Envejecimiento normal}

El envejecimiento normal o primario, implica una serie de cambios graduales biológicos, psicológicos y sociales asociados a la edad, que son intrínsecos e inevitables, y que ocurren como consecuencia del paso del tiempo.

\section{b) Envejecimiento patológico}

El envejecimiento patológico o secundario, hace referencia a los cambios que se producen como consecuencia de enfermedades, malos hábitos, etc., y, que no forman parte del envejecimiento normal y que, en algunos casos, pueden prevenirse o son reversibles.

\section{c) Envejecimiento óptimo}


Es el envejecimiento que tendría lugar en las mejores condiciones posibles (físicas, psicológicas, sociales), teniendo en cuenta los múltiples factores que intervienen en este proceso es el proceso deseable por todas las personas ya que implica pocas pérdidas o ninguna e incluye una baja probabilidad de presencia de enfermedades.

El envejecimiento satisfactorio lo obtienen aquellas personas mayores que favorecen la promoción de su salud (física y psicológica), fomentando su autonomía, mediante la práctica de ejercicio físico o el entrenamiento de sus capacidades cognitivas, mejorando su autoestima, manteniendo hábitos de vida saludables, etc., de forma que eviten, en la medida de lo posible la dependencia y el aislamiento con el establecimiento, por ejemplo de redes sociales. La puesta en marcha de estos aspectos influirá de forma positiva en la calidad de vida, experimentando un envejecimiento óptimo.

Son muchos los distintos conceptos o especificaciones dentro del término "envejecimiento" que se pueden describir y especificar pero teniendo en cuenta la postura de los principales organismos anteriormente descritos, cabe resaltar los dos siguientes:

\section{a) Envejecimiento global}

Hace referencia al efecto generalizado del envejecimiento en la población mundial. En todo el mundo (Kalache, 2000), la proporción de personas que tienen 60 años o más, está creciendo con más rapidez que ningún otro grupo de edad. Entre 1970 y 2025, se prevé que la población con más edad aumente en unos 694 millones (el 223 por ciento). En 2025, se estima que habrá un total de 1.200 millones de personas con más de 60 años. 


\section{b) Envejecimiento activo}

El envejecimiento activo es el proceso de optimización de las oportunidades de salud, participación y seguridad con el fin de mejorar la calidad de vida a medida que las personas envejecen. Este término se aplica tanto a los individuos como a grupos de población. Permite a las personas realizar su potencial de bienestar físico, social y mental a lo largo de todo su ciclo vital y participar en la sociedad de acuerdo con sus necesidades, deseos y capacidades, mientras que les proporciona protección, seguridad y cuidados adecuados cuando necesitan asistencia.

El término "activo" hace referencia a una participación continua en las cuestiones sociales, económicas, culturales, espirituales y cívicas, no sólo a la capacidad para estar físicamente activo. El envejecimiento activo trata de ampliar la esperanza de vida saludable y la calidad de vida para todas las personas a medida que envejecen.

Así pues, el envejecimiento es un fenómeno muy complejo y variable. No sólo los organismos de la misma especie envejecen a ritmos distintos, sino que el ritmo del proceso varía dentro del organismo de cualquier especie. Las razones de que sea así no se conocen en su totalidad. Los factores el entorno también influyen sobre la duración de la vida y el momento de la muerte (Dychtwald, 1986).

El envejecimiento depende de una gran diversidad de influencias o determinantes que rodean a las personas. Estos determinantes pueden aplicarse a la salud de todos los grupos de edad pero se acentúa su influencia en la salud y calidad de vida de las personas de edad más avanzada. Un primer factor que explicaría la importancia creciente del envejecimiento es la revolución demográfica. Las tasas de fertilidad decrecientes y un aumento de la longevidad son factores que asegurarán el 
envejecimiento continuo de la población mundial. En todo el mundo se observan fuertes disminuciones de las tasas de fertilidad, calculándose que para el año 2025, 120 países habrán alcanzado tasas de fertilidad total por debajo de la tasa de sustitución (Lynch, 2000).

Hasta ahora el envejecimiento de la población se había asociado principalmente con las regiones más desarrolladas del mundo (tabla 1), actualmente nueve de los diez países con más de diez millones de habitantes y la mayor proporción de personas mayores está en Europa.

Tabla 1: Evolución de personas mayores en Europa

\begin{tabular}{lll}
\hline & $\mathbf{2 0 0 2}$ & $\mathbf{2 0 0 5}$ \\
& & \\
\hline Italia & $24,5 \%$ & $34,0 \%$ \\
Japón & $24,3 \%$ & $35,1 \%$ \\
Alemania & $24,0 \%$ & $33,2 \%$ \\
Grecia & $23,9 \%$ & $31,6 \%$ \\
Bélgica & $22,3 \%$ & $31,2 \%$ \\
España & $22,1 \%$ & $31,4 \%$ \\
Reino Unido & $20,8 \%$ & $29,4 \%$ \\
Francia & $20,5 \%$ & $28,7 \%$ \\
\hline
\end{tabular}

Fuente: Naciones Unidas, 2001

Además de la evidencia importante de este primer factor o determinante descrito, es útil considerar un amplio conjunto de determinantes que tienen su influencia en el envejecimiento. Se deben diferenciar dos determinantes transversales: la cultura y el género; junto a estos se distinguen otros (Jacobzone, 2002) que tienen su influencia de modo longitudinal:

- $\quad$ Determinantes sanitarios y sociales: promoción y prevención de la salud, asistencia de larga duración, servicios de salud mental. 
- Determinantes conductuales: tabaquismo, actividad física, alimentación, salud bucal, alcohol, medicamentos, cumplimiento terapéutico, etc.

- Determinantes personales: biología y genética, factores psicológicos, etc.

- $\quad$ Determinantes físicos: entorno, seguridad de la vivienda, caídas, agua, etc.

- Determinantes sociales: apoyo social, violencia y abuso, educación y alfabetización.

- $\quad$ Determinantes económicos: ingresos, protección social, trabajo, etc.

Todos estos determinantes, su influencia en el envejecimiento y sus interacciones se reflejan la figura 1:

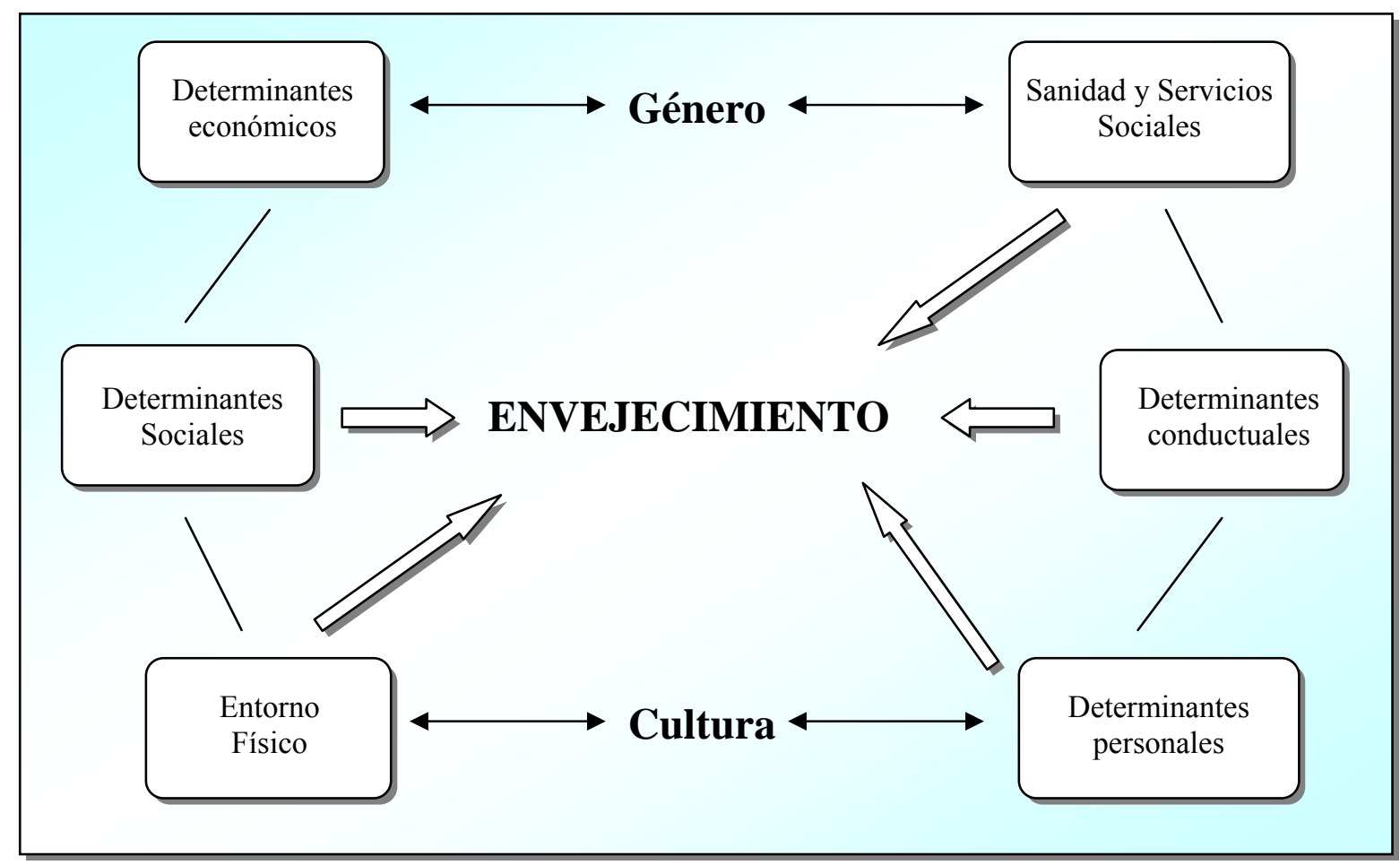

Fig. 1: Determinantes del envejecimiento 


\subsubsection{Envejecimiento femenino}

La definición de la O.M.S. de la salud "como un estado completo de bienestar físico, mental y social" necesita el requisito primordial de asumir el envejecimiento como un proceso continuado, si se aplica esta definición a la mujer que envejece (O.M.S., 1994). Puesto que la salud de una mujer en períodos anteriores de su vida supone la base de su salud en las últimas etapas de su vida, es esencial tratar la salud de la mujer al envejecer desde una perspectiva que tenga en cuenta todo el curso vital.

La dimensión femenina del envejecimiento y la situación de las mujeres mayores en el mundo fue uno de los temas debatidos en la Segunda Asamblea Mundial sobre el Envejecimiento, celebrada en Madrid en el año 2002. En aquel momento, existían 328 millones de mujeres de 60 años y más en el mundo frente a 265 millones de hombres, incrementándose esta proporción a medida que la población envejece. Las estimaciones de Naciones Unidas indican que en el año 2065 habrá 604 millones de mujeres mayores de 60 años, viviendo el 70\% en países desarrollados (Mallol, 2005).

El envejecimiento de la población está acompañado por una mayor esperanza de vida al nacer y a edades más avanzadas para las mujeres que para los hombres, aunque la diferencia se está acortando en las edades más elevadas. En los países desarrollados, las mujeres viven una media de seis años más que los hombres (O.M.S. 1998). Kalache (2005), señala que el proceso de envejecimiento poblacional está condicionado por dos factores fundamentales: el incremento de la expectativa de vida y la disminución de las tasas de fecundidad, al que se ha denominado transición demográfica. 
Respecto a la diferencia entre sexos, la expectativa de vida al nacer mayor para las mujeres comparada con la de los hombres es prácticamente universal. En España, la esperanza de vida media se sitúa en 82,9 años para las mujeres y se estima en 85,1 años en el 2020. Con estas predicciones, las mujeres españolas estarán entras las mujeres con mayor esperanza de vida en el mundo, junto con japonesas y francesas (Fundación Jiménez Díaz, 2005).

El predominio numérico de las mujeres en la última etapa de la vida, que se ha denominado "feminización de la vejez", ha fluctuado desde 1951. Para todos los grupos de edad a partir de los 65 años, la razón mujer-hombre se incrementó hasta los años 70 y 80, momento en el que empezó a declinar y en 2001, para el grupo de 65 a 74 años estaba por debajo del nivel de 1951. Aunque para personas mayores de 85 años esta razón ha disminuido lentamente, la vejez progresivamente tiende a estar menos feminizada.

La edad es un aspecto importante que influye directamente en cuanto a la participación social de las mujeres. Es una condición determinante vinculada a la adquisición y pérdida de poder y autonomía personal. Según Castaño y Martínez (1990), la vejez en nuestra cultura es vista como una “constatación del crepúsculo, no sólo biológico sino social de las personas". Esta concepción pesimista del envejecimiento es aún más crítica para las mujeres ya que amenaza el sistema de valores referente a la visión basada en la "juventud y belleza femenina”.

Laforest (1991) considera que, en la vejez, la mujer debe profundizar en la propia identidad como anciana en un contexto cambiante, lo que implicaría insistir en la propia autonomía, fortalecer el autoconcepto y defender sus derechos propiciando 
su crecimiento personal pero socialmente no reciben un reforzamiento en este sentido.

Los principales problemas de salud de la mujer mayor se considera que surgen de factores económicos, sociales, psicológicos, culturales, políticos y biológicos. Aunque estos determinantes son comunes para los países desarrollados y para los países en vías de desarrollo, existen variaciones notables en el alcance y extensión de sus efectos entre la población de mujeres de edad. La figura 2 representa los diferentes determinantes que influyen en el envejecimiento de la mujer (Nord, 1992):

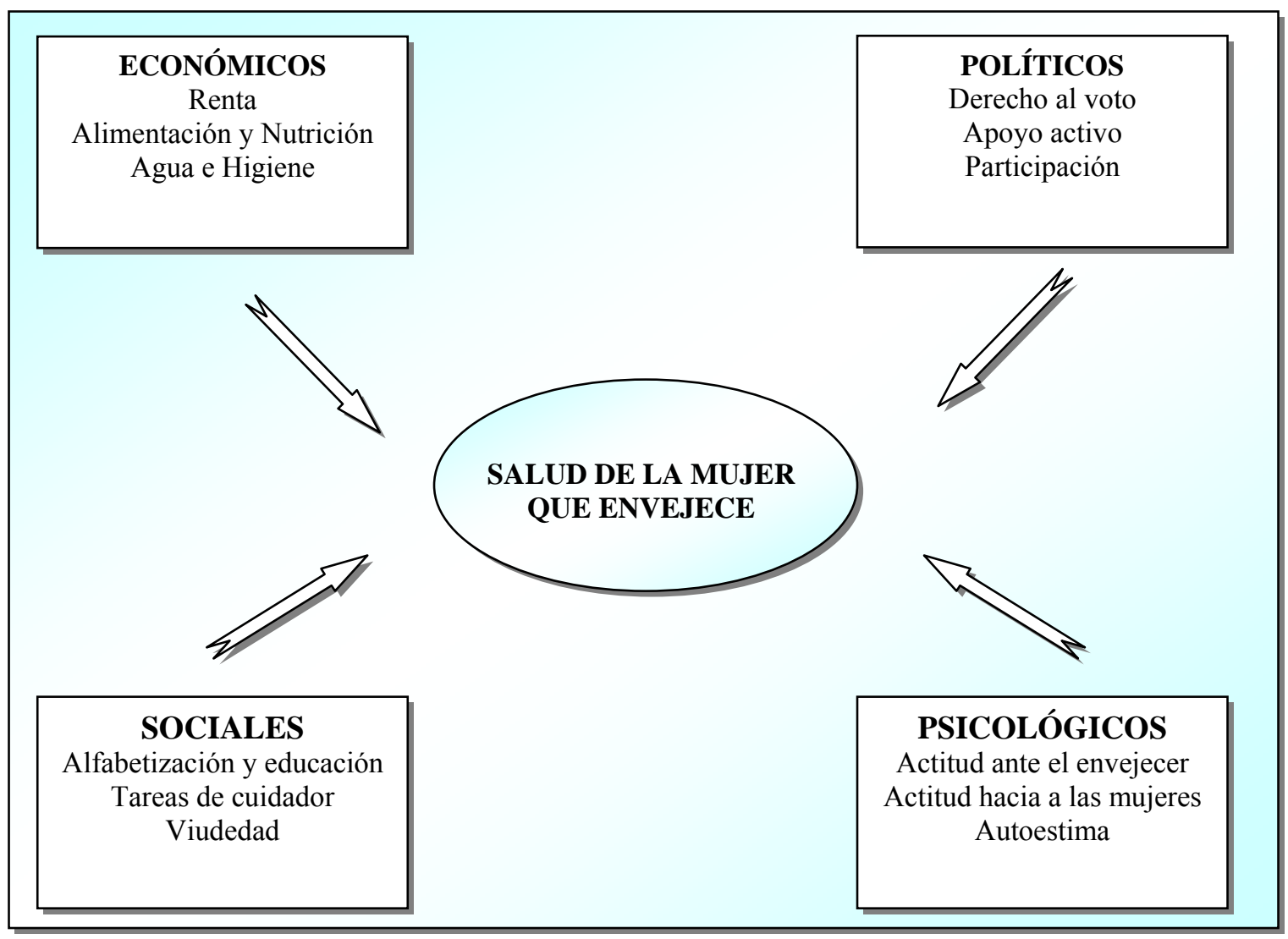

Fig. 2: Determinantes del envejecimiento femenino 
De todo este conjunto de factores nos vamos a centrar en los determinantes psicológicos y, de qué forma influyen en la vivencia que tienen las mujeres de su envejecimiento y su estado de salud. Estos determinantes, son:

- Actitudes ante el envejecimiento: la variabilidad intercultural es enorme en cuanto al papel y posición que se otorga a las mujeres mayores. En las sociedades no industrializadas, la ancianidad se consideraba una oportunidad para ganar prestigio y autoridad, el desarrollo y modernización están reduciendo significativamente estas actitudes en dichas sociedades (Waring, 1988). Trabajos de la Comisión Europea (1994) informan de actitudes positivas hacia el envejecimiento femenino en países del norte de Europa donde mujeres de edad avanzada han conseguido desempeñar funciones relevantes y activas en la sociedad. Sin embargo, en el sur de Europa, no ha surgido una actitud positiva hacia el proceso de envejecer de la mujer.

- Actitudes de las mujeres mayores hacia sí mismas, la autoestima: la relación entre envejecimiento, salud y autoestima tiene muchas implicaciones. La autoestima refleja un sentido de la valía de una misma y de cómo es valorada por los demás. Igual que la autoestima puede contribuir tanto a la salud física como mental, la falta de autoestima tendrá de un efecto negativo directo principalmente en la salud mental. En algunos países desarrollados, la mujer al envejecer se enfrenta a la difícil elección de ceder a la tendencia e intentar mantenerse "joven" o aceptar los papeles estereotipados y limitados asignados a las mujeres mayores. 
En todas las situaciones, el fomento de actitudes positivas ante su propio envejecimiento y el reforzamiento de la autoestima de las mujeres mayores son claves para que tengan una sensación de control de sus vidas y sigan participando activamente en la sociedad.

El punto crítico en el que la demografía se cruza con la salud y determina un incremento de necesidades sanitarias y sociales es la transición menopaúsica, período referido a la larga etapa de transición desde la vida fértil a la senectud. La inclusión del climaterio y, concretamente, de la menopausia como una prioridad de salud en la mujer que envejece, no es voluntaria. Un breve repaso por los criterios definidos por la O.M.S. para considerar un problema como prioritario para la mujer que envejece, nos lleva a una percepción objetiva de la importancia del estudio del período climatérico como predictor e indicador del envejecimiento de cada mujer. Los criterios utilizados son los siguientes:

a) El alcance del problema, es decir que es:

- de máxima trascendencia tanto en países desarrollados como en países en vías de desarrollo.

- muy frecuente en mujeres mayores de 50 años en comparación con mujeres jóvenes.

- de mayor impacto entre las mujeres al envejecer que entre los hombres.

b) La naturaleza del problema, es tal que:

- afecta progresivamente a las mujeres al envejecer. 
- tiene importantes consecuencias sobre las actividades diarias y la independencia así como sobre la mortalidad.

- se puede evitar, por medio de la prevención primaria a lo largo de toda la vida y de la prevención secundaria en la tercera edad.

- puede tratarse en gran parte a través de medidas de asistencia sanitaria básica, incluida la enseñanza de cómo cuidarse a una misma.

c) La aparición del problema:

- está exagerada en algunos casos, infravalorada en otros, y poco investigada en general.

- a menudo, corre el riesgo de recibir excesiva medicación o de sufrir intervenciones inapropiadas.

- ya está reconocida como meta y objetivo a evitar por los programas de salud nacional de algunos países, pero debe centrarse más dicho objetivo sobre la mujer al envejecer.

En suma, como se puede comprobar, pocas patologías o variables asociadas al envejecimiento femenino pueden adecuarse de una manera tan clara a los criterios de "prioridad de salud de la mujer que envejece" como la transición menopaúsica. 


\subsection{Climaterio y menopausia}

\subsubsection{Evolución histórica}

El significado bio-psico-social de la menopausia para la mujer ha ido variando sensiblemente desde la antigüedad hasta la actualidad, pero es generalizado el significado negativo que se le otorga a la pérdida de la menstruación de la mujer, asociándolo de forma clara con la vejez.

A pesar de tratarse tradicionalmente de un tema médico, ha sido a partir del siglo XIX cuando aparecen los principales datos clínicos significativos y referencias que sirven para encuadrar el marco general para el estudio de la menopausia, constituyendo una entidad demográfica y sanitaria Esta escasez de interés en su estudio parece debido principalmente a que la esperanza media de vida de las mujeres no era más alta que la edad de aparición de la menopausia, como indica Wilbush en 1990, ubicando la esperanza de vida de las mujeres en 1330 en 51,1 años, mientras que en 1949 se sitúa en 74,3 años.

La primera referencia de la existencia de un período al final de la vida de la mujer en el que fracasa su capacidad reproductiva, lo encontramos en la Biblia (Génesis 17, 15-17) cuando Abraham, al serle anunciado por Dios su próxima paternidad, responde: “¿Acaso pueden tener hijos un hombre de 100 años y una mujer de 90?".

En el papiro de Ebers (1500 años a. C.) aparece la primera referencia a un síntoma concreto y característico de la menopausia como son las sofocaciones: Cuando se examina a una mujer que ha vivido varios años sin menstruación a veces parece que tenga que vomitar y que tenga fuego bajo su cuerpo le tenéis que decir que es la subida de la sangre desde su abdomen... 
En la Época greco-romana (siglo VI a.C. al siglo V d.C.) las primeras citas hacen referencia a la edad de aparición, la Escuela Hipocrática señala los 42 años al ser múltiplo de 7 (los múltiplos de este números estaban relacionados con acontecimientos importantes de la vida). Aristóteles (Macedonia 384 a. C -Grecia 322 d. C) describe: Las reglas desaparecen en la mayoría de las mujeres en la cuarentena y cuando duran más tiempo subsisten hasta los 50 . Hasta este momento algunas mujeres han tenido hijos, pero nunca más tarde.

Durante la Edad Media (siglos VI a XV) continúan las referencias centradas en la edad de aparición. Después del período bizantino, con la llegada de la Escuela de Salerno, aparece De Egritudinibus de Mulierum (principios siglo XII) y se fijaba la edad de aparición en torno a los 50 años, este libro es atribuido a Trótula de Salerno ( - 1097) considerada la primera mujer que estudió y enseñó medicina en esta prestigiosa Escuela.

El primer razonamiento etiológico de la cesación de la menstruación aparece en la Alta Edad Media en el libro Causae et Curae escrito por Hildegarda de Bingen (Bermersheim, 1098- Alemania, 1179), en el cual aparece la siguiente descripción: las reglas cesan en la mujer a los 50 y algunas ocasiones a los 60 , cuando el útero comienza a estrecharse y contraerse, siendo entonces pequeño para concebir.

En la etapa renacentista y modernista (siglos XVI al XVIII), destaca la primera tesis doctoral sobre los trastornos que acontecen con la menopausia. La tesis es defendida en 1710 en la Universidad de Magdeburgo por Simon Daniel Titius (cit. por Wilbush, 1990)

Posiblemente el libro que supone la primera referencia europea a los trastornos de la menopausia se escribe en 1739 por una autor anónimo que aparece bajo el 
pseudónimo de “A Physician” afirmando la aparición de síntomas como dolores, espasmos, febrícula o malestar, al retirarse las reglas.

El siglo XVIII se convirtió, por tanto, en el inicio histórico del concepto de menopausia y del interés médico del tema, siendo Francia el origen del mayor número de aportaciones. A finales de este siglo se abandonan las viejas creencias de la toxicidad de la sangre y aparece un artículo publicado en 1766 por el médico inglés Fothergill en el que critica los salvajes métodos utilizados, siendo estos los que provocaban las molestias de las mujeres menopáusicas.

A comienzos del siglo XIX el desconocimiento de la ginecología es mayor con respecto a la obstetricia, considerándose a la menopausia dentro del resto de enfermedades del organismo femenino, sin ofrecer un criterio claro acerca de su etiología. Un momento trascendental en la evolución histórica de la menopausia ocurre en 1812 cuando Gardanne describe por primera vez los trastornos que acompañan al cese de las reglas, denominando a este síndrome "La Menopause".

Fue Tilt en 1857 el primer autor que asoció síntomas emocionales a la menopausia. Describió la aparición de trastornos psíquicos, declarando que durante la época de cambio muchas mujeres quedan "profundamente desquiciadas".

El siglo XX se caracteriza por los avances en el conocimiento de la función ovárica y las implicaciones que su cese tiene en la aparición de los síntomas climatéricos. También en nuestro país aumenta el interés por el tema destacando autores como Recasens, Gálvez o Macías Torres.

Destaca Marañón (1937), quien considera el accidente climatérico, no como consecuencia de una simple insuficiencia de la secreción interna del ovario, sino el resultado de una amplia crisis endocrina, desarrollando la "teoría pluriglandular". 
Distingue, de forma brillante, los verdaderos síntomas climatéricos de otros dependientes de estados patológicos previos que la crisis simplemente revela o acentúa.

Autores como Laborde o Sellheim muestran una enérgica actitud en contra de la estigmatización que se le atribuía a la menopausia, proponiendo conceptualizarla como una etapa dentro de la normalidad caracterizada por "alteraciones subjetivas" ( Raera, 1982 ).

La segunda mitad del siglo XX amplia aún más los conocimientos bioquímicos y fisiológicos de la menopausia, donde los avances permiten determinar los cambios hormonales característicos. El aumento de la esperanza de vida y las posibilidades de tratamiento, como consecuencia de los avances teóricos, hacen que la década de los años 60 y 70 sea la de mayor proliferación en el estudio de la menopausia y sus problemas. Las grandes esperanzas creadas en los 70 sobre los tratamientos sustitutivos se vieron trucadas por la aparición de estudios que asociaban la utilización de estrógenos con una mayor incidencia de ciertos cánceres ginecológicos.

La importancia del problema se refleja, en la actualidad, en el gran número de reuniones científicas, congresos y multitud de publicaciones relacionadas con la menopausia. La primera reunión internacional tuvo lugar en Francia en 1976, en el I Congreso Internacional de Menopausia. En 1978 se celebró en Jerusalén el segundo Congreso y se constituyó la Sociedad Internacional de Menopausia.

En España un hecho relevante fue la creación de la Sección de Menopausia dentro la Sociedad Española de Ginecología durante su XX Congreso en el año 1989, y hace ya más de una década que se fundó la Asociación Española para el 
estudio de la Menopausia (AEEM). Este gran avance científico ha motivado estudios y publicaciones cada vez más específicas en los que se detectan aún hoy preguntas sin resolver, y que han provocado el estudio de nuevos conceptos como la calidad de vida y la participación de otros profesionales diferentes a los ginecólogos como psicólogos, psiquiatras, médicos de atención primaria, etc. fomentando la evaluación multidisciplinar de los aspectos relacionados con la menopausia. 


\subsubsection{Concepto, sintomatología y condicionantes}

Desde el punto de vista conceptual se plantean dudas respecto a las equivalencias de algunos conceptos. Siguiendo las directrices marcadas por la "International Menopause Society" (1976), el concepto de menopausia no puede hacerse de forma rigurosa sin diferenciarlo de otros términos.

El término climaterio o climaterium, deriva de la palabra griega Klimáter que significa "escalón o peldaño". El climaterio se define como la época de la vida en la que se pierde la capacidad reproductiva, más concretamente la fase en el proceso de envejecimiento de la mujer que marca la transición desde el período fértil de la vida al no fértil. Por tanto, es el período de transición de la edad reproductiva a la no reproductiva. Es, por tanto, un concepto más amplio que hace referencia a una etapa de la vida de las mujeres con características biopsicosociales específicas en relación con el cese de la capacidad procreativa. Se trata de un período de 15-20 años, durante los cuales se produce una involución de las funciones reproductoras (De la Gándara, 1994).

El término climaterio ha tenido diferentes acepciones, antiguamente se denominaba así a cualquier período de la vida considerado crítico como época de cambio, valorándose de modo especial los años que eran múltiplos de 7 ó 9 . Otras acepciones clásicas del término hacían referencia a la incertidumbre, a lo incierto del devenir o a "estar de mal temple o humor". Han sido muchos los autores y diferentes las conceptualizaciones que se pueden encontrar del concepto climaterio, las más significativas cronológicamente son las siguientes: 
- Jeffcoate en 1971 lo define de la siguiente forma: Es la contraparte de la pubertad y consiste en una fase de transición de dura de uno a cinco años, durante la cual los órganos genitales involucionan en respuesta al cese de la actividad gonadal.

- Para Marañón (1936) se trata de un período de la vida caracterizado por un conjunto de fenómenos circulatorios y nerviosos, cuyo accidente central es la menopausia .

- Del Sol Fernández (1976) afirma que es un período, no una fecha. Es la involución sexual de la mujer pero no se limita sólo a esto, sino que se acompaña de toda una crisis endocrina y vegetativa.

Teniendo en cuenta todas las interpretaciones, el climaterio puede, por tanto, entenderse como una etapa fisiológica de la vida de la mujer, caracterizada por cambios biológicos, biográficos, psicológicos y sociales, íntimamente relacionados con la involución o envejecimiento de las funciones ováricas, lo que conlleva, no sólo la pérdida de la capacidad reproductora y el cese de las menstruaciones, sino todo un reajuste de las funciones hormonales y cambios orgánicos y tisulares generalizados. Todos estos cambios son lentos y paulatinos, por lo que resulta imposible delimitar con criterios temporales estrictos el inicio y el fin del climaterio.

Continuando con el objetivo de identificar todos los conceptos relacionados con la menopausia, conviene diferenciar dos términos a menudo confundidos, e incluso utilizados como sinónimos, cuando no son exactamente lo mismo. Uno de ellos es la perimenopausia.

El término perimenopausia fue introducido por Kistner en 1969 y hace referencia a un período inmediato de tiempo antes y después de la menopausia. Algunas de las definiciones más explicativas de este término son las siguientes: 
- Los términos climaterio y menopausia para muchos autores son sinónimos. Sin embargo, otros reservan el de perimenopausia para referirse al año o dos años que preceden y siguen a la menopausia con sintomatología más florida (Caballero Gordo, 1985).

- Después de unos meses, o a veces un año o más de irregularidades menstruales, la regla ya desaparece del todo. Sólo entonces sabremos a ciencia cierta cuál ha sido la fecha de la menopausia. Parece conveniente que a todo este dudoso período, le llamemos perimenopausia (Botella, 1990).

- Algunos autores utilizan este término para referirse exclusivamente a uno ó dos años antes y después de la última menstruación, período que generalmente muestra los síntomas más evidentes (Comino, 1990).

Se trata por tanto de un concepto fisiológico y cronológico, y como tal permite delimitar etapas transitorias concretas alrededor de la misma. Estas etapas son: premenopausia, menopausia y postmenopausia.

La premenopausia supone el tiempo comprendido entre la disminución de las funciones ováricas y la desaparición de las reglas y designa el período de trastornos que preceden a la terminación de las menstruaciones.(Guillet et al, 1985). Es el período anterior a la menopausia, durante el cual se producen cambios endocrinológicos muy significativos, según la Federación Internacional de Ginecología y Obstetricia (FIGO), este período previo a es de 2 a 8 años.

La utilización del término es muy ambigua, por ello el Comité Científico de la Organización Mundial de la Salud (1980 ) reconoce que el término "premenopausia" puede utilizarse para referirse a los dos años que preceden a la menopausia, o bien, puede referirse a la totalidad del período fértil anterior a la menopausia. En su 
informe dan al término esta última interpretación, y recomiendan que cuando se utilice se defina de forma específica.

La Federación Internacional de Ginecología y Obstetricia (1976) denomina postmenopausia, al período que sigue a la menopausia con una duración media de 1 a 6 años, reduciéndose durante este período la actividad ovárica al mínimo. En 1984, Lauritzen denomina postmenopausia a los años que siguen a la menopausia e introduce el criterio temporal, proponiendo la división de precoz (dos primeros años) y tardía ( más de dos años ).

El término menopausia deriva del griego men (mes) y pausis (cesación) y se refiere al cese permanente de la menstruación resultante de la pérdida de la actividad folicular ovárica (O.M.S., 1981).

González Merlo (1977), la define como la desaparición definitiva de la menstruación, es un signo más del conjunto de fenómenos que definen al climaterio, si bien es sin duda el más importante. En esta misma línea interpreta el concepto Calatroni (1988) afirmando que es el cese definitivo de las reglas, el signo más llamativo del climaterio La menopausia es, por tanto, un síntoma que se produce en el climaterio (Ferrer, 1993).

Para considerar la fecha de la última menstruación como inicio de la menopausia deben pasar 12 meses sin que hayan aparecido muevas hemorragias menstruales, sin embargo algunas clasificaciones (FIGO, 1980), consideran que bastan seis meses sin menstruaciones para poder decir que una mujer está en la menopausia.

Cabe diferenciar entre menopausia artificial y natural, siendo la primera aquella producida por resercciones quirúrgicas, por radicación o por quimioterapia. 
Teniendo en cuenta el criterio cronológico podría aceptarse el concepto de menopausia precoz (cuando aparece antes de los 40 años) y menopausia tardía (si aparece en mujeres mayores de 55 años).

De forma consensuada parecen establecidos dos criterios de "menopausia confirmada": presentar entre 45 y 50 años con una amenorrea de 12 meses de duración, o bien, más de 50 años y amenorrea de 6 meses acompañada siempre de clínica sugestiva.

\section{Sintomatología básica}

Antes de comenzar a detallar los síntomas principales que aparecen en la mujer menopáusica es adecuado destacar que paralelamente a la menopausia fisiológica, la mujer prosigue con su envejecimiento biológico independientemente y estas manifestaciones pueden entremezclarse con el denominado síndrome menopáusico.

Un estudio realizado por la International Health Foundation (1969) indica que el $86 \%$ de las mujeres entre $46-55$ años presentaban trastornos relacionados con la menopausia. Actualmente se aceptan tasas del 75 al $85 \%$ de mujeres menopáusicas que presentan síntomas, pero sólo el $15-20 \%$ solicitan atención médica por este motivo.

Previamente a la exposición de los diferentes criterios de clasificación de la sintomatología menopáusica, y siguiendo el esquema de Olazábal y García (1994), es posible agrupar esta sintomatología en :

- Sintomatología a corto plazo: incluye sintomatología vasomotora, psíquica y sexual. De entre todos estos síntomas destacan los sofocos. Pueden estar presentes incluso 2-3 años antes de que llegue la menopausia. Datos de la Unidad de Menopausia del Hospital Clínico de Barcelona señalan que en la "menopausia 
reciente" (5 primeros años), los sofocos pueden alcanzar tasas del 82\%, mientras que la sequedad vaginal alcanzarían el 69\%, la dispareunia el $56 \%$ y, por último, las alteraciones psicológicas el 50\%.

Dentro esta sintomatología a corto plazo conviene diferenciar, siguiendo a Salvatierra (1992) el Síndrome Climatérico (que guarda relación con los niveles estrogénicos, siendo el síntoma predominante los sofocos), y el Síndrome Afectivo Climatérico (los síntomas psíquicos ocupan el primer lugar y dependen menos de las tasas estrogénicas, pudiendo tener mayor base psicosocial).

- Sintomatología a medio plazo: aparece cuando la mujer lleva más de 5 años sin menstruación y corresponde a las modificaciones trófico-involutivas de los tejidos del aparato urogenital y piel. La atrofia vaginal es el síntoma a destacar en esta etapa.

- Sintomatología a largo plazo: incluye las alteraciones metabólicas que conducen a la osteoporosis y accidentes cardiovasculares.

La figura 3 aclara la evolución de los síntomas clave de cada uno de estas etapas tomando referencias cronológicas más concretas( adaptado de Balasch, 1991 ):

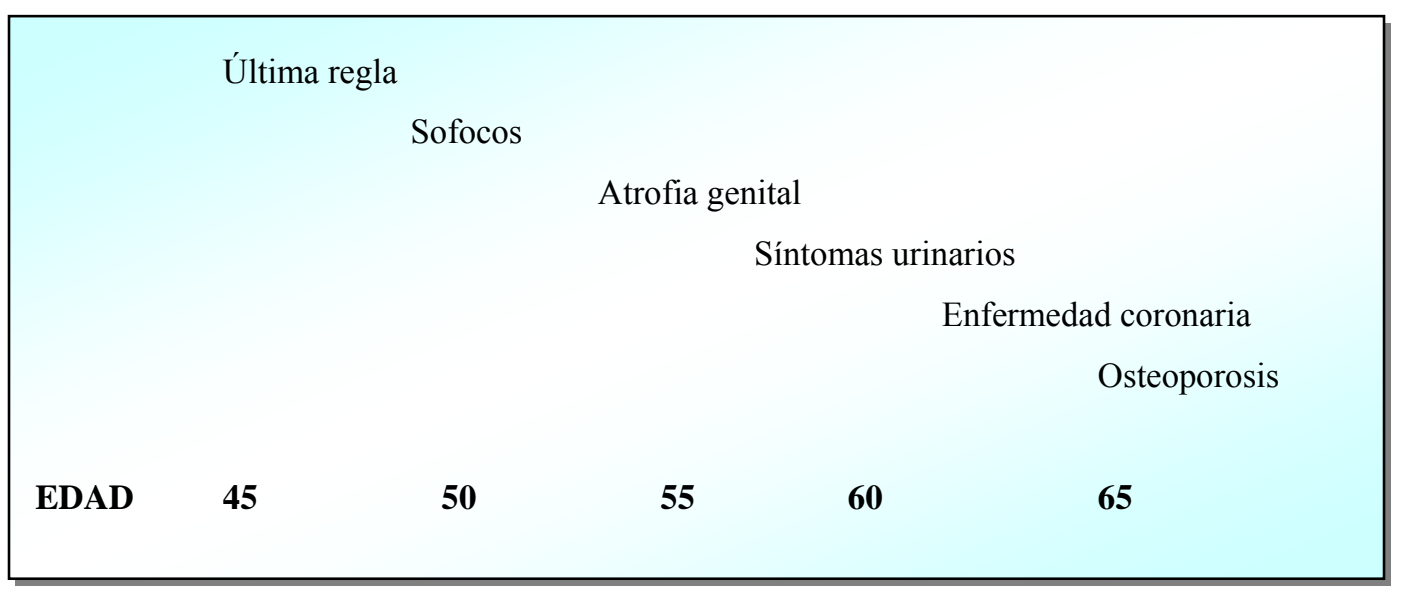

Fig. 3: Clínica de la menopausia ( Balasch, 1991 ) 
No necesariamente el climaterio está asociado con sintomatología. Cuando aparecen estos síntomas suele usarse el término de Síndrome Climatérico, pudiendo incluso aparecer alguno de estos síntomas (alrededor del 15 ) ya en la premenopausia, alcanzando su máxima intensidad dos o tres años después de la menopausia (Studd, 1977).

Comino y Rodríguez (1993) califican la propuesta de clasificación de síntomas somáticos de Utian (1980) como la más adecuada ya que se ajusta de forma más concreta a la realidad. La tabla 2 muestra los principales síntomas somáticos de la menopausia. Estos autores también describen la aportación de diversos autores en la clasificación de los síntomas no físicos en el climaterio, incluyendo síntomas psicológicos, emocionales y neuropsíquicos. La tabla 3 incluye las clasificaciones de diferentes autores en estos tres tipos de sintomatología no somática.

Tabla 2: Síntomas somáticos de la menopausia (adaptado de Utian, 1989)

\begin{tabular}{ll}
\hline Órgano & Síntomas \\
\hline Vulva & Atrofia, distrofia, prurito vulvar \\
Vagina & Dispareunia, vaginitis, sangrado superficial \\
Vejiga y uretra & Cistouretritis, ectropión, poliuria, incontinencia por estrés \\
Útero y suelo pélvico & Prolapso uterovaginal \\
Piel y mucosas & Atrofia, sequedad, disminución de la resistencia, \\
& pelo caído, hirsutismo facial leve, boca seca \\
Cuerdas vocales & Cambios de voz, tonos más graves \\
Sistema cardiovascular & Arterioesclerosis, enfermedades cardiovasculares \\
Esqueleto & Osteoporosis, dolor de espalda \\
Mamas & Disminución de la talla y consistencia \\
Neuroendocrinos & Sofocos, alteración del sueño \\
\hline
\end{tabular}


Sin duda han sido Kupperman y Blatt los autores que más han influído en la apreciación clínica y experimental de la semiología de la menopausia. Estos autores introdujeron el 1lamado BMI (Índice Menopáusico de Blatt) en 1953. Este índice resalta la presencia de síntomas psíquicos o neurovegetativos como componentes esenciales del síndrome menopáusico (insomnio, nerviosismo, melancolía).

Sin embargo este índice ha recibido críticas considerando insuficientes los síntomas psicológicos incluidos en este sistema de evaluación, y considerando necesario evaluar el peso específico de síntomas somáticos y psíquicos para definir el estado menopáusico (Kaufert y Syrotuik, 1981).

Tabla 3: Síntomas no físicos en el climaterio

\begin{tabular}{|c|c|c|}
\hline $\begin{array}{l}\text { Caballero, } 1995 \\
\text { (Psicológicos) }\end{array}$ & $\begin{array}{l}\text { Anderson et al, } 1987 \\
\text { (Emocionales) }\end{array}$ & $\begin{array}{l}\text { Botella, } 1990 \\
\text { (Neuropsíquicos) }\end{array}$ \\
\hline Depresión & Irritabilidad & Sofocos \\
\hline Nerviosismo & Fatiga & Angustia precordial \\
\hline Ansiedad & Tensión & Anorexia, bulimia \\
\hline Irritabilidad & Nerviosismo & Tabaquismo \\
\hline Labilidad emocional & Depresión & Trastornos del sueño \\
\hline Insomnio & Falta de concentración & Trastornos del carácter \\
\hline Fatiga mental & Mal humor & Depresión \\
\hline Amnesia & Desinterés & Trastornos sexuales \\
\hline Disminución líbido & Despertar precoz & Pesimismo,desinterés \\
\hline \multirow[t]{2}{*}{ Melancolía } & Insomnio & Cancerofobia \\
\hline & Pérdida de memoria & Cefaleas \\
\hline
\end{tabular}


Siguiendo esta conceptualización, Salvatierra (1992) propone agrupar la sintomatología menopaúsica en varios factores o constelaciones semiológicas independientes:

- Factor somático: agrupa los síntomas corporales como cefaleas, vértigos, mareos, tensión corporal, embotamiento de extremidades, ganancia de peso, etc.

- Factor vasomotor: incluye los "síntomas neurovegetativos" y que, en sentido estricto, abarcan exclusivamente sofocos y sudoraciones.

- Factor psicológico: según este autor debería estar agrupado en 6 apartados :

- Disminución del rendimiento: pérdida de memoria, dificultades de concentración, incapacidad para tareas delicadas, inhabilidad motora.

- Astenia: fatiga, malestar general.

- Nerviosismo: trastornos de ansiedad.

- Depresión: "melancolía y tristeza, con frecuentes crisis de llanto sin aparente motivo", temores hipocondríacos, pesimismo, sentimientos de inutilidad.

- Insomnio: de conciliación o mantenimiento o interrecurrente.

- Frigidez: disminución de la libido, descenso de la excitación y menor satisfacción. La dispareunia y coitalgia son considerados como síntomas somáticos debidos al hipoestrogenismo.

Palacios y cols. en una comunicación personal realizada en 1991 describen los principales síntomas climatéricos obtenidos de una muestra de mujeres de nuestro país, incluyendo tanto síntomas psíquicos como vegetativos, teniendo en cuenta dos factores de especial relevancia: orden de frecuencia y orden de intensidad (Tabla 4): 
Tabla 4: Síntomas climatéricos en mujeres españolas (Palacios y cols., 1991 )

\begin{tabular}{ll}
\hline \multicolumn{1}{c}{ Orden de frecuencia } & Orden de intensidad \\
\hline Insomnio & \\
Nerviosismo & Insomnio \\
Pérdida de líbido & Pérdida de líbido \\
Melancolía & \\
& SÍNTOMAS VEGETATIVOS \\
Sofocos & Sofocos \\
Sudoración & Sudoración \\
Palpitaciones & Palpitaciones \\
Prurito & Parestesias \\
Parestesias & Prurito \\
\hline
\end{tabular}

Conviene destacar la gran disparidad en la apreciación semiológica, encontrando una escasa concreción de los síntomas y de los patrones de estos, así como la polinomia utilizada. A pesar de esta falta de unificación es necesario resaltar la unanimidad existente al considerar que los síntomas psíquicos constituyen una parte fundamental de la semiología climatérica en las mujeres. Aún admitiendo esta unanimidad no hay que obviar que la existencia o no de problemas en la esfera psicológica durante la menopausia es una respuesta individual que está altamente influenciada por las percepciones y expectativas de cada mujer, así como factores específicos culturales o sociales.

\section{Condicionantes}

La aproximación histórica previa pone de manifiesto la gran cantidad de acepciones prejuiciosas, ridiculización y tabúes por los que ha pasado el concepto de menopausia y sus consecuencias para las mujeres. Lo que debiera ser una transición 
natural entre la etapa reproductiva y la segunda mitad de la vida, se ha transformado, debido al desconocimiento y a la falta de información, en una situación traumática y difícil de asumir para algunas mujeres.

Esta mayor o menor adaptación de la mujer a dichos cambios dependerá en gran medida de la forma de instauración: si el cambio es paulatino, progresivo y procesual, la mujer tendrá mayor oportunidad de adaptarse; por el contrario, si el cambio es brusco, inmediato y crítico, esta adaptación será mucho más conflictiva. Dependiendo de esta instauración, junto con factores de personalidad y psicosociales, dará lugar a la aparición de síntomas más o menos severos en la esfera tanto psíquica como física (Yost, 1990).

La estereotipia social relaciona este período con la pérdida de la juventud, con la disminución del atractivo físico y eventual envejecimiento, con la pérdida de la capacidad procreadora, con el cese de la menstruación y con el cambio del papel materno. La menopausia es vista incluso como un acontecimiento vital negativo de similar magnitud al de la pérdida del cónyuge (Avis y McKinley, 1991). Marca el tránsito a una segunda edad dentro de la madurez que se caracteriza por la pérdida de la juventud, temor a la pérdida de la feminidad y del atractivo sexual, dispersión del familia por la independencia o abandono del hogar de los hijos y la frecuente incorporación de familiares ya mayores que enferman y envejecen (Borrull, 1993). Siendo un suceso fisiológico, no una enfermedad, condiciona un momento evolutivo en la vida de la mujer, pudiéndose vivenciar de forma traumática por la atribución socio-cultural que se le ha dado.

Una variable importante que puede justificar la variabilidad de la influencia de los factores psicosociales es la edad de aparición de la menopausia. Ésta es muy 
variable, no sólo considerada a nivel individual, sino también en los diversos países y comunidades. Es preciso tener en cuenta algunas consideraciones respecto a la sistemática seguida para determinar la edad de la menopausia, para así poder valorarla adecuadamente:

- $\quad$ En primer lugar, no hay en la literatura unificación en los criterios de las cifras dadas por los diferentes autores; por ejemplo, mientras unos dan la media de edad, otros dan la mediana, siendo ésta última generalmente más alta.

- En segundo lugar, tampoco hay coincidencia respecto al tiempo de amenorrea que ha de transcurrir para etiquetar a una mujer como menopáusica. Para algunos autores 6 meses es suficiente, como propone la FIGO, para otros se precisan 12, siendo esta última cifra la más aceptada (Dexeus, 1987).

Parece consensuado que la edad media en los países europeos es de 50 años, en España la edad media se aproxima a los 49.5 años. Múltiples estudios epidemiológicos han intentando demostrar la relación entre diferentes factores psicosociales con la edad de aparición de la menopausia. La tabla 5 muestra los principales factores con influencia sobre la edad de aparición de la menopausia.

\begin{tabular}{cl} 
Tabla 5: Factores que influyen en la edad de aparición de la menopausia \\
(adaptado de Conde v cols.. 1993) & \\
\hline Factores genéticos & Paridad \\
Raza y clima & Edad del último embarazo \\
Condiciones de vida & Obesidad \\
Condiciones nutricionales & Tabaquismo \\
Nivel educacional & Anticonceptivos orales
\end{tabular}


La edad de aparición de la menopausia es, por tanto, variable pero es aceptado que en ese intervalo de edad la mujer está expuesta a circunstancias o cambios vitales que, siguiendo a Bousoño (1993), se pueden clasificar de la siguiente forma:

1) Alteración del papel familiar:

- Enfriamiento de las relaciones afectivas

- Disminución de la importancia de la relación sexual

- Pérdida de la capacidad de tener hijos

2) Cambios en la red de apoyo social:

- Alejamiento de los hijos

- Enfriamiento de las relaciones de amistad

3) Pérdidas afectivas:

- Enfermedad o muerte de los padres y de otros familiares

4) Envejecimiento y aparición de enfermedades:

- Pérdida definitiva de la juventud

- Ganancia de peso

- Deterioro de la imagen corporal y pérdida de la belleza

- Comienzo de enfermedades crónicas y degenerativas

- Pérdida de la fuerza física

5) Cambios psicológicos propios de la edad:

- Pérdida de la autoestima

- Pérdida de las ilusiones relacionadas con la juventud 
- Pérdida de la esperanza de comenzar una nueva vida

- Disminución de la capacidad de adaptación a los cambios

Esta apreciación de la importancia de las condiciones vitales que acontecen durante la menopausia no es nueva, cabe destacar que ya en 1954 English advertía que la mejoría en las actividades culturales o educativas podría facilitar que la mujer se enfrentase adecuadamente a esta etapa de su vida. Siguiendo en esta línea, parece conveniente ser más específicos y determinar la importancia de los estos condicionantes distinguiendo factores sociales, psicológicos y culturales.

Rogers ( 1956 ) critica el estereotipo social y afirma que es un error achacar todos los síntomas más o menos inexplicables de las mujeres de estas edades a la menopausia. En esta misma argumentación están las opiniones de Neugarten y colaboradores (1968) quienes aseguran que la menopausia es peor en la anticipación que en la realidad, y la anticipación negativa es un estereotipo social generalizado en la cultura occidental.

La tabla 6 indica los condicionantes sociales y psicológicos de la sintomatología menopáusica propuestos por De la Gándara (1994) que servirá como guía para describir los diferentes factores que influyen en la apreciación subjetiva de la sintomatología climatérica.

Tabla 6: Condicionantes psicosociales de la sintomatología climatérica ( adaptado de De la Gándara, 1994 )

Condicionantes sociales

Estereotipo social negativo ( anticipación )

Nido vacío

Pérdidas afectivas reales o simbólicas

Acontecimientos vitales estresantes

Peculiaridades culturales o étnicas
Condicionantes psicológicos:

Factores psicodinámicos

Antecedentes psiquiátricos

Personalidad previa

Dinámica psicológica premenopáusica

Actitudes psicológicas previas 57 
Salvatierra (1992) resalta la importancia de este condicionante social conceptualizando el "estereotipo menopáusico", que implica una visión negativa y patológica de la menopausia. Según este autor estos estereotipos hacen de la menopausia una "enfermedad somática" con un claro "condicionamiento folclórico negativo".

Deykin y colaboradores (1966) describen el "Síndrome del nido vacío" como una situación, concebida como una crisis biográfica, que se manifiesta cargada de síntomas físicos, relacionada con la suspensión de los cometidos maternales de la mujer al marcharse los hijos de casa. La revisión de Hunter (1990) considera que existen datos suficientes para aceptar que la presencia de los hijos en casa es favorable para las mujeres climatéricas. Pero algunas revisiones critican esta tesis, como las de Ballinger (1975) o Krystal y Chiriboga (1979), y concluyen que la salida de los hijos del hogar no sólo no es creadora de tensiones, sino que puede ser vivenciada como una liberación.

De la Gándara (1996) se refiere al "nido lleno o repleto y no vaciable" como aquél en el que la mujer no puede ver independizados a sus hijos y, esta situación puede suponer para la mujer menopáusica una situación altamente estresante. Coincidente con esta postura Salvatierra afirma que la situación actual socio-laboral de nuestro país hace que muchas mujeres al no poder ver a sus hijos independizados por motivos de estudios o trabajo, supongan un estrés más fuerte para las mujeres que la propia menopausia.

Sin embargo, Hunter (1990) y Diez y cols., (1994), conceden más importancia a otros sucesos relevantes en la vida de las mujeres en edad menopáusica y afirma que el riesgo de sufrir pérdidas importantes, con gran repercusión psíquica, es elevado. 
La pérdida de los padres, la viudedad, el divorcio, la insatisfacción o ruptura matrimonial son hechos que inciden frecuentemente en estas edades, realizando un efecto sumatorio.

Un factor de especial importancia es la calidad de la relación matrimonial, según los datos que recogieron Mussen y cols. (1979), la relación matrimonial durante esta época tiende a deteriorarse. La separación matrimonial durante la menopausia afecta a la mujer hasta el punto de ser uno de los predictores más fuertes de síntomas menopáusicos. Una relación afectiva adecuada y satisfactoria, no sólo proporciona una íntima gratificación, sino que además es protectora frente a otras circunstancias estresantes, dando menor vulnerabilidad a la mujer en esta etapa de la vida (Diez y cols., (1994)).

Un estudio que analiza la pérdida de la madre es el realizado por Tejerizo y cols. (1992), el análisis consideraba la muerte real de la madre menopáusica o su ausencia simbólica por distancia geográfica, senilidad o demencia. Este situación supone, para muchas mujeres tomar conciencia de la soledad y de la desprotección afectiva. Para un número considerable de autores los síntomas psíquicos de la menopausia dependen más de factores sociales que de biológicos (Greene y Cooke, 1980), según estos autores los cambios de rol familiar, pérdidas irreversibles o el envejecimiento son determinantes.

La relación entre estas circunstancias estresantes y síntomas menopáusicos han sido evaluadas mediante los Proyectos Manitoba y Massachussets. En el primero Kaufert (1984) sugirió que la mayoría de las mujeres atraviesan la menopausia y concluyen el climaterio casi sin problemas, y que son las más vulnerables psicológicamente las más proclives a sufrir una menopausia patológica. 
Por otra parte las relaciones entre clase social y manifestaciones climatéricas son complejas. Ballinger, en su revisión ya mencionada, indica que las mujeres de niveles socio-culturales más bajos presentan más síntomas que las más cultas. Jazsmann (1969) concluye que las mujeres solteras con más educación y más ingresos sufren menos síntomas. Por último, Van Keep (1983) la sintomatología emocional en los índices menopáusicos correlaciona negativamente con nivel socioeconómico y con el tipo de trabajo, así aumenta en las mujeres que trabajan fuera del hogar si son de nivel elevado y disminuye si son de nivel bajo, y los síntomas son más elevados en las amas de casa de bajo nivel socioeconómico.

Conviene destacar la importancia de la sexualidad en esta edad, condicionada por las diferentes implicaciones culturales y sociales. El declive durante la menopausia estaría en relación con:

a) Factores personales: concepto individual de la sexualidad, historia anterior de hábitos sexuales,

b) Factores orgánicos: atrofia de la mucosa vaginal con disminución de la lubrificación y elasticidad,

c) Factores de pareja: sexualidad anterior en la que con frecuencia la educación represiva no ha permitido la adopción de un papel satisfactorio. Un hecho adicional puede ser la falta de pareja o su ausencia por cambios de situación o actitud (Kinsey y cols., 1963).

d) Factores culturales: en nuestra sociedad la mujer se siente influida por el temor de no resultar atractiva con sus cambios corporales lo que condiciona un miedo al fracaso en una sociedad que exalta la juventud, la fuerza y el vigor. 
Dentro de los condicionantes psicológicos, Hallstrom (1977) considera que la presencia de trastornos preferentemente psíquicos de la menopausia, es producto de una personalidad previa que interactúa con las pautas de reacción a los acontecimientos vitales actuales. Afirma que la asociación de neuroticismo a sentimientos de culpa y asertividad neurótica, predispone a síntomas depresivos. Estos rasgos pueden derivar tanto de una educación infantil inadecuada, como de patrones genéticos hereditarios. Continuando con la influencia de la personalidad previa, Kruskemper (1975) afirma que las puntuaciones en la tríada neurótica (hipocondría, depresión, histeria) en el MMPI, son más elevadas en mujeres menopáusicas que en controles.

Un estudio de especial relevancia es el que realizaron Van Keep y Prill (1975), éstos propusieron que los estilos individuales de afrontamiento y resolución del estrés, junto con los rasgos de personalidad subyacentes, determinan la reacción ante la menopausia. Según ellos habría cuatro estilos de reacción fundamentales:

- Adecuada: 60 al 70\% de las mujeres, que presentan síntomas leves, y los superan fácilmente mediante compensaciones apropiadas y adoptando un papel activo y saludable.

- Impersonal: 15 al 25\% de las mujeres, que se limitan a aceptar de forma pasiva la llegada de la menopausia.

- Neurótica: 8 al 15\% de las mujeres, que adoptan una actitud negativa, rígida e inadaptada. Son mujeres con antecedentes psicosomáticos o neuróticos que acaban manifestando "doctor shopping” por sus numerosos síntomas. 
- Activas: 5 al $10 \%$ de las mujeres, que son personalidades fuertes, dinámicas, que derivan su actividad a otras tareas compensatorias, negando o reprimiendo su realidad. Sufren poco, pero esta actitud puede implicar otros riesgos psico-sociales.

Helson y cols. (1992) realizan un estudio sobre la personalidad y los cambios psicológicos de las mujeres en la edad premenopáusica. Sus conclusiones muestran una disminución en rasgos de dependencia y autocensura, y mejorías de rasgos como seguridad, decisión, estabilidad de opiniones, tolerancia a situaciones ambiguas, análisis racional y capacidad de resolución intelectual.

Otro factor psicológico de suma importancia son las actitudes previas sobre la clínica menopáusica. En general se admite que la anticipación negativa de la misma conlleva el riesgo de padecer más síntomas, especialmente psicológicos (Diez y cols., 1994).

El concepto de menopausia se ve afectado por las creencias y las expectativas de las mujeres respecto a los síntomas que deben esperarse y la repercusión en la salud de la mujer. Se pueden distinguir dos tipos de actitudes (adaptado de Borrull, 1993):

a) La mujer que acepta inconsciente o resignadamente su papel predeterminado culturalmente con acomodación a los hechos de la vida y a las condiciones reinantes. Se produce especialmente en los estratos socioeconómicos bajos.

b) La mujer que tiende a impacientarse y quiere revalidar su vida, tomar decisiones acerca de sí misma y de su futuro. Se plantea su propia vida, cómo ha sido, qué es y qué puede hacer en el futuro.

Sobre la esta influencia de tener unas expectativas negativas sobre la menopausia sobre la peor percepción de los síntomas, se admite que las expectativas 
hacia la menopausia son bastante buenas individualmente, y que estas expectativas mejoran a medida que transcurren la misma.

Un factor que parece influir sensiblemente en la vivencia de la menopausia son las experiencias previas con la pubertad y la menstruación (Botella, 1990). La vivencia temerosa de la menarquia, la aversión hacia la menstruación y los problemas asociados al embarazo suelen ser predictores de una actitud negativa hacia la menopausia.

Hay que destacar el análisis de Freixas (1992) sobre el impacto y el significado de la menopausia en la vida de la mujer. Cree que no es posible admitir que los grandes cambios psicológicos de esta edad estén determinados por las transformaciones fisiológicas, ni siquiera por el climaterio o menopausia en sí, sino por factores concurrentes. La menopausia debe ser entendida como un conjunto de cambios biológicos, psicológicos y sociales en un contexto concreto.

Tampoco para Neugarten y Wood (1963) la menopausia es un gran problema para muchas mujeres. Aunque en su estudio existe un sesgo evidente, ya que sólo las mujeres que acuden al médico tienen problemas con la menopausia, mientras que las que no los sufren no consultan nunca por este problema.

En el apartado de condicionantes culturales, los mitos relacionados con los tabúes respecto a la menstruación, así como las actitudes de la sociedad hacia la fertilidad y el envejecimiento, han generado una imagen de la menopausia fuertemente asociada al declinar físico y emocional.

En la figura 4, muestra la influencia de los diferentes factores en las alteraciones psíquicas durante la menopausia. 
Pero los estudios transculturales ofrecen ejemplos de comunidades donde las mujeres tienen actitudes positivas hacia la menopausia y presentan escasos síntomas. La hipótesis en la que se basan los estudios transculturales con respecto a la menopausia, es que las normas y valores de una cultura particular determinan el significado de conceptos tales como sexualidad, menstruación, fertilidad, esterilidad, menopausia y envejecimiento.

Existen pocos datos en los que se comparen las actitudes y las reacciones ante la menopausia en distintos medios culturales. Los estudios disponibles indican que aún cuando esas diferencias pueden ser notables, sus orígenes pueden ser complejos. La cultura puede cambiar la fisiología de una mujer (qué come y cuánto, si hace ejercicio, si fuma y cuántos niños es probable que tenga) de forma que parece influir sobre la edad de la menopausia y los síntomas presentados. De igual modo la cultura también influirá en la respuesta individual, ya que una mujer puede experimentar sus 
sofocos como una pequeña molestia mientras que otras, cuyos sofocos no son objetivamente peores, puede sentir que afectan de forma grave a su calidad de vida.

Estudios por todo el mundo han encontrado que la prevalencia de sofocos oscilan desde el $0 \%$ en las mujeres mayas hasta el $80 \%$ en mujeres holandesas (Beyene,1980). Teniendo en cuneta esta disparidad en los resultados obtenidos es necesario valorar si los problemas residen en el diseño del estudio. Una posibilidad es que las pacientes que consultan a sus médicos son las que cabe esperar que comuniquen más síntoma, otra posibilidad es que los investigadores no realicen las preguntas de la misma forma, o que interroguen a partes no comparables de la población, o que no se pregunte en el mismo momento. Wilbush propone que los estudios puede que no estén encontrando síntomas sino lo que este autor denomina "semeions", que conceptualiza como sensaciones subjetivas obtenidas mediante preguntas.

La mayoría de los estudios transculturales encontrados han sido realizados en Asia y Europa. Los siguientes son algunos de los más relevantes:

- Las mujeres de una determinada casta india (Rajput) de situación relativamente privilegiada, comunicaron menos trastornos perimenopáusicos que mujeres de Estados Unidos, con escasos síntomas aparte de los cambios del ciclo menstrual. Flint (1975) atribuyó esto a las diferencias culturales entre ambos medios, ya que la mujer india se libera de muchas de las limitaciones que antes se le imponían (el "purdash”, llevar velo y estar más o menos recluidas y se les permite hablar $\mathrm{y}$, en algunas zonas, hablar con los hombres), al mismo tiempo que asciende en su situación social 
dado que las mujeres de más edad de esta cultura son reverenciadas como modelo de sabiduría y experiencia. Mientras, que la americana prevé que su situación va a empeorar en una sociedad orientada hacia la juventud.

- $\quad$ Lock (1991) halló en Japón que el 65\% de las mujeres referían la menopausia como un acontecimiento de poco o ninguna importancia para ellas. Incluso, no encontró una palabra en su idioma que describiera los sofocos. Sugirió que esta carencia de importancia percibida es debida al hecho de que la menopausia nunca ha sido considerada como estado social especial.

- McCarthy (1990), del Departamento de Ginecología del National University Hospital de Singapur realizó un estudio que venía a confirmar los hallazgos respecto a la escasa importancia que se le concede en oriente a la menopausia. Estudió 400 mujeres procedentes de Hong Kong, Malasia, Filipinas, Corea del Sur, Taiwán, Indonesia y Singapur. El estudio mostraba que tanto los síntomas vasomotores como psicológicos eran menos frecuentes que los encontrados en países occidentales, el autor concluye que “el síndrome climatérico parece ser un fenómeno menos grave en esta parte del mundo".

- Otro estudio tailandés llevado a cabo por Chompootaweep y cols. (1990) en grupos urbanos, concluyó que la edad media de la menopausia era de 45 años y que el 58\% de las mujeres en la 
premenopausia sufrían síntomas climatéricos, el más común de los cuales eran los sofocos.

- También se encontraron en un estudio que evaluaba las diferencias entre mujeres judías de clase media y mujeres cubanas, en los Estados Unidos. Las segundas experimentaban más problemas que las primeras y además estaban peor integradas en la sociedad estadounidense.

- Del mismo modo, cinco grupos étnicos distintos de mujeres de Israel (judíos procedentes de Europa Central, Persia, Turquía y Norte de África,y uno árabe) mostraron distintas actitudes hacia la menopausia (las árabes tenían una actitud más positiva, las judías europeas más indiferentes y las persas la más negativa, siendo las diferencias más acusadas en la relación conyugal, ya que mientras las árabes esperaban que sus maridos les manifestaran mayor interés, las de origen persa eran las más pesimistas), si bien después coincidieron en las manifestaciones somáticas, inclusive sofocos y sudores.

Aunque se conoce más respecto a la prevalencia de los síntomas climatéricos en las mujeres occidentales, así como respecto al tipo de mujer en riesgo de desarrollarlos, sigue habiendo grandes contradicciones. En general, los estudios sobre la población llevados a cabo en Europa tienden a confirmar una proporción significativa de sofocos y otros síntomas vasomotores, aunque los investigadores no llegan a un consenso de cómo afectan en la calidad de vida de la mujer. 
Oldenhave (1990) en su estudió realizado en la Universidad de Leiden en Holanda, encontró que cerca del $80 \%$ de las mujeres holandesas no tienen sofocos, aunque hay que señalar que en el estudio estaban incluídas mujeres que recibían tratamiento hormonal sustitutivo pero se excluyeron a mujeres histerectomizadas.

Un estudio relevante, al tratarse de un diseño longitudinal, fue el realizado por Holte (1991). Entrevistó, anualmente durante un período de cinco años, a una población de mujeres de entre 45 y 55 años seleccionadas al azar. Era un grupo de mujeres noruegas que no habían sido histerectomizadas ni estaban recibiendo terapia sustitutiva. Según avanzaban en el climaterio, se vio que aumentaban las palpitaciones, sequedad vaginal, quejas vasomotoras y disfunción social, mientras que disminuían las cefaleas, sensibilidad mamaria y la calidad de vida.

McKinlay (1990) realizó un estudió longitudinal con 2570 mujeres seguidas en series de seis entrevistas telefónicas, confirmando el acusado efecto del tabaquismo sobre la edad de la menopausia en una población general, llegando las fumadoras a la edad de la menopausia un promedio de 1,5 años antes que las no fumadoras.

A pesar de los hallazgos contradictorios, Payer (1991) considera que parecen existir algunas áreas de acuerdo:

a) La edad de la menopausia es la misma en Asia, Europa y Norteamérica, aunque se ha comunicado que es más precoz en algunas sociedades de tipo tradicional; las fumadoras alcanzan la menopausia un promedio de 1,5 años antes que la media poblacional, mientras que las mujeres sanas la pueden alcanzar más tarde.

b) La menopausia parece estar asociada con síntomas menores y menos graves en Asia que en los países occidentales. 
c) Los sofocos y síntomas vasomotores son comunes en Europa y Norteamérica, y mientras que los factores sociales en estos países pueden, hasta cierto punto, predecir quiénes están en situación de riesgo, el estado menopáusico parece ser el factor causal primario por sí mismo; incluso hay un cierto porcentaje de mujeres que refieren sofocos muchos años antes de que comience la menopausia, alcanzando el pico al final de la perimenopasuia.

d) Otros síntomas como la depresión, parecen relacionados con mucha más intensidad con otros factores distintos de la menopausia real.

e) Las mujeres histerectomizadas padecen, en su totalidad, síntomas más graves que las que han llegado a la menopausia de forma natural.

f) Mientras que con la edad existe un declinar general en diversas medidas de la sexualidad, tales como deseo y frecuencia de relación, una minoría de mujeres manifiestan un aumento de la sexualidad después de la menopausia.

Obviamente aún existen muchos problemas en los estudios transculturales, por ejemplo no se han comparado los valores hormonales de las mujeres menopáusicas en las distintas culturas, asumiéndose que la duración y la intensidad de los cambios endocrinológicos es similar entre ellas. De todos modos, como concluye Dennerstein y cols. (1993), existe información suficiente para afirmar que los factores culturales influyen en la respuesta de la mujer a los cambios biológicos y en la expresión de los cambios percibidos. 


\subsubsection{Menopausia como indicador del envejecimiento femenino}

En cuanto a la menopausia como indicador fundamental del envejecimiento femenino, la Comisión Mundial sobre la Salud de la Mujer se creó para impulsar la adopción y ejecución de acciones efectivas con la relación a la mujer, para asegurar la firme consolidación del tema de la salud de la mujer en la agendas nacionales e internacionales, y para defender a nivel internacional los intereses de la mujer en materia de salud. En el Documento inicial sobre los temas a tratar, "Women's Health:Towards a Better World" (O.M.S. 1994) se presentó en la primera reunión de la Comisión celebradas ese año.

En discusiones posteriores, la Comisión Mundial determinó que debía prepararse un escrito con la información previa disponible sobre envejecimiento y salud, que abarcara los siguientes puntos:

- principales temas de salud respecto a la mujer postmenopáusica y la mujer al envejecer;

- determinantes sociales, culturales, políticos y económicos de la salud de la mujer postmenopáusica y de la mujer que envejece;

- necesidades específicas de asistencia sanitaria de la mujer al envejecer;

- y planes futuros de acción.

Parece clara entonces, la necesidad de valorar el proceso menopáusico como indicador principal e inequívoco del envejecimiento de la mujer y su gran influencia como predictor del envejecimiento femenino. El estudio del proceso menopáusico no se puede separar del proceso de envejecimiento de las mujeres. Si bien es cierto que la menopausia se experimenta aproximadamente entre los 45 y 55 años, es con esta 
transición con la que las mujeres toman conciencia de que están envejeciendo. Este proceso de desarrollo no sólo permite a las mujeres la posibilidad de reorientar su propio sentido de vida, sino que las obliga a enfrentarse con las contradicciones que surgen de la confrontación de necesidades de independencia y reafirmación personal. Estok y O’Toole (1991) consideran que la vivencia del proceso menopáusico tiene que ver con los significados asignados a la menopausia en cada cultura y estos influyen directamente en las respuestas de las mujeres a la menopausia y también en el tipo de atención en salud que las mujeres reciben en esta época.

La menopausia es un hecho que tiene un significado único en la vida de una mujer en comparación con un hombre. La menopausia es considerado como un proceso universal, que tiene lugar alrededor de los 50 años tanto en países desarrollados como en aquellos en vías de desarrollo.(Kending y cols., 1992). Mientras que el desarrollo provoca cambios importantes en los sucesos que ocurren a lo largo de la vida antes de la menopausia, en especial la reducción del período reproductivo y el gran alargamiento de las etapas de la vida posteriores a la menopausia, la edad misma en que se produce la menopausia permanece relativamente constante.

Pérez y cols. (2007) realizan una aproximación muy completa de la importancia del climaterio como indicador del envejecimiento femenino y, concretamente, de la menopausia como predictor del envejecimiento de las mujeres. El "síndrome climatérico" se caracteriza por la presencia, con relativa frecuencia, de alteraciones psicológicas (irritabilidad, depresión, ansiedad, nerviosismo, disminución de la libido, etc.); alteraciones genitourinarias (sequedad vaginal, prurito, disuria, 
incontinencia urinaria, etc.); y síntomas neurovegetativos (sofocación, sudoración, parestesias, insomnio,etc.).

Cerca del 70\% de las mujeres refieren algunos de estos síntomas y signos entre los que se encuentran un conjunto de síntomas o malestares pertenecientes a la esfera psicosocial, que pueden estar condicionados por factores relacionados con el medio en que se desenvuelve la mujer y por factores condicionados por su carácter y personalidad (Navarro, 1999).

El conocimiento de esta etapa vital por parte de la mujer, las actitudes y expectativas ante la menopausia, su capacidad para adoptar un papel activo en este estadío inicial de envejecimiento y el afrontamiento de las decisiones personales, médicas, etc. va a condicionar de forma directa la vivencia su propio envejecimiento y la calidad de vida de percibida por cada mujer. 


\section{Variables psicológicas y menopausia}




\section{3.- VARIABLES PSICOLÓGICAS Y MENOPAUSIA}

\subsection{Expectativas y menopausia}

Una de las variables que aparece citada en la mayoría de las teorías que atribuyen algún papel a los factores cognitivos en la motivación son las expectativas (Weiner, 1974). El concepto de expectativa parte de los trabajos de Tolman (1932) y Lewin (1936) para quienes una expectativa es la valoración subjetiva de la posibilidad de alcanzar un objetivo particular. Partiendo de esta definición, Bandura (1977, 1986) distingue dos clases de expectativas:

a) Expectativa de eficacia:

Se trata de una estimación probabilística de la persona sobre si puede ejecutar adecuadamente una conducta o una serie de conductas. Las expectativas de autoeficacia se crea de cuatro formas diferentes:

- $\quad$ Experiencia directa: es la manera más importante y determinante.

- Experiencia vicaria: la forma en la que esta experiencia afecta a las expectativas depende de la similitud del observador respecto al actor y de que cuanto menos experiencia tenga el observador respecto a la conducta observada mayor será el efecto de la observación.

- $\quad$ Persuasión verbal: siempre que no se contradiga la experiencia mediante un feedback de rendimiento discrepante.

- Estado fisiológico: la expectativa puede cambiarse a través de la monitorización del propio estado fisiológico. La fatiga, el mareo, el dolor, el estrés, el miedo, señales de tensión, etc. son indicios de ineficacia. El bienestar es síntoma de eficacia. 


\section{b) Expectativa de resultado:}

Explica la creencia de la persona de que siguiendo un determinado patrón conductual, se conseguirá el resultado o consecuencias deseadas. Los individuos persiguen con más probabilidad metas y objetivos que piensan que tienen gran probabilidad de alcanzarlos. Es fundamental para adquirir este tipo de expectativa, el feedback del resultado, la dificultad de la tarea, la información de comparación social y diferencias de personalidad.

Otro de los factores determinantes de las expectativas, que ha obtenido una gran aceptación científica, es la percepción por parte del sujeto de la posibilidad de controlar o no controlar personalmente la consecución de una meta (Rotter, 1966). Este autor afirmó que hay personas que tienden a considerar que la consecución de sus metas se haya bajo su control, mientras que hay otras que piensan que son factores ajenos a ellos mismos los que determinan el que aquellas puedan alcanzarse o no. Para describir estas diferencias, acuñó el término locus de control, compuesto de dos polos: el interno, que agruparía a los descritos en primer lugar, y el externo.

El hecho de que un sujeto se sitúe en el locus interno dependerá de que perciba que la consecución de sus metas se halla necesariamente asociada a sus acciones, mientras que el otro polo dependerá de que no se perciba esa asociación. Rotter consideró inicialmente el locus de control como una característica general, sin embargo investigaciones posteriores han puesto de manifiesto las limitaciones de su conceptualización inicial. En este sentido, se acuñaron conceptos relacionados como control personal, expectativas de autoeficacia, controlabilidad como concepto diferente del lugar de causalidad, control percibido o contingencia. 
Otra de las teorías más influyentes en el desarrollo del concepto de expectativa hasta la actualidad es la Teoría de la indefensión aprendida cuya formulación original se debe a Overmier y Seligman (1967). El término indefensión aprendida hace referencia al estado psicológico que se produce cuando un individuo no puede controlar ni predecir los acontecimientos que configuran su vida, y como consecuencia del cual se originan una serie de perturbaciones motivacionales, cognitivas y emocionales que afectan a todo su comportamiento.

Seligman (1975) denominó indefensión aprendida a la convicción por parte de una animal o persona de que ha perdido el control, de que nada de lo que pueda hacer reportará cambio alguno en ningún aspecto importante de su vida. Para este autor, esta situación era provocada por la existencia de la creencia de poder hacer nada por cambiar la situación, por lo que tampoco se tiene ninguna motivación para intentarlo. Las personas en esta situación se muestran incapaces para aprender una respuesta que incluso pudiera hacer controlar el resultado, ya que consideran que el resultado es traumático y conllevaría caer en un estado depresivo.

Todos estos conceptos guardan una gran relación entre ellos, todos ellos derivan de teorías del aprendizaje en las que se enfatiza el concepto de expectativa y tienen que ver de un modo más explícito o implícito con la noción de control, de ahí que Palenzuela (1991) haya empleado la expresión expectativas de control para referirse a todas ellas conjuntamente e integrarlas en una teoría específica: la teoría de las expectativas generalizadas de control. Las Expectativas Generalizadas de Control engloba cuatro tipos de expectativas:

- Las expectativas de éxito y de locus de control (LOC), derivadas de la Teoría del aprendizaje social de Rotter. 
- La expectativa de indefensión, derivada de la Teoría original de la indefensión aprendida de Seligman.

- La expectativa de autoeficacia, derivada de la Teoría cognitivo social de Bandura.

Se trata de un planteamiento novedoso que pretende englobar las aportaciones de diferentes autores fundamentales en relación con el concepto psicológico de autoeficacia. Pretende complementar el enfoque propuesto por Bandura (1977) quien sólo distinguía dos tipos de expectativas, anteriormente descritas:

La figura 5 representa gráficamente la distinción entre ambas expectativas, tal como lo propuso Bandura (1977):

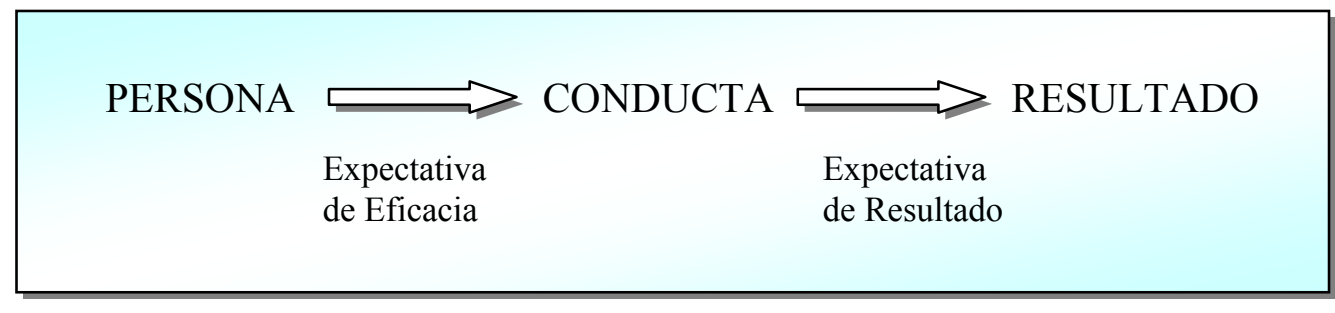

Fig. 5: Diferencia entre expectativa de Eficacia y Resultado

Bandura (1977, 1986) engloba en sus expectativas de resultado diferentes tipos de expectativas formuladas con anterioridad, como las expectativas de locus de control y éxito y la expectativa de indefensión o incontrolabilidad. A esta expectativa Bandura (1977) añadió una nueva, la expectativa de autoeficacia. De este modo, como queda reflejado gráficamente en la figura 5, las expectativas de locus de control, éxito e indefensión quedaron absorbidas en el concepto de Bandura de expectativa de resultado.

La novedad que introduce Palenzuela (1992), es establecer una relación adicional que no aparece en el modelo de Bandura (1977). Es la relación directa 
entre la persona y el resultado; es decir, que coincidiría con lo que en la literatura se ha venido denominando desde los trabajos pioneros de Tolman y Rotter expectativa de refuerzo, meta o éxito. El planteamiento reflejado gráficamente en la figura 6, viene a aclarar el nuevo modelo propuesto a partir del inicial de Bandura, el cual ha sido centro de atención de un gran número de teorías psicológicas y han generado abundante investigación y han tenido importantes aplicaciones.

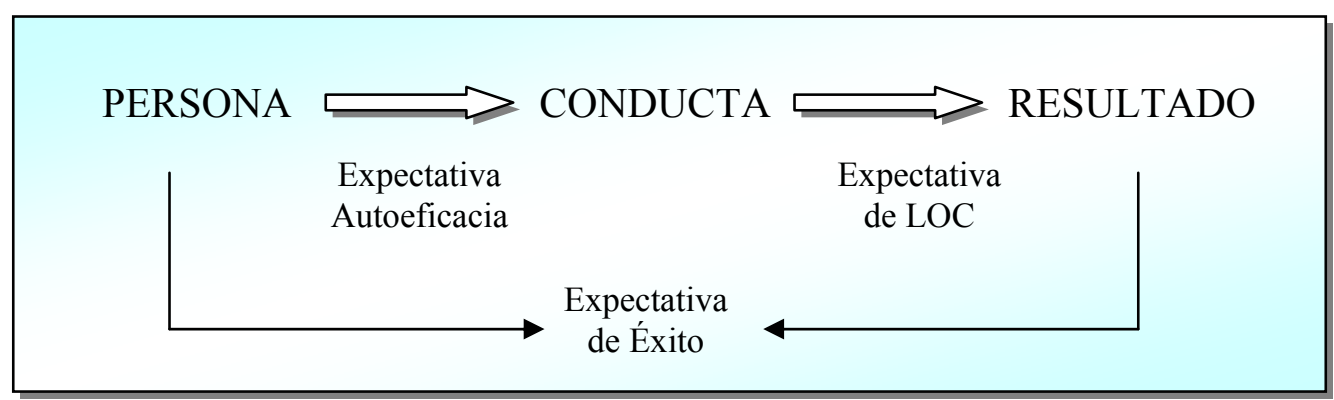

Fig. 6: Diferencia entre expectativa de Autoeficacia, LOC y Éxito (Palenzuela, 1992)

Teniendo en cuenta la figura 6 , se observa como las expectativas de control y resultados están colocadas en el mismo lugar, pudiéndose pensar que son equivalentes, pero no es así. Es cierto que guardan una mayor relación conceptual con respecto a las demás, pero la expectativa de resultado sólo es comparable conceptualmente con el componente interno del locus de control (LOC), nada tiene que ver con el componente externo.

Además, mientras que la expectativa de LOC recoge la noción de contingencia versus no contingencia entre resultados (refuerzos) y conductas derivada de las teorías del aprendizaje, la expectativa de resultado formulada por Bandura (1977) parece enfatizar la capacidad de los seres humanos de anticipar un determinado resultado o consecuencia dada una determinada conducta. De este 
modo, una persona no necesitaría realizar una conducta para observar sus consecuencias, sino que es capaz de anticipar el resultado antes de realizar la conducta. Esta asunción se ajusta perfectamente a su definición de expectativa de resultado pero tiene muy poco que ver con la expectativa de indefensión o incontrolabilidad, la expectativa de LOC externo, o con la expectativa de éxito.

Finalmente, como última observación sobre este modelo, en la figura 6 aparecen reflejadas explícitamente la expectativa de autoeficacia, las expectativas de resultados y LOC y la expectativa de éxito, pero no la expectativa de indefensión o incontrolabilidad. De acuerdo con la perspectiva teórica de Palenzuela (1988), la expectativa de indefensión constituye uno de los componentes del LOC de control externo.

La expectativa de locus de control contiene tres facetas:

- La expectativa de contingencia o internalidad (referida al control interno) se refiere al grado en que uno espera que los acontecimientos o resultados que puedan acontecerle o tener lugar en su vida sean contingentes con sus acciones.

- La expectativa de indefensión o no contingencia (propia del control externo) se refiere al grado en que uno espera que los acontecimientos o resultados que puedan acontecerle o tener lugar en su vida serán independientes de sus acciones.

La expectativa o creencia en la suerte (control externo)se refiere al grado en que uno cree en la suerte, en qué grado cree que las cosas que a uno puedan ocurrirle en su vida estarán a merced del azar y la casualidad. 
Por su parte, la expectativa de autoeficacia hace referencia a los juicios de las personas sobre sus propias capacidades, en qué medida uno se siente capaz de emprender o realizar acciones concretas para conseguir determinados resultados.

La expectativa de éxito se refiere a una estimación subjetiva de la medida en qué una persona espera conseguir una meta, un refuerzo o un resultado deseado.

Después de la breve aproximación teórica al concepto de expectativa, destacamos los principales estudios que analizan esta variable en muestras de mujeres menopáusicas. Apenas existen trabajos de investigación que utilicen este concepto específico de expectativas generalizadas de control, menos aún relacionado con las variables de este estudio (síntomas climatéricos, calidad de vida, menopausia, etc.). Además muchos de los estudios analizados presentan sesgos o confusiones entre términos distintos pero relacionados con las expectativas como creencias o actitudes. Se ha pretendido aclarar estos términos, haciendo referencia a continuación a estudios que hacen referencia, con una nomenclatura u otra, al concepto de expectativa en general.

La menopausia se ve afectada por las creencias y expectativas de las mujeres respecto a los síntomas que deben esperarse y la repercusión en su salud. La mayor o menor autoaceptación dependerá en buena parte de lo que se ha logrado realizar a lo largo de la vida, en relación con las expectativas sociales. Los mayores los viven aquellas mujeres que, habiéndose centrado en sus hijos, no logra readaptarse a su nueva situación, o aquellas que consideran que ya no podrán cumplir con un determinado proyecto de vida. Existe, por tanto de un desajuste entre expectativas y realidad conseguida (López y Fuertes, 1989). 
Uno de los trabajos más interesantes es el realizado por Avis y McKinlay (1991), dentro del Estudio Massachussets sobre la salud de las mujeres, al que ya nos hemos referido en varias ocasiones anteriormente. Estos autores examinaron las actitudes hacia la menopausia a 2565 mujeres seleccionadas aleatoriamente de la población de dicha ciudad en un estudio longitudinal y prospectivo. Fueron preguntadas sobre las actitudes hacia la menopausia y si han estas actitudes variaron debido a la menopausia. La mayoría refería sentimientos neutros respecto a la cesación de la menstruación y que estos sentimientos se tornaban en más positivos a medida que experimentaban la menopausia. Las mujeres que informaron de actitudes negativas hacia la menopausia mostraban mayor sintomatología relevante $\mathrm{y}$ depresión. Los autores concluyen que el síndrome menopáusico puede deberse, por tanto, en mayor medida a las características personales que al desarrollo de la menopausia en sí.

Holte y Mikkelsen (1991) analizaron los determinantes psicosociales de las quejas o demandas más frecuentes durante el climaterio. De 2349 mujeres noruegas, de entre 45 y 55 años, obtuvieron cinco síntomas de mayor frecuencia durante la menopausia cuya relación con diferentes parámetros psicosociales fue analizada. El análisis determinó que cinco factores era los que, en mayor medida, explicaban la variabilidad: dificultades durante la menstruación en edad más temprana, relaciones interpersonales, complicaciones en el climaterio de la madre, edad cronológica y expectativas negativas acerca de la menopausia.

Standing y Glarzer (1992) en su publicación en la valoraban la percepción hacia la menopausia de 66 mujeres de nivel socioeconómico bajo. Los resultados también indicaron una valoración positiva generalizada. 
En 1994, Liao, Hunter et al estudiaron las creencias sobre la menopausia en una muestra de mujeres de mediana edad. Parte de la hipótesis que estudios sobre población general sugieren que la experiencia de una transición normal a la menopausia, es relativamente generalizada pero las creencias negativas estereotipas sobre la menopausia puede empeorar esta experiencia. Consideran que una mayor información sobre la menopausia puede modificar creencias erróneas y atribuciones falsas.

Díez (1994) analiza las variables psicosociales asociadas a la depresión climatérica concluyendo, tras un pathanálisis con variables latentes, que existe una génesis multifactorial en la depresión postmenopaúsica, con incidencia importante de las expectativas de autoeficacia y contingencia, del pensamiento anticipatorio y de la relación de pareja. El estudio incluye por primera vez la batería que evalúa las expectativas generalizadas de control como variable en un estudio relacionado con el climaterio y la menopausia, no habiendo encontrado otra investigación similar hasta la actualidad.

Otro estudio relevante y que incluye una variable novedosa como es la diferencia de edad, es el realizado por Wagner, Kuhn et al (1995). Se propusieron determinar las diferencias, entre un grupo de mediana edad y otro de chicas en edad escolar, sobre la percepción subjetiva hacia la menopausia. El análisis de los cuestionarios mostró una visión más positiva de la menopausia por parte de las mujeres de mediana edad. Esta variabilidad relacionada con la edad, demuestra según los autores, la necesidad de fomentar la información sobre las opciones terapéuticas y una mayor educación, teniendo en cuenta el desconocimiento evidenciado por el grupo de escolares. 
Wilbur, Miller et al (1995) analizaron la influencia de las características demográficas (raza, estado civil, número de hijos, etc.), el estado y los síntomas físicos y psicológicos menopáusicos sobre las actitudes hacia la menopausia. La muestra estaba compuesta por 149 mujeres de edades comprendidas entre los 35 y 65 años, siendo estratificada en función de la edad, la profesión y la raza. La mayoría de las mujeres, independientemente del nivel económico o de las variables sociodemográficas, muestran unos sentimientos neutrales respecto a la menopausia. En cambio, las mujeres postmenopáusicas informan actitudes más positivas hacia la menopausia, lo que indicaría que una vez pasada la menopausia, valoran esta etapa como menos amenazante de lo que anticiparon antes de llegar a esta etapa en sus vidas. Por último, los autores refieren que las actitudes negativas estaban relacionadas con síntomas psicológicos, concretamente con mayores puntuaciones en las escalas de depresión, lo que supone que estas mujeres tendrán más dificultades para la transición que supone la menopausia.

Una investigación cuyos objetivos son semejantes al anterior, aunque incluye variables sociales y psicológicas de mayor relevancia como la autoestima, se llevó a cabo en población mexicana. Bell (1995) pretendía determinar la relación entre las actitudes y diferentes variables demográficas y personales (nivel socioeconómico, nivel cultura, estado y sintomatología menopáusica, autoestima y apoyo social). En la muestra de 130 mujeres mexicanas, y edades entre 28 y 75 años, encontró que las actitudes apenas diferían en función del nivel socioeconómico o la frecuencia/intensidad de los síntomas. Por el contrario, sí obtuvo relaciones significativas entre una actitud positiva con un nivel cultural más bajo y con mujeres con mayor autoestima. En general, la menopausia era percibida como una época de transición potencialmente turbadora en la que esperaban un aumento de la 
irritabilidad y ánimo depresivo. Para el autor, estos resultados sugieren que una mayor accesibilidad a la información relacionada con la menopausia para reducir las expectativas negativas, que sin duda influyen en la percepción subjetiva de la menopausia.

Otra publicación que valora una población, con un tipo racial específico, la realizan Holmes- Rovner, Padonu et al (1996) sobre una muestra de mujeres americanas de descendencia africana. También pretendían determinar las expectativas sobre menopausia y THS. Los resultados indican que la mayoría de las mujeres refieren expectativas claras de tener diferentes síntomas durante la menopausia, pero no creen que les causarán un malestar importante. También evidenciaban un conocimiento deficiente de los cambios en la menopausia, infravalorando riesgos como los problemas cardiovasculares, y de la THS. Estos autores vuelven a proponer la necesidad de una mayor educación relacionada con la menopausia para que puedan resultar más efectivas estrategias de prevención que se ven condicionadas por el desconocimiento de las mujeres objeto de estudio.

Una investigación realizada con población israelí mostraba las expectativas de estas mujeres respecto a la menopausia. 171 mujeres fueron encuestadas telefónicamente y 41 mediante correo convencional. Blumberg, Kaplan et al (1996) obtuvieron que un $80 \%$ de las mujeres tenía unas expectativas neutras o positiva sobre la menopausia.

Como estamos señalando, al estudiar aspectos como las creencias, expectativas o actitudes es innegable la influencia cultural que condiciona la visión de una etapa tan relacionada con la edad como la menopausia. Esto lo encontramos en el artículo de Chen y Voda (1996) sobre las actitudes y creencia, respecto a la menopausia, de 
las mujeres de raza china de mediana edad. Se evaluaron 208 mujeres de raza china residentes en Taiwan, de edades entre 35 y 55 años. Los resultados mostraron que casi el 92\% de las mujeres percibían la menopausia como un fenómeno natural, sin existir diferencias estadísticamente significativas en las actitudes en relación con la intensidad de los síntomas menopáusicos, con el recibir o no tratamiento hormonal o por las creencias religiosas. Obtuvieron descripciones de la menopausia que la definían como: "una demostración de lo logrado", "un signo de maduración" o "la etapa para comenzar a disfrutar de la vida”. Los autores proponen que este estudio debe servir de ejemplo para conseguir un cambio de actitudes y expectativas en la cultura occidental, ya que es evidente los aspectos culturales y tradicionales influyen en la vivencia de la menopausia.

Pham y Griso (1997) realizan una investigación muy semejante a esta , pero evalúan las diferencias en las actitudes hacia la menopausia entre las mujeres americanas de origen africano y mujeres americanas de raza blanca. Encontraron diferencias significativas en las expectativas y actitudes entre ambos grupos, e informaron que las mujeres de origen africano tenían unas expectativas más positivas y estaban más dispuestas a recibir información sobre la menopausia (sobre a todo en el entorno familiar). Estos conclusiones son limitadas y no pueden ser asumidas debidos a las deficiencias metodológicas (muestra limitada y población clínica).

La conceptualización que le otorgan las mujeres a los cambios que padecen en la menopausia, y las explicaciones de estos tienen una gran importancia en las expectativas que presentan, como demuestran Woods, Saber et al (1998) en su investigación sobre la relación existente entre las expectativas hacia la menopausia y 
los paradigmas explicativos de la menopausia (el que considera a la menopausia como un evento natural, no traumático, en la vida de la mujer o la visión biomédica que tiende a patologizar la menopausia). Los resultados sobre las 2092 mujeres evaluadas demuestran que las mujeres que consideraban la menopausia como una deficiencia hormonal cuyos síntomas pueden ser tratados, presentaban unas expectativas más positivas hacia los cambios propios de la menopausia. Los autores concluyen que a pesar de estos hallazgos no existe evidencias estadísticas que confirmen una relación entre las expectativas positivas hacia la menopausia y la adopción de un modelo biomédico o del desarrollo para explicar la menopausia, porque esta valoración subjetiva es multidimensionales y está influenciada por múltiples factores.

La Sociedad Norteamericana de Menopausia también se interesa por la influencia de las actitudes, creencias y expectativas durante la menopausia y realiza durante el año 1997 un estudio sobre 750 mujeres de edades entre 45 y 60 años. Esta investigación fue liderada por Kaufert , Boggs y Utian (1998). Se preguntó a las mujeres sobre su conocimiento de la menopausia, sus fuentes de información sobre el tema, los cambios en su salud que anticiparon antes de la cesación total de la menstruación, los motivos de la utilización de la THS y su valoración de la menopausia como un evento natural o como una enfermedad. Los síntomas que las mujeres más asociaron con la menopausia, fueron la ansiedad, irritabilidad o depresión, incluso más que los problemas cardiovasculares. La mayoría de las mujeres que comenzaban a tener los cambios propios de la premenopausia o que eran postmenopáusicas presentaron en su mayoría actitudes neutrales ( $42 \%$ ) o positivas ( $36 \%$ ). En cuanto a la interpretación de las causas, las mujeres se dividieron entre las dos opciones (evento natural o enfermedad), sin obtenerse una postura unánime. 
Jiménez y Pérez (1999) también estudian las expectativas y actitudes hacia la menopausia y su influencia en el climaterio en un estudio transversal y observacional con 425 mujeres mexicanas de edades entorno a los 50 años. Aunque un 57\% de las pacientes calificaban de forma negativa a la menopausia, del total de la muestra 180 mujeres mostraban una actitud positiva y 245 mujeres actitudes negativas hacia la menopausia. Los síntomas que referían como más frecuentes estaba la fatigan, la irritabilidad, inestabilidad emocional y depresión. Los análisis estadísticos demuestran que la predisposición y las actitudes negativas antes de la menopausia favorecen la aparición y la frecuencia de síntomas psicológicos.

Una investigación que introduce un concepto psicológico escasamente estudiado es la que se realizó en Seattle por Woods y Mitchell (1999). Evaluaron la anticipación de la menopausia mediante la imagen, que tenían las mujeres, de la menopausia y de las expectativas en función de su propia experiencia. Los resultados de las 508 mujeres estudiadas. Muy pocas mujeres conceptualizaron a la menopausia como "período de síntomas" o "riesgo de enfermedades", por el contrario, la mayoría catalogan esta etapa de sus vidas como "cambio de vida" o "cambios emocionales". Muchas de las mujeres confirmaron que las expectativas que tenían antes de comenzar la sintomatología básica no eran congruentes con lo que realmente habían vivido durante su menopausia.

Una investigación de mayor rigor metodológico, también realizada en Estados Unidos la dirigieron Sommer, Avis y cols. (2000), quienes asumen que las actitudes juegan un papel fundamental en la experiencia de la menopausia. Examinaron el posible desacuerdo existente en las actitudes entre diferentes grupos étnicos y raciales de Estados Unidos. Los resultados se obtuvieron de más de 16000 mujeres, 
estando representados cinco grupos étnicos o raciales (africanos, blancos, chinos, japoneses e hispanos). Entre las conclusiones destacan la confirmación, en otro estudio, de que las actitudes hacia la menopausia, de las americanas-africanas era $n$ significativamente más positiva. Los grupos que mostraban unas actitudes más negativas fueron las americanas de raza china o japonesa y con bajo nivel cultural. Aunque en general, los autores consideraban que las mujeres presentaban unas actitudes neutrales o positivas hacia la menopausia, se puede considerar que existen factores asociados a estas actitudes, como pueden ser la pertenencia a un grupo racial determinado o el estado menopáusico en el momento de la evaluación.

Centrado en las diferencias culturales de diferentes razas o etnias y sus consecuencias en las expectativas ante la menopausia se realizó en Gran Bretaña un estudio sobre mujeres de origen asiático. Sethi y Pitkin (2000) intentaron establecer el punto de vista y las actitudes de este grupo de mujeres respecto a la menopausia . El $82 \%$ afirmaba comprender lo que supone la menopausia y el $77 \%$ definía la menopausia como un fenómeno natural.

Betti, Orsini et al (2001) realizan, en Italia, una investigación preliminar sobre las actitudes específicas hacia la menopausia y los estilos comportamentales en mujeres menopáusicas. De las 88 mujeres que acudían a su Unidad de Menopausia de Milano, y fueron la muestra seleccionada, 43 recibían tratamiento con THS. Evaluaron los cambios de intereses y nuevas aficiones después del climaterio y los sentimientos de pérdida o de inutilidad. Las respuestas de las mujeres mostraban gran variabilidad interpersonal y relataban síntomas negativos (ansiedad, sofocos, etc.) asociados frecuentemente con experiencias positivas (nuevos hobbies o cambios en el estilo de vida). Los cambios propios de la menopausia eran vivenciados tanto de 
forma objetiva (aumento de peso, pérdida de memoria...) y subjetiva (cambio en el carácter, pérdida de atractivo...). La frecuencia de la ansiedad y depresión fue congruente con otros estudios. Según los autores, estos resultados confirman que los cambios físicos y psicológicos que representa la transición a la menopausia son integrados por las mujeres. Con el objetivo de preservar la calidad de vida durante la menopausia, consideran que es fundamental conseguir una estabilidad en el ánimo de las mujeres menopáusicas y unas actitudes positivas ante los cambios que se van a producir o se estén ya produciendo.

En un artículo publicado por Stotland (2002),se explica la importante influencia de las expectativas sociales en la realidad de las mujeres menopáusicas. Considera que el contexto histórico y social condiciona significativamente las expectativas implícitas y explícitas. Considera que la sociedad americana se orienta hacia los valores de la juventud, considerando la menopausia como una etapa de atención a la familia caracterizada por la pérdida del interés sexual. Cree que estas expectativas sociales "presionan" a las mujeres menopáusicas y tienen muchas dificultades para no caer en este rol estereotipado. Crítica el apelativo de "sustitutivo" que se le da a la terapia estrogénica, considerando que ha acentuado los miedos en las mujeres de mediana edad.

Buchanan, Villagram et al (2002) analizan la comunicación existente sobre la menopausia en un triángulo que formarían la mujer, la menopausia y la información. La comunicación afecta y puede modificar las actitudes, creencias o conocimientos de las mujeres respecto a la menopausia. Se basan en la teoría de Glaser y Strauss (1967) para aproximarse a la comunicación pérdida que está relacionada con las experiencias que las mujeres han vivído durante el climaterio. Sus resultados resaltan 
y demuestran la pérdida consistente de información, lo que genera desconocimiento o desinformación sobre los cambios producidos en la menopausia y favorece el mantenimiento de creencias falsas o actitudes desadaptativas hacia la menopausia.

George (2002) pretende explicar la experiencia que supone la menopausia, desde el punto de vista y perspectiva de la mujer. Para entender la complejidad que supone el tema e intentando acotar todas las variables, propone dos puntos fundamentales de estudio: el examen e interpretación de la realidad durante la transición a ala menopausia, experimentada por las mujeres y la identificación de elementos y temas que acontecen como resultado de la complejidad de esta etapa vital. Los datos apoyan las premisas del estudio y sugieren que la experiencia de la menopausia es única, siendo esta individualidad la que explica las diferencias perspectivas encontradas. Esta individualidad está constituida por el significado personal que se le otorgan a las experiencias, por las expectativas, las actitudes y las creencias sobre la menopausia.

Von Gruchalla y cols. (2003) analizan qué factores determinan la autoimagen y autoconcepto de las mujeres en la peri y postmenopausia encontrando que la percepción de su cuerpo ( tanto en su estado físico como en el atractivo ) son los factores que más condicionan el bienestar y las expectativas de las mujeres en esta etapa. Bertero (2003) estudia en Suecia qué piensan las mujeres respecto a la menopausia, realizando un estudio cualitativo de las expectativas. Concluye que las mujeres que tienen información y conocimiento de los cambios propios de esta etapa, consiguen integrar adecuadamente estos cambios en su actividad diaria mostrando unas expectativas más positivas y adaptativas. 
Busch y cols. (2003) analiza las expectativas de una muestra de 130 mujeres respecto a la menopausia, obteniendo que el $57 \%$ de ellas tenían expectativas neutras respecto a la transición menopaúsica, el 31\% tenían expectativas negativas y el 12\% presentan una expectativa positiva. Concluye que, en general, las mujeres tienen una perspectiva negativa de la transición menopáusica y sus expectativas no son adecuadas.

En una revisión previa al inicio de esta investigación, De la Gándara y cols. (2003) evaluamos la influencia de las expectativas, actitudes y creencias en la adaptación a la menopausia obteniendo diferencias significativas en la percepción subjetiva de la transición menopáusica y en la aumento de síntomas psicológicos (depresión y ansiedad), entre las mujeres que ofrecían unas expectativas adecuadas y creencias normalizadas frente las mujeres que mostraban creencias irracionales y expectativas negativas de futuro.

En otra referencia destacada $\mathrm{Wu}$, Tang y Kwok (2004), analizan la asociación entre locus de control sobre la salud, la autoeficacia y el malestar psicológico en mujeres mayores. Sus resultados permiten señalar que tanto la autoeficacia como las creencias de control sobre la salud son predoctores importantes del funcionamiento psicológico. Concluyen que el locus de control externo sobre la salud tiene una gran influencia como predictor negativo del estado mental de las participantes, observando esta influencia incluso cuando se controla el efecto de la autoeficacia.

En un estudio con una muestra de mujeres hispanas residentes en los Estados Unidos, Esposito (2005) concluye que mostraban más iniciativas y una expectativa personalizada e individualizada acerca de su etapa menopáusica presentaban mejores indicadores de salud. Relacionando la influencia de diversos factores, entre ellos las 
expectativas, sobre la sintomatología climatérica Kalpakjian (2005) asume que existe una relación compleja y multifactorial entre los constructos que parecen validados para medir estado menopáusica y la realidad clínica de las mujeres menopáusicas.

En los últimos años, se han reducido si cabe, los estudios que incluyen las expectativas en investigaciones relacionadas con la menopausia. Hvas (2006) valora las características de las expectativas de las mujeres respecto al envejecimiento, y concretamente respecto a la menopausia, considerando necesario alertar a los profesionales para reorientar a las mujeres hacia actividades saludables que supongan un afrontamiento positivo de sus problemas diarios.

Leggett (2007) considera la menopausia como un punto de inflexión que ofrece la oportunidad de mejorar el crecimiento personal de las mujeres en esta etapa. Para ello, considera fundamental educar a las mujeres menopáusicas para conseguir una mayor adaptación y ajuste a los cambios físicos, relacionales y laborales.

Respecto a las publicaciones e investigaciones realizadas en nuestro país apenas se han realizado estudios sobre las expectativas en la menopausia. De los encontrados, vamos a referirnos a los siguientes por ser novedosos en su planteamiento y por mantener un rigor metodológico adecuado.

Aparte del realizado por Díez ( 1994 ), comentado anteriormente, Olazábal, Pastor et al (2000) realizan un estudio sobre la adscripción a los diversos modelos de concebir la menopausia del personal sanitario de Salamanca y las actitudes del personal sanitario respecto a la transición climatérica. Participaron 260 médicos y enfermeros de atención primaria. Los resultados indican que el modelo de adscripción más prevalente es el holístico o integral (47\%). La adscripción a los diversos modelos está influida por la edad y por el tipo de profesional, pero no por el 
sexo o lugar de trabajo del sanitario. El modelo holístico es más frecuente entre los sanitarios más jóvenes y en los profesionales de enfermería.

Una investigación realizada en Granada en el año 2001 por Delgado et al, evalúa las actitudes de 101 mujeres sobre la menopausia y cómo se relacionan estas actitudes con ciertas variables personales. Un $90 \%$ de las mujeres evaluadas consideran que la menopausia es una etapa más en la vida de la mujer y sus resultados muestran un $54,5 \%$ de actitudes positivas ante la menopausia, un $22 \%$ manifiesta actitudes negativas y otro $22 \%$ no tiene una actitud formada.

Otro artículo de gran interés y que se basa en una teoría psicológica muy concreta, como es la Teoría Constructivista es el que han llevado a cabo en Córdoba. Castro, Moreno et al (2002) a analizar el papel modificador de la menopausia en los valores, creencias y expectativas femeninas. La muestra estaba compuesta por 80 mujeres divididas en dos grupos según el tipo de menopausia que presentaran: fisiológica o quirúrgica. Ambos grupos fueron analizados siguiendo la técnica proyectiva de los constructos personales de Kelly, llegando a varias conclusiones:

- $\quad$ El período climatérico produce una construcción de la realidad que depende tanto de enfermedades ginecológicas intercurrentes en este período, como de estereotipos sociales, existiendo diferencias cualitativas en función del tipo de menopausia.

- Las mujeres con menopausia fisiológica poseen un sistema constructivo débil y permeable, trasladando los atributos de identidad femenina desde su imagen real a la ideal, producido por el largo proceso que permite asumir un nuevo rol. 
- $\quad$ Las mujeres con menopausia quirúrgica presentan una construcción impermeable, situando a la mujer en una realidad muy personal.

Un proyecto internacional de gran relevancia en el que ha participado la Universidad Complutense de Madrid, se titula Decisiones Terapeúticas en la Menopausia. El objetivo de este estudio es conocer en qué medida sufren las mujeres los síntomas menopáusicos, qué factores influyen en su forma de vivir esta etapa de transición y qué decisiones terapeúticas se toman. En la valoración que Echeverri y Bustamante (2004) realizan de sus percepciones durante la evaluación de las mujeres indican que no existe una interacción entre médico y paciente a la hora de tomar decisiones terapéuticas; que a pesar de manifestar numerosos síntomas, la mayoría de las mujeres entrevistadas afirman que su salud es buena; y, por último, que se aprecia una actitud positiva ante la menopausia, aceptando este signo de envejecimiento con optimismo.

De esta revisión de las investigaciones más relevantes sobre el tema se asume, sin ningún tipo de duda, la importancia de las expectativas y actitudes hacia le menopausia y su influencia sobre cómo experimentan las mujeres los cambios propios del climaterio. Aceptado esto, todavía queda un largo camino por recorrer en la clarificación y explicación de esta influencia ya que gran parte de los estudios ofrecen conclusiones contradictorias al encontrar altos porcentajes de actitudes neutras o positivas, pero no se corresponde con una mejoría en la adaptación a la nueva situación vital que supone la menopausia. Nuestro interés en este contexto, es utilizar un concepto menos amplio, más específico y concreto, como son las expectativas generalizadas de control. 
Influencia de las expectativas y la calidad de vida en el estado de ánimo durante la transición menopáusica 


\subsection{Calidad de vida en la menopausia}

El interés por la calidad de vida ha existido desde hace mucho tiempo, sin embargo, la aparición del concepto como tal y la preocupación por la evaluación sistemática y científica del mismo es relativamente reciente. García Riaño e Ibáñez (1996) consideran que la definición de salud dada por la Organización Mundial de la Salud en 1946, bienestar físico, mental y social, es el preludio del concepto de calidad de vida. La idea comienza a popularizarse en la década de los 60 hasta convertirse hoy en uno de los más utilizados en ámbitos muy diversos, como son la salud, la salud mental, la educación, la economía, la política y el mundo de los servicios en general.

Aunque su prehistoria data de las civilizaciones griega, romana, egipcia y hebrea, es en el contexto del debate entre los indicadores materiales y subjetivos del bienestar en el que surge propiamente el término. En un primer momento, la expresión calidad de vida aparece en los debates públicos en torno al medio ambiente y al deterioro de las condiciones de vida urbana. Bech (1993) considera que la primera persona pública que utilizó el término fue el Presidente estadounidense Lyndon B. Jonson en 1964.

Durante la década de los 50 y a comienzos de los 60 , el creciente interés por conocer el bienestar humano y la preocupación por las consecuencias de la industrialización de la sociedad hacen surgir la necesidad de medir esta realidad a través de datos objetivos, y desde las Ciencias Sociales se inicia el desarrollo de los indicadores sociales, estadísticos que permiten medir datos y hechos vinculados al bienestar social de una población. Estos indicadores tuvieron su propia evolución siendo en un primer momento referencia de las condiciones objetivas, de tipo 
económico y social, para en un segundo momento contemplar elementos subjetivos (Arostegui, 1998).

El desarrollo y perfeccionamiento de los indicadores sociales, a mediados de los 70 y comienzos de los 80 , provocará el proceso de diferenciación entre éstos y la calidad de vida. La expresión comienza a definirse como concepto integrador que comprende todas las áreas de la vida (carácter multidimensional) y hace referencia tanto a condiciones objetivas como a componentes subjetivos. La inclusión del término en la primera revista monográfica de EE UU, "Social Indicators Research", en 1974 y en "Sociological Abstracts" en 1979, contribuyó a su difusión teórica y metodológica, convirtiéndose la década de los 80 en la del despegue definitivo de la investigación en torno al término.

Transcurridos más de veinte años, aún existe una falta de consenso sobre la definición del constructo y su evaluación. En el Symposium celebrado en Londres en 1987 sobre "Calidad de vida: evaluación y tratamiento", se subrayaba el hecho de que cada vez más profesionales de la salud de diversas especialidades y disciplinas son conscientes de que uno de los objetivos principales de las intervenciones médicas es mejorar la calidad de vida de los pacientes. De la misma forma, intensificar la calidad de vida es tan importante como otros objetivos médicos tradicionales como prevenir, curar, aliviar síntomas o dolor, prevenir complicaciones, proporcionar atención humana o prolongar la vida (Patrick y Erikson, 1987).

Ha habido diferentes definiciones del concepto e incluso Spitzer (1987) aceptaba que no existía una definición de calidad de vida y que el término era definible de forma operativa. La OMS propuso, en 1994, la siguiente definición para intentar lograr el consenso: "Percepción personal de un individuo de su situación en 
la vida, dentro del contexto cultural y de valores en que vive, y en relación con sus objetivos, expectativas, valores e intereses".

Son muchos los modelos conceptuales que han intentado explicar el concepto de calidad de vida, aumentando muchos de ellos la confusión y la complejidad en torno al mismo. Históricamente han existido dos aproximaciones básicas: quienes lo conciben como una entidad unitaria y, quienes lo consideran un constructo compuesto por una serie de dominios. Esta última postura parece ser la que más aceptación tiene en la actualidad. Bobes (1995) en la revisión de las distintas conceptualizaciones considera que casi todas las definiciones coinciden en "el carácter subjetivo y multidimensional del concepto".

Felce y Perry (1995) formulan cuatro modelos conceptuales diferentes todos ellos relacionados con la Calidad de Vida:

- Calidad de las condiciones de vida de una persona.

- Satisfacción experimentada por la persona en dichas condiciones vitales.

- Combinación de componentes objetivos y subjetivos (es decir, la calidad de las condiciones de vida junto con la satisfacción que la persona experimenta).

- Combinación de las condiciones de vida junto con la escala de valores, aspiraciones y expectativas personales.

En el contexto de la salud, este concepto se convirtió, desde 1977, en categoría de búsqueda en el Index Medicus y en palabra clave en el sistema Medline, aunque llegó a ser realmente popular entre los investigadores de la salud durante la década del 80. A partir de entonces, la tendencia ha sido al crecimiento, en gran parte determinado por la prevalencia de enfermedades crónicas y el aumento en la 
esperanza de vida. Es frecuente, encontrar en la literatura el concepto "calidad de vida relacionada con la salud".

La salud es considerada uno de los principales valores del hombre, uno de los determinantes más importantes de la calidad de vida total, a la vez que repercute en el resto de los elementos o valores presentes en la $\mathrm{CV}$ y esta es una resultante también de la atención a la salud. Por ello, muchos autores consideran que el concepto de salud no sólo es el valor predominante, sino aglutinante, entre los distintos integrantes de la calidad de vida (Kaplan, 1985 ).

La calidad de vida relacionada con la salud (CVRS) se relaciona con el impacto de la enfermedad en el bienestar físico, emocional y social. Schumacher y Naughton (1996) definen la CVRS como la percepción subjetiva, influenciada por el estado actual de salud, de la capacidad para realizar aquellas actividades importantes para el individuo.

El grupo WHOQOL (1994) propuso una serie de puntos o características de consenso en la conceptualización del término: subjetiva, multidimensional, es variable en el tiempo e incluye sentimientos positivos y negativos. Aunque existe cierta variabilidad en las dimensiones que deben ser evaluadas para determinar la CVRS, existiendo debates en cuanto a cuáles son las dimensiones que han de explorarse. Según la OMS en la evaluación y conceptualización de la CVRS se debe incluir, al menos, las siguientes dimensiones, al tratarse de valores universales de las diversas culturas:

- Física: percepción de su estado físico (síntomas producidos por la enfermedad, y los efectos del tratamiento, etc.) 
- Psicológica: percepción del individuo de su estado cognitivo y afectivo (el miedo, la ansiedad, incomunicación, perdida de autoestima, incertidumbre por el porvenir, etc.).

- Social: percepción del individuo de sus relaciones interpersonales y roles sociales en la vida (necesidad de apoyo familiar y social, relación médicopaciente, etc.)

- Espiritual / religioso / creencias personales (significado de la vida, actitud ante el sufrimiento, etc.).

Se pueden establecer tres problemas fundamentales en la investigación de la calidad de vida en el contexto de la salud:

a) Indistinción conceptual, determinada en gran parte por su naturaleza compleja. Como resulta con muchos otros constructos, ha resultado más fácil medirla que definirla; suele confundirse con otras acepciones como bienestar, nivel de vida, satisfacción y felicidad. Campbell y cols (1976) han señalado que la calidad de vida es una entidad vaga y etérea, algo de lo que todo el mundo habla, pero que nadie sabe exactamente de qué se trata. Levi y Anderson (1980), asumiendo una propuesta de la ONU, afirman que es una "medida compuesta de bienestar físico, mental y social, tal como la percibe cada individuo y cada grupo, y de felicidad, satisfacción y recompensa".

Asociado a lo anterior, se erigen los problemas relacionados con la naturaleza de la CV: de sus componentes subjetivos y objetivos. Al primero de ellos corresponden definiciones globales basadas en el bienestar y sus dos marcadores básicos: la satisfacción y la felicidad. El componente objetivo se refiere a las condiciones materiales de vida, al nivel de vida e incluye factores que determinan o 
influyen sobre la percepción que tiene el sujeto (presencia o no de síntomas, funcionamiento físico) y que suelen aparecer en las definiciones multidimensionales usadas para el desarrollo de instrumentos de medición (Grau, 1997).

b) Problemas de metodología . En los últimos años, parece mucho más útil el estudio de su componente subjetivo, de su naturaleza psicológica, evaluada por el propio individuo. Si la calidad de vida es una valoración subjetiva, no puede prescindirse entonces de la valoración del sujeto. El papel de los factores psicológicos que condicionan el grado de satisfacción o bienestar es determinante para el proceso de evaluación. Así, desde el campo de la Psicología, la calidad de vida se convierte en un concepto básicamente referido al tipo de respuesta individual y social ante el conjunto de situaciones de la vida; se centra en la percepción de ese bienestar, en el análisis de los procesos que conducen a esa satisfacción y en los elementos integrantes de la misma.

Otro problema de trascendencia metodológica que se discute actualmente es el de los componentes, es decir, si la calidad de vida debe definirse como una medida global que se evalúa en su totalidad o si se define en función de determinadas dimensiones relevantes en un contexto determinado. Últimamente se observa cierto consenso en considerar a la calidad de vida como un constructo incluyente de todos los factores que impactan sobre la vida del individuo.

c) Dificultades en la evaluación. Un problema de los instrumentos utilizados para evaluar la calidad de vida es el de la validez y la fiabilidad de los métodos de evaluación. Para poder medir fiabilidad hay que suponer la estabilidad de la variable medida. Sin embargo, este supuesto no resulta válido en muchas mediciones de calidad de vida; en particular, cuando se intenta evaluar el estado de salud o su 
impacto en el bienestar subjetivo a través de variables inestables. Por otra parte, no siempre es posible establecer la consistencia interna a través del establecimiento de grupos de variables que tienden a covariar conjuntamente. La propia validez depende en mucho de la definición operacional de la variable medida, por lo que muchos autores reportan dificultades al establecer elementos criteriales $\mathrm{o}$ al intentar validaciones de constructo (Grau, 1997).

En relación con la evaluación de la calidad de vida en la menopausia, Wiklund (1996) resalta varias consideraciones:

- Se ha producido un cambio desde la medicina tradicional, centrada en la curación, hacia una medicina preventiva.

- Las valoraciones se hacen sobre los resultados fisiológicos, estando estos muy alejados de la valoración subjetiva que cada paciente hace del impacto de la sintomatología menopáusica sobre su propia calidad de vida.

- La atención debería centrarse sobre cómo se sienten las mujeres menopáusicas, preguntándoles acerca de su percepción personal y sobre sus sentimientos de bienestar o distrés.

- Las mediciones de la calidad de vida durante la menopausia son un buen criterio para seguir la evolución clínica y de los tratamientos.

A pesar de su relevancia actual, el concepto de calidad de vida es reciente y todavía es motivo de reconceptualizaciones o matizaciones. Por tanto, los primeros estudios de calidad de vida y menopausia aparecieron hace relativamente poco tiempo, comenzando en los inicios de la década de los 90, siendo pocos los estudios que ofrecen unas conclusiones metodológicamente generalizables. Cada año 
aumenta el número de investigaciones que incluyen la calidad de vida como uno de los objetivos de estudio.

En el campo de la menopausia, está tendencia también se evidencia aunque las diferencias del resto de variables hacen que existan gran variabilidad en las conclusiones. Von Sydow y Reimer (1995) indican en ese año que las publicaciones que estudian los síntomas menopáusicos apenas incluyen la evaluación de la calidad de vida. Estos autores realizaron una revisión bibliográfica de la literatura sobre menopausia entre los años 1988 y 1992, observando que cerca de 100 estudios analizaban aspectos ginecológicos o médicos en general pero alrededor del $90 \%$ de estos obviaban los aspectos psicológicos. Sólo en 58 estudios mencionaban entre sus palabras clave la calidad de vida o aspectos psicológicos.

Se trata por tanto de un concepto fisiológico y cronológico, y como tal permite delimitar etapas transitorias concretas alrededor de la misma. Estas etapas son: premenopausia, menopausia y postmenopausia.

Utian (1989) realiza una revisión sobre menopausia y calidad de vida cuestionándose si el fallo ovárico producido en la menopausia empeora la calidad de vida de las mujeres. Pone de manifiesto deficiencias, en estudios previos, sobre la definición apropiada de menopausia o la necesaria diferenciación entre menopausia natural y quirúrgica. Este autor concluye con hay una urgente necesidad de conocer el alcance del síndrome climatérico y cree que es necesario un modelo bio-psicosocial con vistas a aumentar la calidad de vida en la menopausia. En este sentido, destaca el estudio realizado por Daly et al (1993) diseñando una investigación con el objetivo de examinar el impacto de los síntomas menopáusicos en la calidad de vida de la mujer. En este caso, la muestra estaba compuesta por 63 mujeres, reclutadas 
aleatoriamente en una clínica de menopausia y en dos consultorios generales. No hubo criterios de inclusión. Los resultados indicaron según los autores como la calidad de vida está seriamente comprometida por los síntomas menopáusicos.

Adler y Ross (1993) replicaron el estudio de Daly criticando la extrema heterogeneidad de la muestra, en que no se especificó ninguna variable sociodemográfica y en la inadecuación de las descripciones dadas sobre los síntomas. En este mismo año, Hunter analiza los aspectos psicosociales que pueden predecir los síntomas menopáusicos. Considera que los factores con mayor influencia sobre la calidad de vida durante la menopausia parecen ser la situación emocional previa, su situación social, la vivencia de situaciones vitales estresantes (principalmente divorcios o separaciones) y, las creencias acerca de la menopausia. Así mismo, el estudio sugiere una serie de áreas sobre la promoción de la salud, con el objetivo de aumentar la calidad de vida durante la menopausia. Estas áreas son las siguientes:

a. Potenciar la información sobre la menopausia a las mujeres y a sus familias.

b. Discusión y debate de las actitudes sobre la menopausia, haciendo hincapié en las creencias pesimistas y estigmatizadoras.

c. Sesiones de promoción y educación para la salud, centrándose principalmente en la dieta, ejercicio y tabaquismo (factores asociados con la salud general y, específicamente, con la osteoporosis).

d. Sesiones de afrontamiento de las situaciones de estrés.

e. Grupos de discusión personal, sobre la salud y situación social, que sirva de encuentro para mujeres menopáusicas (cercano a un grupo de autoayuda). 
Una investigación relevante en la valoración de la calidad de vida durante la menopausia es la que llevaron a cabo Ledesert et al (1994). Su objetivo era evaluar el efecto de la menopausia sobre la calidad de vida de las mujeres postmenopáusicas. La muestra seleccionada estaba compuesta por 1171 voluntarias que trabajaban para la compañía nacional francesa de gas y electricidad, de edades entre 45 y 52 años. Se les envió por correo un cuestionario autoadministrado (Cuestionario de Salud General) y el Perfil de salud de Nottingham (NHP), para medir calidad de vida. De este grupo, 289 eran postmenopáusicas y el resto premenopáusicas. Se obtuvieron los siguientes resultados:

- Las postmenopáusicas tienen peor percepción del estado de salud que las premenopáusicas en las siguientes secciones del NPH: dolor, sueño, energía, aislamiento social. No obtuvieron diferencias en cuanto a la movilidad física y reacciones emocionales.

- No se encontraron diferencias en la calidad de vida según el tipo de menopausia.

- Para dos mujeres de la misma edad, si una es postmenopáusica describirá con más frecuencia que la premenopáusica síntomas como sofocos, sequedad vaginal, alteraciones del sueño o dolores articulares.

- Observaron que la salud percibida por la mujer menopáusica no dependía del estado menopáusico, sino de los síntomas que la mujer refiera.

La conclusión a la que llegaron estos autores fue que la disminución de la calidad de vida en el climaterio está relacionada con la salud, es decir, con la sintomatología que la mujer menopáusica presente. 
Sin embargo, Zichella (1995) considera que la influencia de los estilos de vida sobre la salud es clara. En este contexto considera que los estudios deberían analizar la reciprocidad y la influencia de tres aspectos: el estilo de vida, el tratamiento recibido y la calidad de vida.

En su revisión sobre calidad de vida en la menopausia, Pasini (1997) refiere que la menopausia es un período de la vida de la mujer relativamente largo, con cambios hormonales y correlatos psicosomáticos, psíquicos y comportamentales. Considera tres aspectos fundamentales: el concepto de pérdida, los trastornos psicosomáticos y la toma a cargo de la mujer menopáusica por el especialista.

McAllister (1998) considera que los estudios demuestran la falta de información que sufren las mujeres sobre esta época de su vida. Esta desinformación, puede hacer que la mujer sufra síntomas en la menopausia o que estos sean más acentuados de lo que hubieran sido, por lo que su calidad de vida también está relacionada con la información que reciben sobre esta etapa de la vida.

La Sociedad Norteamericana de Menopausia (NAMS) en el año 2000 realiza un consenso de actuación clínica partiendo de la asunción que durante la menopausia se producen cambios físicos y psicológicos que afectan a la calidad de vida de las mujeres. En este sentido, Di Corrado, Di Nuovo et al (2001) realizan una investigación experimental sobre la calidad de vida durante la menopausia. Evaluaron a 100 mujeres que acudían a una clínica de menopausia, con edades entre 44 y 59 años, con un cuestionario de calidad de vida (QOL) y un test de medición de estrés psicológico. Los resultados indican que son las condiciones contextuales (tipos de cambios en la familia, asunción de nuevo rol familiar o el número de hijos) las 
variables que parecen ser más relevantes en las reacciones psicofísicas ante el estrés y en la calidad de vida percibida.

Brzyski, Medrano et al ( 2001 ) examinan la calidad de vida en mujeres menopáusicas cuyas características hacen que no sean incluidas en las investigaciones habituales (bajo nivel cultural, razas étnicas especiales, etc), por no ser representativas. Las mujeres tenían edades de 45 a 60 años, todas ellas con más de 5 años desde la última menstruación. Las participantes completaron un cuestionario de información demográfica y dos cuestionarios de calidad de vida: Menopause Quality of Life Instrument (MENQOL) y la forma abreviada del cuestionario SF-36. Estos autores concluyen que el bajo nivel educacional no afecta de forma significativamente en la calidad de vida de las mujeres menopáusicas. En cambio, afirman que las características socioeconómicas están asociadas con el incremento de la sintomatología menopáusica.

Ewies (2001) elabora una serie de consejos para mejorar la calidad de vida durante la menopausia independientemente de si han elegido recibir tratamiento hormonal sustitutivo o no. Entre estas medidas aconsejadas destacan la realización de ejercicio físico de forma regular, tomar calcio y vitamina $\mathrm{D}$, la reducción de situaciones de estrés o el mantenimiento de una dieta adecuada. También Schneider (2002) considera que la calidad de vida relacionada con la salud durante la menopausia es un parámetro subjetivo que indica el estado físico individual y los aspectos del funcionamiento psicosocial. Pretende evaluar la calidad de vida de las mujeres postmenopáusicas y considera que hay varias escalas que cumplen los requisitos metodológicos. De entre estas escalas, una establece diferentes tipos o estilos de afrontamiento en la menopausia (Menopause Rating Scale). Los factores 
más importantes analizados fueron la pérdida de atractivo, la reorientación del estilo de vida y la relación de pareja. Compara los resultados de las dimensiones somática y psicológica de esta escala con la forma abreviada del cuestionario de calidad de vida relacionada con la salud SF-36, concluyendo que es la severidad de los síntomas menopáusicos los que reflejan la calidad de vida en esta etapa.

Fuh et al (2003) afirman que aunque parece razonable sugerir que las mujeres menopáusicas experimentan cambios significativos en su calidad de vida, pocas investigaciones han cuantificada estos cambios. Evaluaron 1360 mujeres de la Isla de Kinmen, excluyendo las que recibían terapia hormonal sustitutiva o presentaban menopausia inducida quirúrgicamente. Los resultados de este estudio sugieren que las mujeres peri y postmenopáusicas presentan un estado de salud percibido peor que el que experimentan las mujeres premenopáusicas.

Un estudio de gran relevancia por el tamaño de muestra utilizado (8653 mujeres) es el llevado a cabo por Mishra y cols.(2003) en Australia. Su objetivo era medir los cambios en la salud física y mental encontrando que la mayoría de las mujeres presentaban, de forma significativa, cambios en casi todas las dimensiones de calidad de vida del cuestionario SF-36, principalmente las dimensiones que evalúan aspectos físicos y de salud general, observando, en estas dimensiones, un declinar en el bienestar de las mujeres.

Pero también existen estudios que intentan evaluar los aspectos positivos en el bienestar durante la transición menopáusica. Deeks (2004) analiza mediante subescalas de bienestar psicológico a 304 mujeres premenopáusicas y postmenopáusicas, concluyendo que se observa una peor percepción del bienestar en las mujeres postmenopáusicas. La interpretación de este autor propone que estos 
resultados sugieren que la menopausia puede indicar en la mujer un período de cambios en su rol. Propone la necesidad incorporar los aspectos y cambios psicosociales a la vida de las mujeres y cree necesario realizar más estudios longitudinales para explorar de forma más concisa los factores que influyen en el bienestar de la mujer durante la menopausia.

La evaluación global de la calidad de vida durante la menopausia analizando variables sociodemográficas, estado de salud, estilo de vida y variables psicosociales demuestran que las mujeres menopáusicas informan de una calidad de vida percibida más baja que en las mujeres premenopáusicas, pero que estos resultados no muestran asociaciones significativas entre las variables analizadas (Avis, 2004).

Utilizando el mismo instrumento para evaluar la calidad de vida percibida, que nuestra investigación, el Cuestionario SF-36, Yost y cols. (2005), analizan la calidad de vida de una muestra de mujeres menopáusicas con sintomatología climatérica (sofocos, sequedad vaginal, alteraciones del humor, etc.) frente a una muestra de mujeres premenopáusicas. Los resultados no muestran un descenso en los niveles de calidad de vida percibido en el grupo de mujeres menopáusicas.

Satoh (2005) realiza un estudio en Japón con el que pretende determinar la calidad de vida durante la transición menopáusica, analizando la correlación entre la severidad de los síntomas menopáusicos y el descenso en la calidad de vida percibida. Obtiene que el $24,4 \%$ de las mujeres perimenopáusica y el $26,6 \%$ de las postmenopáusicas padezcan síntomas menopáusicos de intensidad moderada o severa. Concluye que el descenso del nivel de calidad de vida correlaciona con la severidad de los síntomas menopáusicos en ambos grupos de mujeres 
En una muestra de mujeres turcas, Ozkan y cols.(2005) analiza estas mismas variables, es decir, analizar la calidad de vida de las mujeres y su relación con la presencia e intensidad de los síntomas propios de la menopausia en un grupo de mujeres postmenopáusicas comparado con un grupo de mujeres que aún no están en esta transición. Estos autores no encuentran diferencias significativas en la calidad de vida percibida por las mujeres postmenopáusicas frente a las premenopáusicas.

Lain (2006) evalúa el impacto de la transición climatérica sobre la calidad de vida relacionada con la salud. Obtiene que las mujeres muestran unas puntuaciones significativas bajas en las dimensiones de calidad de vida referentes al estado de salud en general, salud mental y relaciones sociales.

Otro estudio que determina un descenso en la calidad de vida percibida en la menopausia lo desarrolla Magyar (2006) quien divide los síntomas climatéricos en varios grupos (vasomotores, función física, cardiovascular, alteraciones articulares y síntomas urogenitales).Observa un decrecimiento de la calidad de vida si se compara con cada uno de los síntomas, pero no existe una correlación tomando los síntomas menopáusicos en conjunto. Valora como esencial el conocimiento, por parte de las mujeres, de los síntomas propios de este período y los posibles tratamientos e intervenciones terapéuticas.

Bankowski (2006) señala que no se evidencia un declinar de la calidad de vida de la mujer menopáusica pero que las puntuaciones bajas en calidad de vida obtenidas en algunas mujeres pueden explicarse por sentimientos de ineficacia y cambios de humor, no por otros síntomas menopáusicos.

Un grupo de investigación brasileño liderado por Conde (2006) se planteó evaluar la calidad de vida en una muestra de 81 mujeres menopáusicas e identificar 
los factores asociados. Los resultados del Cuestionario SF-36 no indican puntuaciones significativamente bajas en las dimensiones de calidad de vida pero hallan una correlación significativa entre los síntomas menopáusicos negativos y las dimensiones de salud física y salud mental

De Lorenzi y cols. (2006) observan que la calidad de vida percibida durante la menopausia no sólo está influenciada por factores biológicos sino también psicosociales y culturales. Argumentan que en muchas ocasiones, las mujeres atribuyen síntomas puntuales a esta etapa menopáusica o distorsionan la vivencia de la transición menopáusica al asociarla con dificultades emocionales que ya presentaban previamente. En este sentido, consideran primordial la educación para conocer los cambios propios de la menopausia y reducir la ansiedad y el estigma existente. Consideran la sexualidad un factor de gran peso en la percepción de la calidad de vida relacionada con la salud durante la menopausia.

Entre las investigaciones más recientes, cabe reseñar dos estudios turcos realizados por Budakoglu y Karacam (2007). El primero, obtiene puntuaciones de calidad de vida peores en las mujeres postmenopáusicas, comparándolas con las premenopáusicas. También presentan peores puntuaciones, en el grupo de postmenopáusicas las mujeres de mayor edad. El segundo estudio, asume que los síntomas menopáusicos tienen un efecto directo negativo sobre la calidad de vida y considera que se deben incluir en los programas de atención a la mujer menopaúsica, prácticas de promoción para la salud y estrategias para el manejo del estrés.

Chen (2007) no obtiene diferencias significativas en la relación entre calidad de vida y los síntomas menopáusicos. No certifica un descenso del nivel de calidad de vida percibida en la muestra de mujeres analizada pero indica que los principales 
síntomas referidos (vasomotores y sexuales) pueden estar asociados con la percepción subjetiva de la salud.

Otra investigación que no estable una asociación entre menopausia y descenso de calidad de vida (Cheng y cols.,2007) describe en un estudio longitudinal que no existe un efecto significativo del efecto de la transición menopáusica sobre la calidad de vida. Para estos autores, las limitaciones percibidas están directamente relacionadas con la presencia o no de síntomas vasomotores.

Lindh-Astrand (2007) analiza la calidad de vida relacionándola con la concepción que tienen las mujeres sobre la transición menopáusica. En función de los resultados obtenidos, asume que la transición es entendida por las mujeres como un proceso natural que está condicionada por factores endocrinos, del estilo de vida, psicosociales, circunstancias vitales y por la propia edad. Pero no encuentra una peor calidad de vida asociada a la menopausia.

Por último, Nelson (2008) considera que son múltiples los síntomas que se han atribuído a la menopausia pero sólo los síntomas vasomotores y la sequedad vaginal están asociados, de forma significativa, con la transición menopáusica. No determina una relación entre menopausia y peor calidad de vida y considera que muchas cuestiones sobre esta transición deben aclararse y resolverse.

En suma, la revisión de la literatura científica sobre la calidad de vida y el climaterio, confirma la falta de unanimidad sobre si la transición menopáusica supone una pérdida en la calidad de vida de la mujer o si, por el contrario, no existe una relación causal y sólo dependería de las diferencias individuales de cada mujer. Nuestro intento es determinar un perfil con las dimensiones de calidad de vida de las 
mujeres de nuestra muestra y evaluar si existe una relación entre la calidad de vida y estado de ánimo. 


\subsection{Estado de ánimo y menopausia}

Una multiplicidad de síntomas se han atribuido a la menopausia, sin apenas distinguir entre los síntomas resultantes de la pérdida folicular ovárica, de otros asociados al proceso de envejecimiento o de factores socioambientales específicos de este período de la vida de la mujer. Es común atribuir a la menopausia una gran patogeneidad psiquiátrica, pero la relación entre síntomas psicológicos y menopausia es controvertida. Y uno de los trastornos psiquiátricos tradicionalmente asociado a la menopausia es la depresión.

Según Weissman y Klerman (1977) parece descartarse el concepto de que existen cuadros psiquiátricos relacionados etiológicamente con la menopausia, como suceso biológico únicamente, y también que los trastornos detectados durante este período tengan características propias diferenciales. Esta postura se reafirma con la desaparición en el Manual diagnóstico y estadístico de los trastornos mentales (DSM IV, 1994) de los apelativos "menopáusico" para la generalidad de los trastornos depresivos.

En cambio, la controversia sobre la relación entre menopausia y depresión continúa actualmente sin una postura unánime y clara. Persiste la idea hoy en día, de que aún no existiendo un síndrome clínico involutivo diferente, el riesgo de desarrollar un trastorno mental es mayor durante la menopausia que en otras épocas de la vida. De hecho, la Décima Revisión de la Clasificación Internacional de las Enfermedades (CIE- 10, 1992), admite la existencia de "Otros procesos frecuentemente asociados con alteraciones mentales y del comportamiento", entre los que incluye las alteraciones menopáusicas y otras afecciones perimenopáusicas, 
como "estados menopáusicos y climatéricos femeninos" o "estados asociados con menopausia artificial”.

Cabe destacar que son muy escasos los estudios que refieren una relación específica de la menopausia con síntomas depresivos compatibles con un diagnóstico de Trastorno depresivo mayor (según los criterios de DSM-IV-TR). Los estudios que admiten esta relación causal explican una sintomatología depresiva moderada siendo necesario también tener en cuenta las diferencias en cuanto a la intensidad de los síntomas en los que se basan el resto de investigaciones que determinan sintomatología depresiva leve o alteraciones leves del humor y la inexistencia de afectación depresiva en la mujer menopáusica. Teniendo en cuenta esta diferenciación clínica, los diferentes estudios se posicionan no tanto por la intensidad sintomatológica sino por la etiología de la misma, es decir, intenta determinar si la etapa menopáusica se caracteriza por la presencia de síntomas depresivos y, si éstos, tienen unas características de aparición, mantenimiento o acentuación propias, relacionadas exclusivamente con los cambios que acontecen en la menopausia (hormonales, psicosociales,etc.) o forman parte del estado emocional y afectivo de cada mujer independientemente del momento del ciclo vital en el que se encuentre.

Comenzaremos señalando los estudios que no obtienen una asociación específica, para posteriormente comentar los que apoyan la relación entre menopausia y depresión.

Uno de los trabajos clásicos en el estudio de esta cuestión es realizado por Winokur (1973), quien no observó un incremento significativo del riesgo de aparición de cuadros depresivos en la menopausia al compararla con otras fases de la 
vida; en cambio, detectó tasas más elevadas de depresión entre las mujeres que acudían a clínicas o unidades de menopausia y a consultas externas de ginecología.

Para Cooke (1984) la intensidad de los síntomas psicológicos empieza a detectarse al final de la treintena, alcanzando del pico más alto a principios de los 40 años y volviendo a declinar su frecuencia e intensidad hacia el final de la cuarta década de la vida. En este mismo año, Osborn considera que la relación entre depresión y menopausia, no debería ser asumida.

Por su parte Avis y McKinlay (1991) encontraron que el grupo con tasas más elevadas de cuadros depresivos correspondía a mujeres que habían experimentado recientemente una menopausia quirúrgica, pero tampoco detectaron un exceso de riesgo para aquellas con una menopausia natural. Estos mismos autores, junto con Brambilla y Vass, realizan un trabajo en 1994 en el que exponen los resultados de su estudio longitudinal en el que evaluaban la relación entre menopausia y depresión, concretamente sobre un período perimenopáusico extenso. Las conclusiones de este estudio indican que la asociación entre una larga perimenopausia y depresión son explicadas por el incremento de la sintomatología menopáusica más que por el estado en sí. También indican que este incremento de la depresión durante una extensa perimenopausia es transitorio.

Schmidt y Rubinow (1991) rechazan la posibilidad de un tipo de trastorno específico de la menopausia y dedujeron que, si tras una cuidadosa exploración sintomatológica y semiológica no era posible identificar un trastorno específico, entonces el ánimo depresivo o "desmoralización" tantas veces referida en el climaterio por la mujeres, no debe entenderse como una entidad depresiva distinta a las ya descritas. Acaban señalando que no es aceptable ni la clásica asunción acrítica 
de los trastornos afectivos menopáusicos, ni el rechazo absoluto de los mismos, existiendo graves problemas metodológicos al estudiar esta cuestión.

Chinchilla y cols. (1993) opinan que no es posible establecer una relación directa entre menopausia y trastornos afectivos. Incluso, de sus datos parece desprenderse que la menopausia no juega ningún papel preponderante en la determinación de las depresiones. Coincidente con Kahn y cols. en 1994, quienes realizan un trabajo en el que analizan los síntomas climatéricos de 247 mujeres. Encontraron que los síntomas evaluados, que estaban en relación con el estado de ánimo (irritabilidad, excitabilidad, depresión y falta de concentración) no se incrementaban en la menopausia, sugiriendo que estos síntomas están más relacionados con la menstruación que con la etapa menopáusica.

Sydow y Reimer (1995) en su revisión comentan que si bien es cierto que las pacientes menopáusicas presentan diferentes síntomas, esto sucede también en algunas mujeres y varones con independencia de las variaciones hormonales. Afirman que, aunque se ha mantenido durante mucho tiempo la idea de que la menopausia se asociaba a un estado depresivo, en estudios longitudinales se ha demostrado que el estado psíquico apenas cambia durante este período. Comprobaron que las mujeres menopáusicas presentan las mismas tendencias depresivas que otras mujeres de la misma edad o más jóvenes. Por contra, sí confirman que las mujeres con antecedentes de tendencias depresivas en su juventud presentaban estos síntomas con más frecuencia durante la menopausia, lo cual podría también establecer cierta asociación entre menopausia y depresión.

Nicol-Smith (1996) revisa 94 artículos de los últimos treinta años sobre la causa de la depresión durante la menopausia. No encuentra evidencias significativas que 
justifiquen el mantenimiento de las teorías que apoyan la tesis de que las alteraciones menopáusicas provocan o favorecen un episodio depresivo. También describe los problemas y errores metodológicos y estadísticos que condicionan la investigación de este tema.

Dennerstein (1996) analiza todos los síntomas climatéricos encontrados en la transición a la menopausia y en relación con los síntomas psicológicos considera que no existe un incremento de la incidencia de la depresión mayor durante la menopausia. Concluye que el ánimo depresivo no está asociado con la menopausia, si se ha producido una transición natural a ella. Encuentra como factores asociados al ánimo depresivo son: menopausia quirúrgica, estado de salud general, estresores sociofamiliares y actitudes negativas hacia la menopausia.

Hunter (1996) subraya como los estudios epidemiológicos no apoyan la hipótesis de que el humor deprimido u otros síntomas psicológicos se incrementen en la menopausia y hace notar como la variación transcultural arroja dudas sobre lo biológico como causa de distrés en la menopausia. Considera que mientras es posible que los cambios hormonales de la menopausia tengan influencia sobre el humor en alguna mujer, los factores psicosociales lo tienen en la mayoría. Concluye que:

- Las mujeres no son más propensas a deprimirse durante la menopausia que en otras épocas de la vida.

- No existe relación entre los niveles de estrógenos y los posibles síntomas depresivos.

- Los factores psicosociales son causa frecuente de distrés en esta época de la vida.

- Los estrógenos no producen mejoría en mujeres deprimidas. 
- Existen evidencias a favor de una mejoría en el humor de mujeres tratadas con estrógenos en menopausia quirúrgica.

Bebbington y cols. (1998) realizaron un estudio en el que analizan las variables edad y sexo, así como su influencia en la prevalencia de la depresión. Analizaron 9792 mujeres británicas incluídas aleatoriamente en la muestra objeto de estudio. Estos autores afirman en sus conclusiones que su estudio viene a confirmar la tendencia que indica que las diferencias existentes en la prevalencia de depresión en función del sexo, disminuyen significativamente después de los 55 años, además indican que la menopausia puede influir en esta tendencia y niegan cualquier relación entre menopausia y depresión.

Becker y cols. (2001) quienes en un estudio realizado sobre una muestra de 189 mujeres seleccionadas al azar, proponen que las alteraciones psicológicas durante la transición a la menopausia, incluida la sintomatología depresiva, parece indicar una mayor vulnerabilidad personal más que una reacción específica a los cambios propios de la menopausia.

Bosworth, Bastian y cols. (2001) consideran que las causas por las que estudios previos confirman un aumento de los niveles de depresión durante la menopausia no están claras. Toman para su estudio una muestra de 581 mujeres en un intervalo de edad concreto, de los 45 a los 54 años. Estos autores concluyen que el aumento de los síntomas depresivos durante la menopausia es debido a la presencia de sintomatología climatérica pero descartan la asociación entre menopausia y depresión.

En la línea de estos autores, encontramos una nueva investigación realizada por Avis y cols. (2001) con 309 mujeres de edades comprendidas entre 43 y 53 años. En 
este estudio longitudinal concluyen, de forma más específica que estudios previos, que la relación entre depresión y menopausia está explicada principalmente por niveles hormonales, alteraciones del sueño y síntomas vasomotores durante la menopausia.

Otra investigación que no admite una asociación directa entre depresión y menopausia, ni la presencia de trastornos afectivos específicos durante la menopausia, se realizó en el 2002 por Woods, Mariella y Mitchell. Afirman que para la mayoría de las mujeres, la menopausia no supone una etapa que favorezca la aparición de episodios depresivos. Sólo en una minoría, no significativa, encuentran una asociación entre depresión y menopausia, considerando diferentes factores desencadenantes como estresores vitales, síntomas vasomotores o una percepción mala de la salud.

Un trabajo de especial interés fue sido publicado por Miller y cols (2002) donde comparaban niveles de depresión y funciones cognitivas (fluidez verbal y memoria de trabajo) en tres grupos: mujeres premenopáusicas, mujeres postmenopáusicas y hombres. Los resultados indican que las mujeres menopáusicas no presentaban niveles de depresión mayores, e incluso, algunas mujeres postmenopáusicas ofrecían una mejor ejecución en las pruebas cognitivas que los otros dos grupos de estudio.

Lindaker (2004) encuentra diferencias significativas en los valores de depresión pero considera que no están asociados a la menopausia si no a etapas anteriores. Concluye que es necesario programas de educación para la salud en los que la mujer aprenda a identificar muchos de los síntomas climatéricos, lo que reduciría el disconfort de las mujeres ante estos síntomas. 
O’Connel (2005) rechaza la posible asociación entre menopausia y estado de ánimo depresivo considerando una aproximación multidisciplinar para informar, prevenir y combatir los síntomas climatéricos. Observa una mejoría de esta sintomatología en mujeres que se sometieron durante 10 semanas a un grupo que combinaba información y educación, entrenamiento en relajación, apoyo grupal, modificación de estilos de vida y estrategias de afrontamiento psicológicas.

Para Schnatz (2005) considera que existe una predominancia de ánimo de depresivo en mujeres estadounidenses con ciertas características sociodemográficas (hispanas con bajo nivel socioeconómico y experiencias negativas en su vida) pero no determina una relación, al contrario, considera que la menopausia debe ser uno de los mejores momentos en la vida de cada mujer.

En un estudio desarrollado en Polonia, Waslazek (2006) obtiene puntuaciones que indican estado depresivo en la menopausia, de forma significativa, pero atribuye las puntuaciones altas en las escalas de depresión utilizadas, a condiciones psicosociales no al estatus hormonal definido en la menopausia. Otro estudio de ese año que evalúa el estado de ánimo en la menopausia, es el liderado por Woods en la ciudad de Seattle ( 1999 ). Este autor afirma que la mayoría de las mujeres vive su transición menopáusica sin experimentar sintomatología depresiva destacable y las pocas mujeres que padecen estos síntomas los sufren desde etapas anteriores a la menopausia. Considera que estos síntomas no están asociados al síndrome premenstrual si no que son los acontecimientos vitales los que contribuyen a la aparición de estos síntomas.

Willbur (2006) evalúa los síntomas que con más intensidad aparecen en una muestra de mujeres menopáusicas, encontrando que tanto en la perimenopausia como 
en la postmenopausia, predominan los síntomas músculoesqueléticos, gastrointestinales y vasomotores pero no las alteraciones del humor.

Uno de los estudios más recientes que apoya esta argumentación es el de Becker (2007) para quien existe una asociación significativa de que las posibles alteraciones del humor en la menopausia tienen la misma etiología que las alteraciones que pueden aparecen en cualquier momento de la vida de las mujeres y que está etiología está explicado por factores hormonales, psicológicos o la interacción de ambos.

El interés de Rohde (2007) en estudiar el estado de ánimo en la mujer parte de la prevalencia de la población general que indica que el doble de mujeres que de hombres, padece depresión. Considera que existe una génesis multifactorial y multicausal para explicar este hecho y destaca que las fases de transición hormonal y determinados sucesos vitales influyen en la aparición de síntomas depresivos,.Admite que deben ser consideradas las características especiales que puede vivir cada mujer en determinados momentos de su vida (embarazo, postparto, pérdida de un hijo, nido vadío, menstruación, menopausia,etc.) pero que no se puede establecer ningún patrón estable de respuesta anímica en ninguno de esos momentos.

Callegari (2007) parte de sus datos preliminares que confirman una alta correlación entre antecedentes de trastorno depresivo y depresión recurrente en el período menopáusico. En cambio, no encuentra un aumento de incidencia de la depresión en la menopausia aunque son los antecedentes el factor predictivo con más peso para posibles alteraciones del humor en la menopausia. Considera que si existe un período de mayor riesgo para el desarrollo de síntomas depresivos, es la perimenopausia pero no la postmenopausia. 
El artículo más reciente encontrado respecto a este posicionamiento lo firman Freeman, Samuel y cols. ( 2008) quienes han realizado un estudio longitudinal de 9 años ( Penn Ovarian Aging Study ) concluyendo la irritabilidad y las alteraciones del humor muestran un vínculo leve con la transición menopáusica y su intensidad decrece en esta etapa debido a los cambios fisiológicos que tienen lugar.

La postura contraria en la controversia sobre la relación entre menopausia y depresión también es extensa y se obtienen un número importante de investigaciones que postulan esta relación. El informe final del grupo de científicos encargados del estudio de la menopausia para la OMS (1980), concluye que es posible detectar un incremento de éstos y otros síntomas psicológicos en el período premenopáusico y un descenso de la frecuencia de dichos síntomas después de la menopausia. Son muchos los autores que proponen que existe un aumento de la incidencia de la depresión durante la menopausia, debida principalmente a los cambios hormonales que acontecen durante esta etapa. Algunos incluso llegan a proponer la existencia de un trastorno depresivo específico en la menopausia.

Jaszman (1973) considera bien establecida la incidencia de depresión en la etapa media de la vida de la mujer, pero la máxima frecuencia suele coincidir con los años previos a la total cesación de la menstruación. Incluso las consultas por motivos emocionales o afectivos en atención primaria se incrementan notablemente en mujeres en la etapa perimenopáusica y en los primeros años de la postmenopausia (Shepherd et al., 1966).

Son muchos los factores que pueden desencadenar la aparición de un trastorno depresivo durante la menopausia, los cambios hormonales pueden actuar como detonantes de estos trastornos en mujeres condicionadas por factores de personalidad, 
antecedentes psiquiátricos, conflictos sociales o una predisposición especial a sufrir cambios emocionales como consecuencia de las variaciones hormonales como etapa de especial vulnerabilidad (Dennerstein, 1987).

Kukopulos (1980) señala que la menopausia puede actuar como factor agravante del curso de la patología afectiva. Montgomery y cols. (1987) y Palacios (1988) sugieren que las mujeres que se muestran ansiosas ante la llegada de la menopausia tienen más probabilidades de sufrir depresión durante ésta, y que, por otra parte, el hecho de sufrir síntomas ansiosos o depresivos conlleva un sufrimiento exagerado por los cambios asociados a la etapa climatérica.

Utian (1989) considera que los estudios confirman el incremento en la perimenopausia de síntomas psiquiátricos menores, pero señala los numerosos problemas metodológicos que se presentan cuando se trata de estudiar los llamados "síntomas psiquiátricos menores": muestras heterogéneas, insuficiente descripción del tipo de paciente y del estado menopáusico, selección no aleatorizada de la muestra, definición inadecuada de la sintomatología, etc.).

Kaufert, Gilbert y Tate (1992) realizan el Proyecto Manitoba en el que reevaluaron la relación existente entre menopausia y depresión. Entrevistaron a 477 mujeres, en seis ocasiones durante tres años. Los resultados confirman la relación y proponen que más que los cambios hormonales, estresores familiares y sociales parecen explicar esta relación significativa.

Para Bousoño et al (1993) existe un incremento de la prevalencia, y por tanto, de la incidencia de trastornos depresivos coincidentes con el climaterio lo que provoca un mayor consumo de psicotropos en la menopausia. Abraham, un año más tarde, sugiere la posibilidad de una posible base psicológica tanto para los síntomas 
de la menopausia, como para los del síndrome menstrual. Partiendo de este supuesto, concluye que la asistencia a las mujeres con síntomas premenstruales puede ayudar a mejorar su calidad de vida en la menopausia.

De la Gándara (1994) distingue y revisa diversos tipos de depresión y asume su asociación con la menopausia y el climaterio, ya sea por su frecuencia o por sus características clínicas. Entre los tipos de depresión que explica de forma pormenorizada se encuentran: melancolía involutiva, depresión mayor, distimia (neurosis depresiva), trastorno adaptativo con depresión y síndrome del nido vacío.

Bancroft et al (1994) investigaron durante 6 meses todas las primeras consultas de una clínica de menopausia, con el fin de detectar trastornos depresivos en ese momento y trastornos psiquiátricos anteriores. Se pretendía así verificar si las mujeres deprimidas en ese momento presentaban historia de depresión. Encontraron una asociación intensa entre la enfermedad depresiva actual y pasada, ya que 29 de las 35 mujeres deprimidas en el momento de la asistencia a la clínica habían presentado depresión con anterioridad. No obstante, se demostró un claro pico de enfermedad en el período perimenopáusico (el 35\% de las pacientes con enfermedad depresiva pasada o actual experimentaron su primer episodio de la enfermedad cuatro años antes o después de la última menstruación).

Singular por la interpretación que realiza de la sintomatología depresiva en la menopausia es el trabajo llevado a cabo por Bemesderfer (1996). Realiza una revisión desde el punto de vista psicoanalítico de la menopausia y considera que punto de vista tradicional para explicar la depresión en esta etapa había que recurrir a la reacción por la pérdida de la capacidad reproductora. Esta postura se basaba en la teoría del desarrollo sexual femenino, principalmente en el complejo de castración, 
donde la inevitable depresión menopáusica provoca un removilización de este complejo y lleva a una reexperimentación del miedo a la castración. Este autor propone un nuevo punto de vista basado en el concepto de identidad femenina primaria con el que completa la teoría del complejo de castración, relacionándolo con el concepto de ansiedad de castración. Afirma que en la menopausia se deber redefinir la identidad materna.

Ya en publicaciones de más reciente aparición también se observan investigaciones que defienden la tesis de una mayor incidencia de la depresión durante la menopausia. Carandag et al (2000) asumen la mayor incidencia de la depresión en función del sexo y argumentan la variabilidad encontrada en cuando a los síntomas, la evaluación o el tratamiento de los síntomas depresivos. Consideran que la menopausia, junto con otras vivencias en la vida de las mujeres (partos, etc.), puede causar depresión o bien acentuar los síntomas existentes.

Soares y Almeida (2001) también relacionan depresión con menopausia e incluso obtienen un porcentaje significativo de casos que cumplen criterios diagnósticos de trastorno depresivo mayor. Benazzi (2000) no sólo confirma un aumento de la depresión durante la menopausia, sino que sugiere una fisiología diferente de la depresión en esta etapa respecto a la que ocurre en otras etapas de la vida de la mujer. Afirma que las diferencias pueden deberse a los cambios propios de la menopausia, como los cambios hormonales.

Sagsoz et al (2001) se propusieron investigar la ansiedad y depresión en una muestra de mujeres postmenopáusicas. Estudiaron a 32 mujeres postmenopáusicas y 32 premenopáusicas de edades entre 40 y 55 años mediante la Inventario de Depresión de Beck (BDI) y el Cuestionario de Ansiedad Estado- Rasgo (STAI). 
Obtuvieron niveles de depresión significativamente más altos en mujeres menopáusicas.

Taylor (2001) siguiendo la misma línea, considera que la menopausia parece incrementarse los trastornos depresivos como resultado del cambio de los niveles de estrógeno sobre la actividad serotoninérgica $\mathrm{y}$ su impacto sobre otros neurotransmisores.

Aunque explica de forma tangencial este debate, es interesante el reciente trabajo publicado por Harlow et al (2003) por la importancia que otorgan a la sintomatología depresiva en la aparición de la menopausia. Analizan el impacto de tener antecedentes de episodios de depresión mayor sobre la transición precoz a la menopausia. Compararon 332 mujeres con historia previa de depresión y 644 mujeres sin ningún antecedente de alteración del estado de ánimo, todas ellas con edades comprendidas entre 36 y 45 años. Los resultados obtenidos indican que presentar una historia de depresión mayor parece estar asociado a un declinar temprano de la función ovárica.

Sánchez y cols. (2003) realizamos una aproximación al problema y obtuvimos una mayoría de investigaciones que apoyaban la tesis de la relación entre menopausia y alteraciones del estado de ánimo, aunque con intensidad leve en cuanto a la sintomatología depresiva.

En un estudio realizado por Freeman (2004) en Pennsylvania, obtiene resultado congruentes con la relación de síntomas depresivos durante la transición menopáusica, decreciendo en la postmenopausia. Indica que las asociaciones hormonales parecen corroborar esta evidencia y considera fundamental la 
contribución de los cambios hormonales en el humor disfórico durante la menopausia.

También en el año 2004, Dennerstein realiza un estudio con mujeres australianas concluyendo que los mayores niveles de humor depresivo aparecían en el grupo de edad de 57 a 67 años. Considera que el humor negativo previo, historia de complicaciones en la premenopausia, actitudes negativas acerca de la menopausia y la edad y problemas de salud generalizados son las variables que predicen ese humor depresivo en la edad menopáusica.

Schmidt (2004) sugiere que la perimenopausia parece estar asociada con un incremento de la susceptibilidad de las mujeres a padecer depresión. No confirma una relación directa pero sí una predisposición o mayor vulnerabilidad a presentar un trastorno afectivo durante la menopausia.

Parry (2006) confirma la existencia de síntomas depresivos asociados a la menopausia y los compara con los encontrados en otros ciclos de la mujer (como el síndrome premenstrual y la depresión postparto), considerando que los síntomas en la menopausia son más intensos.

Entre los estudios más recientes que siguen está postura, encontramos el realizado por Chendraui (2007) para quien el humor depresivo está presente en el $75 \%$ de las mujeres menopáusicas y considera que este humor, junto otros síntomas climatéricos (como sofocos e insomnio) está más presente, de forma significativa, en las mujeres postmenopáusicas que en la premenopausia.

Tatebayashi (2007) afirma que es significativo el aumento de sintomatología depresiva en la mujer durante la menopausia e insta a la autoridades sanitarias a realizar programas preventivos ante el progresivo aumento del envejecimiento de la 
mujer al aumentar la esperaza de vida. Semejantes conclusiones aporta Freeman (2007) argumentando que el humor depresivo aumenta en la menopausia y lo considera un indicador de la transición menopáusica de la mujer.

En su estudio sobre las variables que influyen en la disminución de la libido durante la menopausia, Reed (2007) considera que la depresión es un síntoma específico que aparece tanto en la transición menopáusica como en la menopausia precoz o temprana. Determina que este estado depresivo es un factor asociado a la disminución del deseo sexual en la mujer menopáusica.

En este mismo año, Nelson (2008) asume la relación existente entre menopausia e incremente de las alteraciones del humor y se propone determinar la influencia de la actividad física en esta relación. Concluye que los niveles de ansiedad, estrés y depresión en las mujeres menopáusicas descienden significativamente con la actividad física comparadas con mujeres menopáusicas inactivas.

Por último, Price (2008) analiza una muestra de mujeres menopáusicas de procedencia rural, encontrando cambios en su bienestar físico y mental. Afirma que las mujeres describen esta transición como una etapa de impacto relevante en sus relaciones personales, en su red de apoyo social y en su humor. Este autor asume como primordial dotar a la mujer menopáusica de habilidades de afrontamiento a través de la educación y el apoyo social.

También encontramos algunas investigaciones que no aceptan una postura $u$ otra, sino que dudan de la relación entre depresión y menopausia pero por otro lado confirman que la menopausia puede favorecer la presencia de sintomatología depresiva. Entre estas investigaciones destaca la realizada por Ballinger (1990), para 
quien las diferencias se derivan de la falta de evaluación rigurosa de los efectos placebo de los estrógenos y la confusión conceptual entre síntomas o síndromes climatéricos y psicopatológicos.

Díez y cols.(1995) estudiaron 128 mujeres postmenopáusicas sin antecedentes psiquiátricos, sin tratamientos farmacológicos y sin eventos vitales recientes, con el fin de averiguar los índices de depresión en la postmenopausia y si esta sintomatología depresiva es derivada de los desequilibrios hormonales o bien existe una génesis múltiple de variables no sólo biológicas sino también psicológicas y sociales. Los resultados indicaron un elevado índice de depresión, relacionado con las diferentes variables pero con mayor incidencia, sobre la misma, del pensamiento anticipatorio negativo.

Jiménez y Pérez (1999) en el que incluyen una variable psicológica que permite explicar la variabilidad en la apreciación subjetiva de estos síntomas durante la menopausia. Para estos autores la depresión, junto con la irritabilidad y la inestabilidad emocional son síntomas predominantes y consideran que una actitud y predisposición negativa hacia la menopausia antes de la aparición de la sintomatología favorece la frecuencia e intensidad de los síntomas psiquiátricos.

Banger, en su artículo publicado en el 2002, afirma que los trastornos depresivos, siguiendo criterios CIE-10, no aparecen de forma más frecuente durante la perimenopausia, ya que considera que los episodios depresivos que acontecen durante la menopausia no tienen suficientes síntomas o no son los suficientemente graves como para el diagnóstico de trastorno depresivo. Por ello cree que es fundamental describir de forma precisa conceptos como "síndrome subdepresivo", que puedan adecuarse a estos episodios depresivos. Finaliza su investigación, dada la 
complejidad y relevancia de la menopausia en la vida de las mujeres, una intervención multidisciplinar que incluyera médicos de atención primaria, ginecólogos, psiquiatras y psicólogos.

De gran interés es el trabajo publicado por Cairney y Wade (2002) en el que parten de la hipótesis que las diferencias de género sobre la incidencia de la depresión disminuye a partir de la menopausia, concretamente alrededor de 55 años. Concluyen su estudio descartando esta hipótesis, y por tanto, no consideran la menopausia como el punto de inflexión a partir del cual la incidencia de la depresión disminuye en relación con el sexo, proponiendo nuevos estudios futuros para intentar solucionar las inconsistencias encontradas con otros trabajos.

Kornstein (2005) considera que las alteraciones del humor en la mujer tienen una etiología hormonal, por lo que no existe una asociación exclusiva con la menopausia si no con todas las etapas evolutivas de la mujer. Afirma que la presencia de depresión en la mujer menopáusica está directamente relacionada con la presencia de síndrome premenstrual o no. Esta misma conclusión presenta Richards (2006) en su investigación, pero especifica que la intensidad de los síntomas depresivos en el síndrome premenstrual no tiene porqué ser equivalente en la menopausia.

En un trabajo de investigación reciente, realizado sobre una muestra de mujeres menopáusicas italianas, que especifica las conclusiones encontradas por el mismo autor en unas investigación previa del año 2004, Amore (2007) postula que es mayor la incidencia de los síntomas depresivos en las mujeres postmenopáusicas que en las premenopáusicas pero que el humor depresivo y los síntomas ansiosos aparecen con la misma intensidad e incidencia en la pre, peri y postmenopausia. Considera que son los antecedentes de depresión la mayor variable predictiva para que aparezca un 
cuadro depresivo en la transición menopáusica junto con la presencia de acontecimientos vitales.

Como se puede observar en esta revisión de las principales investigaciones sobre menopausia y depresión, las diferencias encontradas en los resultados e interpretaciones realizadas acrecientan, aún hoy, la controversia sobre si la menopausia constituye un período de la vida de la mujer en la que se observa un incremento de la sintomatología depresiva o se trata de una etapa vital con el mismo riesgo de padecer alteraciones del estado de ánimo que cualquier otro período de la vida de la mujer, no pudiéndose llegar a ninguna conclusión definitiva. 


\section{Objetivose Hipótesis}


Influencia de las expectativas y la calidad de vida en el estado de ánimo durante la transición menopáusica 


\section{4.- OBJETIVOS E HIPÓTESIS}

- Objetivo general: estudiar qué tipo de variables podrían explicar el estado de ánimo de la mujer menopáusica.

\section{- Objetivos específicos:}

1. Conocer si el tipo de sintomatología derivada de la menopausia podría incidir en el humor de las mujeres.

2. Determinar si la presencia de síntomas depresivos están influenciados por las expectativas generalizadas de control y la calidad de vida percibida.

3. Intentar explicar los distintos niveles de estado de ánimo a través de las variables analizadas.

\section{- Hipótesis:}

1. Los síntomas climatéricos producen una mayor vulnerabilidad hacia la alteración del estado de ánimo.

2. Un nivel de expectativas positivo y la mayor calidad de vida percibida, ejercen un efecto protector en el humor.

3. Las variables psicológicas estudiadas permiten clasificar psicopatológicamente a las mujeres menopáusicas 


\section{5.- METODOLOGÍA}

\section{1.- Muestra}

La selección de la muestra, al azar, debería cumplir los siguientes criterios de inclusión:

- Período máximo de tres años desde que cada mujer recibió el diagnóstico confirmado de menopausia.

- Mujeres con menopausia fisiológica, no quirúrgica.

- No acuden a las consultas de salud mental, ni reciben tratamiento psicológico o psiquiátrico en el momento de su inclusión.

La muestra total quedó formada por 138 mujeres menopáusicas, con una edad comprendida entre 45 y 56 años (media $=51,22$ y $\mathrm{Dt}=2,54)$. La distribución de esta variable se refleja en la figura 7:

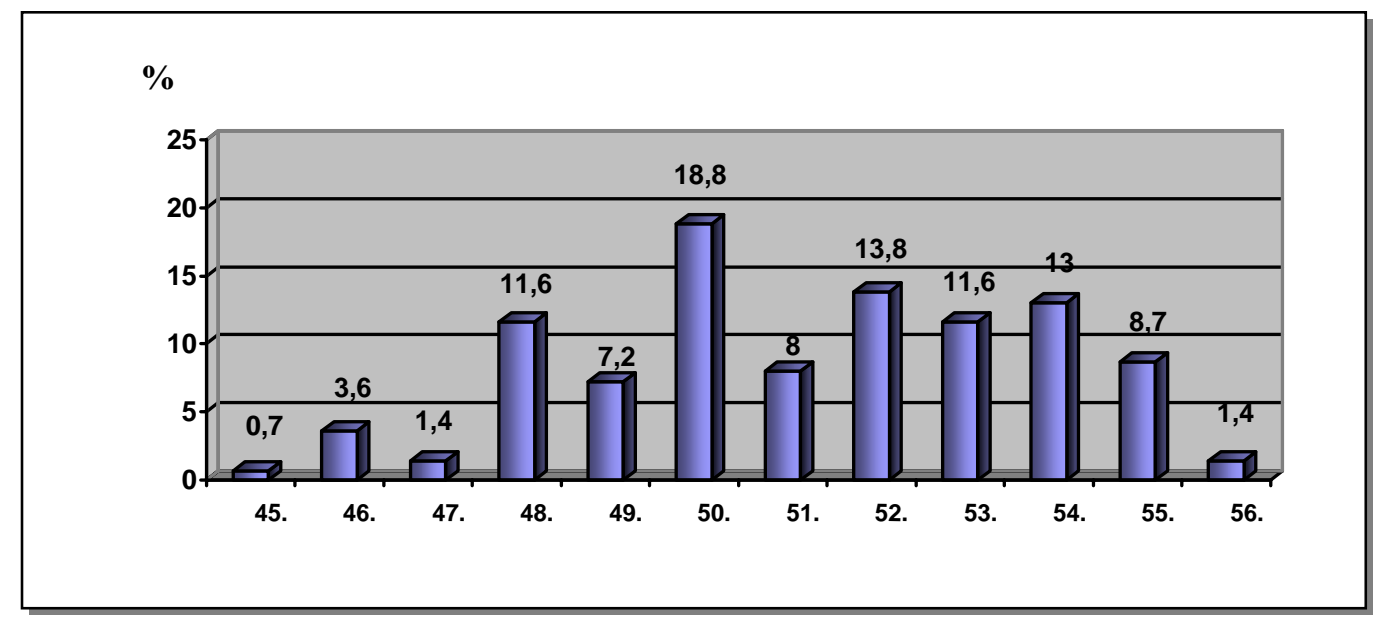

Fig. 7: Distribución de la variable edad

Como se puede comprobar la distribución se ajusta prácticamente a la normalidad, con valores entre 45 y 56 años, con ligera asimetría negativa (As= -.196) 
$\mathrm{y}$ una curtosis de $\mathrm{C}=\quad-.757$, es decir las puntuaciones referente a la edad son ligeramente altas.

La mayoría es de procedencia urbana $(71,7 \%)$, correspondiendo el menor porcentaje a mujeres del ámbito rural $(28,35)$ (figura

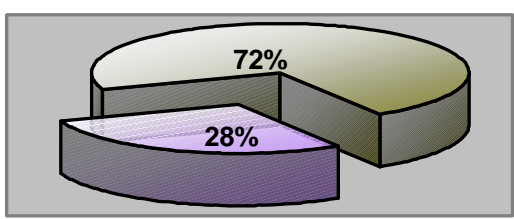

$\square$ Urbano $\square$ Rural

Fig. 8: Pictograma del ámbito de procedencia 8):

Con respecto al estado civil, como era de esperar, la mayoría están casadas (69\%), un 26,1\% solteras, y tan sólo un 5,1\% son viudas (figura 9):

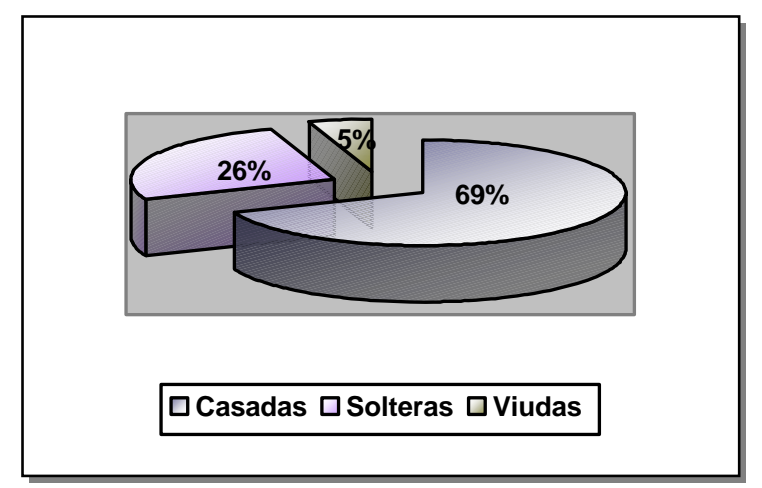

Fig. 9: Pictograma del estado civil

La mayor parte de la muestra han tenido hijos, la moda está ubicada en 2, ajustándose a las características demográficas del país, y tan sólo un 9,4\% no tenían descendencia (figura 10): 
$\%$

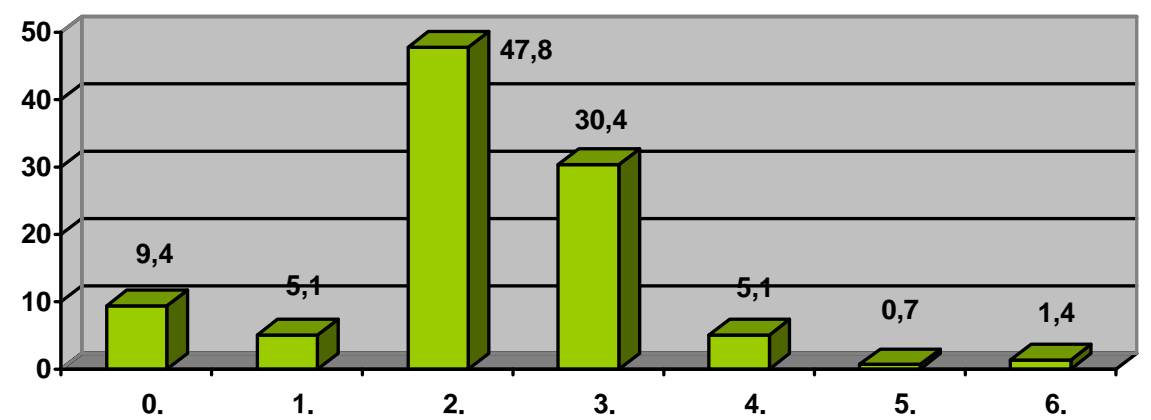

0.

1.

3.

4.

5.

6.

Fig. 10: Distribución del número de hijos

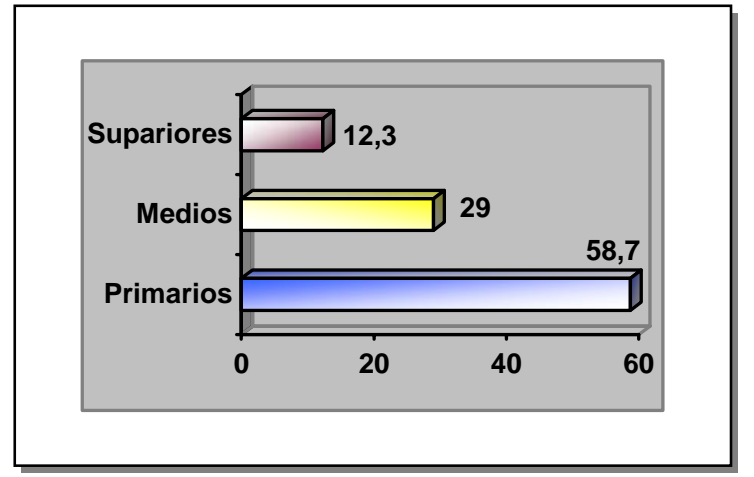

Fig. 11: Pictograma del nivel educacional
El nivel educacional, (figura 11) evidencia que la mayoría poseen tan sólo estudios primarios $(58,7 \%)$, un $29 \%$ secundarios, y únicamente el $12,3 \%$ son universitarias.

Las profesiones están muy dispersas especificándose en la figura 12. El mayor porcentaje corresponde a mujeres que trabajan en el hogar (43\%), seguido de las mujeres que desempeñan su trabajo en el sector de servicios (17\%). Los menores porcentajes corresponden a mujeres obreras y dedicadas a la agricultura $(2 \%$ y $1 \%$, respectivamente).

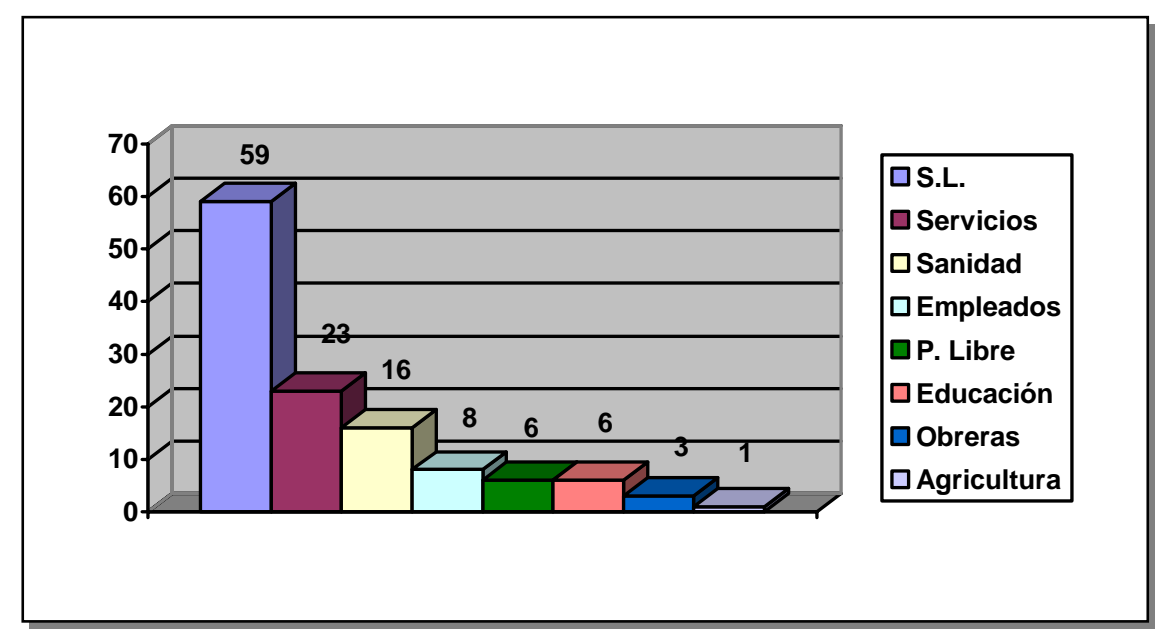

Fig. 12: Profesiones 
Para finalizar, describir una variable de interés en el estudio como es el tiempo de menopausia (figura 13).

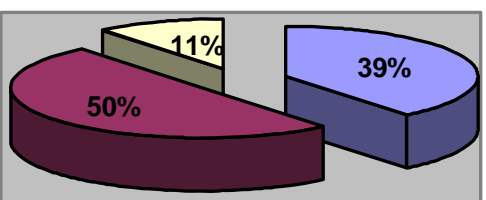

$\square 1$ año $\square 2$ años $\square 3$ años

La mitad de la muestra tienen una evolución como menopáusicas de 2 años, el resto se distribuyen entre un 39\% con un año mínimo y el 11\% que llevan 3 años en esta condición fisiológica. 


\section{2.- Batería de instrumentos}

El protocolo aplicado a la muestra, objeto de estudio, se compone de una primera parte en la que se recogen datos sociodemográficos y otros relevantes en función de los objetivos planteados, y que ha sido específicamente elaborado para esta investigación (fecha última regla, tratamiento o no en salud mental, profesión, etc.). Junto con estos datos de la anamnesis inicial, la batería total constaba de cuatro cuestionarios:

- Escala de Sintomatología Climatérica (AEEM),

- Cuestionario de Calidad de Vida Relacionada con la Salud (SF-36) (Short Form Health Survey de Ware y Sherbourne,1992; versión española de Alonso y cols.,1995),

- Inventario de Depresión de Beck, BDI (Beck y cols, 1961; versión española de Vázquez y Sanz, 1991)

- Batería de Escalas de Expectativas Generalizadas de Control (BEEGC) (Palenzuela 1991,1997)

La elección de estos instrumentos, y no otros, en este trabajo fue realizada en base a los siguientes criterios:

- Se trata de instrumentos de reconocido prestigio nacional e internacional, que se encuentran validados y estandarizados en nuestro país con baremos españoles.

- Consideramos que son los que más se adecuan a cada uno de los objetivos propuestos.

- Por las características de la población de estudio. 


\section{a) Escala de sintomatología climatérica (AEEM):}

Instrumento de medición y evaluación de los principales síntomas asociados a la transición menopáusica desarrollado por la Asociación Española para el Estudio de la Menopausia (AEMM).

Evalúa los síntomas mediante una escala ordinal con cuatro graduaciones diferentes, como opciones de respuesta. Los síntomas climatéricos consensuados como principales para este grupo de estudio y que forman parte de la Escala, son los siguientes.

Sofocos

Trastornos del sueño

Irritabilidad

Ánimo Depresivo

Sequedad vaginal

Interés sexual

Dolor en articulaciones

Relación de pareja 
b) Cuestionario de Calidad de Vida Relacionada con la Salud (SF-36) (Short Form Health Survey de Ware y Sherbourne,1992; versión española de Alonso y cols.,1995 )

Los instrumentos de medida de calidad de vida en función del estado de salud pueden clasificarse en dos grandes tipos: genéricos y específicos. Mientras que los específicos están diseñados para su utilización en pacientes con un tipo de problema de salud concreto, los genéricos son independientes del diagnóstico y se han desarrollado para poder ser utilizados en diferentes pacientes o poblaciones. Entre las ventajas de los instrumentos genéricos destaca a posibilidad de comparar el impacto de diferentes enfermedades sobre el estado de salud, así como obtener valores poblaciones de referencia.

Este instrumento se desarrolló a partir de una extensa batería de cuestionarios utilizados en el Estudio de los Resultados Médicos (Medical Outcomes Study) (MOS) (Ware y cols., 1992).

Detecta tanto estados positivos de salud como negativos y explora salud física y salud mental. Se encuentra adaptado en nuestro país por Alonso y cols.(1995) y la validez de la versión española ha sido analizada por Ayuso-Mateos y cols. (1999).

Se trata de un cuestionario autoadministrado, que consta de 36 ítems, que exploran 8 dimensiones del estado de salud: función física, función social, limitaciones del rol: problemas físicos, limitaciones del rol: problemas emocionales, salud mental, vitalidad, dolor y percepción de la salud general:

- Funcionamiento Físico: evalúa el grado en que la salud de un individuo limita una serie de actividades físicas como andar, ejercicios intensos, etc. 
- Rol físico: evalúa hasta qué punto los problemas de salud física interfieren con el funcionamiento ocupacional del paciente.

- Dolor: evalúa el grado del mismo con la interferencia que produce en la vida del paciente.

- Salud General: hace referencia a la percepción personal del estado de salud, así como a una serie de creencias respecto a la salud del paciente.

- Vitalidad: evalúa la fatiga y la energía del paciente.

- Funcionamiento Social: interroga acerca de las limitaciones en la vida sociofamiliar por problemas de salud.

- Rol emocional: evalúa hasta qué punto los problemas emocionales interfirieron en el funcionamiento ocupacional del paciente.

- Salud Mental: intenta evaluar el estado de ánimo del paciente, inquietud, intranquilidad, desánimo, etc. durante el último mes.

Junto a estas 8 dimensiones, se puede obtener otra dimensión en la corrección final de cuestionario, es la Percepción del cambio de salud en el tiempo, que hace referencia la valoración de la mujer sobre si cree que existe un cambio en su salud en las últimas 4 semanas.

Se han propuesto dos formas diferentes de puntuación. La primera (Rand Group) establece una graduación de las respuestas para cada ítem desde 0 a 100. No todas las respuestas tienen el mismo valor, que depende del número de posibilidades de respuesta para cada pregunta. La segunda forma de puntuación (The Health Institute) otorga diferentes pesos específicos a cada respuesta, según unos coeficientes que no siguen una distribución lineal. Sea cual sea el método empleado, 
el significado de la puntuación es el mismo: cuanto mayor sea, mejor estado de salud refleja.

Posee una elevada consistencia interna ( 0.8 para todas las escalas, salvo para “función social” que es 0.76) (Brazier y cols., 1992). El coeficiente de correlación intraclase es de 0.85 (Beaton y cols., 1994). Los valores psicométricos de la adaptación al español, son similares a los originales, salvo la fiabilidad de la dimensión "función social", que es algo menor. La validación española ha encontrado valores consistentes y superponibles a los de la escala original.

Los ítems y las dimensiones del cuestionario proporcionan unas puntuaciones que son directamente proporcionales al estado de salud; cuanto mayores sean, mejor estado de salud. El rango de las puntuaciones para cada dimensión oscila de 0 a 100 . Resulta útil disponer de valores normalizados de referencia en población general.

Las medias y desviación estándar en población general española estos valores son: función física 94,4 (SD 12,8), función social 96 (SD 14,1), limitación rol: problemas físicos 91,1 (SD 25,7), limitación rol: problemas emocionales 90,1 (SD 26), salud mental 77,7 (SD 17,3), vitalidad 69,9 (SD 18,4), dolor 82,3 (SD 24,8), percepción de la salud general 80 (SD 18,8) (Alonso y cols., 1995).

El test detecta tanto estados positivos de salud, como negativos. El contenido de las cuestiones se centra en el estado funcional y el bienestar emocional. Su ámbito de aplicación abarca población general y pacientes y se emplea en estudios descriptivos y de evaluación. Existe una "versión estandar" que hace referencia al estado de salud en las 4 semanas anteriores y una "versión aguda" que evalúa la semana anterior. 
c) Inventario de Depresión de Beck, BDI (Beck y cols, 1961; versión española de Vázquez y Sanz, 1991)

Fue desarrollado como una escala autoaplicada de 21 ítems para evaluar la gravedad (intensidad sintomática) de la depresión, conteniendo cada ítem varias frases evaluativos. En 1979, Beck y sus colaboradores dan a conocer una nueva versión revisada de su inventario, adaptada y traducida al castellano por Vázquez y Sanz (1991), siendo ésta la más utilizada en la actualidad.

En esta revisión actualizada se sistematizan 4 alternativas de respuesta para cada ítem, que evalúan la gravedad/intensidad del síntoma y que se presentan ordenadas de menor a mayor gravedad. El marco temporal hace referencia al momento actual y a la semana previa. Su contenido enfatiza más el componente cognitivo de la depresión, ya que los síntomas de esta esfera representan más del $50 \%$ de la puntuación total del cuestionario. De los 21 ítems, 15 hacen referencia al componente cognitivo-psicológico de la depresión y sólo 6 a los síntomas somáticos vegetativos (Schotte y cols., 1997)

El paciente debe seleccionar, para cada ítem, la alternativa de respuesta que mejor refleje su situación en el momento actual y última semana. La puntuación total se obtiene sumando los valores de las frases seleccionadas, que van de 0 a 3.El rango de la puntuación obtenida es 0 a 63 puntos. Como cualquier otro instrumento de medición de síntomas, el objetivo del BDI es cuantificar la sintomatología no proporcionar un diagnóstico. Los puntos de corte aceptados son los siguientes:

- No depresión:0-9 puntos

- Depresión Leve:10-18 puntos 
- Depresión Moderada:19-29 puntos

- Depresión Grave: $\geq 30$ puntos

Se trata posiblemente del cuestionario autoaplicado más citado en la bibliografía. Proporciona una estimación adecuada de la gravedad de los síntomas depresivos y es ampliamente utilizado en la evaluación de la eficacia terapéutica por su sensibilidad al cambio y, en la investigación básica, para la selección de sujetos. Posee una adecuada validez para el cribado o detección de casos en la población general. 
d) Batería de Escalas de Expectativas Generalizadas de Control (BEEGC) (Palenzuela 1991,1997)

Se trata de un instrumento construido a partir de la Teoría del Control Personal propuesta por Palenzuela .De acuerdo con esta teoría, la BEEGC evalúa tres dimensiones de las expectativas de control: Locus de Control (LC), Autoeficacia (SE) y Expectativa de Éxito (EOS). El locus de control es concebido como un constructo con 3 dimensiones (contingencia, indefensión y suerte). Consta de 28 ítems en forma de afirmaciones relacionadas con aspectos relevantes respecto a las a las expectativas generales del sujeto. De esta forma, cada individuo ha de indicar hasta qué grado se identifica con cada afirmación, desde el "1" (no se identifica nada con la afirmación en cuestión) hasta el "9” (se identifica completamente ).

Siguiendo la propuesta del autor, el instrumento ofrecería una medida de las siguientes expectativas:

1. La expectativa de locus de control contiene subdimensiones:

- La expectativa de contingencia o internalidad (referida al control interno) se refiere al grado en que una persona atribuye a sus conductas o comportamientos, las consecuencias o resultados que obtiene en su vida diaria.

- La expectativa de indefensión o no contingencia (propia del control externo) se refiere al grado en que uno espera que los acontecimientos o resultados que puedan acontecerle o tener lugar en su vida serán independientes de sus acciones. 
- La expectativa o creencia en la suerte (control externo) se refiere al grado en que uno cree en la suerte, en qué medida las cosas ocurren debido al azar no las acciones de uno mismo.

2. La expectativa de autoeficacia hace referencia creencia de las personas sobre sus propias capacidades, en qué medida uno se siente capaz de emprender o realizar acciones concretas para conseguir determinados resultados.

3. La expectativa de éxito se refiere a una estimación subjetiva de la medida en qué una persona espera conseguir un objetivo propuesto. 


\section{3.- Procedimiento}

La selección muestral se realizó desde las consultas externas del Servicio de Ginecología del Complejo Asistencial de Burgos, siendo incluídas las mujeres que cumplían los requisitos de especificados anteriormente. El muestreo fue, por tanto al azar intencionado.

Inicialmente, se llevó a cabo una reunión con los diferentes profesionales que atendían dichas consultas para presentarles la investigación, solicitarles su colaboración y especificar su labor en la selección de la muestra. Los ginecólogos que finalmente se implicaron en la investigación (2 ginecólogos de 4 consultas externas) disponían del protocolo de estudio con los cuestionarios en sus consultas, en un sobre con el membrete del Hospital General Yagüe de Burgos.

El médico, una vez que identificaba a una mujer compatible con los criterios de inclusión, le informaba brevemente del objetivo de estudio, de forma general, e insistía en el carácter anónimo del mismo.

Posteriormente, las mujeres se llevaban a su domicilio en un sobre de tamaño medio todos los cuestionarios, y una vez contestados los enviaban por correo ordinario, ya que el sobre incluía la dirección (la misma consulta del Hospital General Yagüe en la que fueron atendidas), sin que supusiera ningún coste económico para cada mujer.

En el protocolo que contestaba cada mujer en su domicilio, se especificaba de nuevo el objetivo de esta investigación y el carácter totalmente anónimo de la misma. De igual modo, en el encabezamiento de cada cuestionario se detallaba, de forma clara y comprensible, de qué forma se debía contestar a cada instrumento y las características de cada opción de respuesta. 
El tiempo de recogida de muestra fue de aproximadamente 9 meses con un número total de cuestionarios entregados de 240. El número final de cuestionarios recibidos fue de 186, obteniéndose un índice de respuesta en la investigación del $77,5 \%$. De los cuestionarios recibidos, se descartaron 48 por existir errores en las contestaciones, respuestas en blanco y diversas equivocaciones en cuanto a la batería específica de instrumentos de evaluación.

El intervalo de tiempo entre la presentación de la investigación a los ginecólogos e inicio de la recogida de muestra y la recepción del último cuestionario fue de aproximadamente 11 meses. Después de analizar las respuestas de forma detallada, podemos considerar que la dificultad del protocolo diseñado era asumible para la mayoría de las mujeres ya que apenas han ofrecido errores en las contestaciones, siendo la mayor parte de los 48 cuestionarios excluidos por respuestas en blanco u omisiones. Finalmente con las 138 mujeres seleccionadas se inició el proceso de análisis de datos. 


\section{4.- Análisis de datos}

El tratamiento de los datos se inició con la conveniente codificación y preparación de la matriz o base de datos (Microsoft Excel 2000 del Microsoft Office), luego a través del paquete de software estadístico SPSS-11 (Windows) implementado para PC, se ejecutaron los análisis.

Para describir la muestra se realizaron análisis descriptivos, que incluían cálculos y gráficos de los diferentes estadísticos de las variables analizadas.

Para probar las hipótesis planteadas se realizaron diferentes análisis:

- ANOVAS o análisis de varianza de uno y dos factores, todos ellos han sido de efectos fijos. Informan sobre la existencia de diferencias significativas entre los diferentes subgrupos en los que se han separado los sujetos de nuestro estudio, sobre la base de las categorías establecidas por la variable predictora o factor. Se realizaron comparaciones "a posteriori” entre los diferentes grupos, mediante el test de Scheffé.

- Análisis multivariado: que poseen la propiedad de poder establecer correspondencias entre distintas variables o factores con una o más variables dependientes. El análisis multivariado es útil para explicar relaciones entre una gran cantidad de indicadores o para explorar efectos no conocidos entre éstos. Mediante ellos se pueden abordar todos los indicadores disponibles para un fenómeno determinado. De los métodos existentes se ha elegido el dirigido a organizar sujetos el análisis discriminante, que es una de las técnicas de clasificación de sujetos en grupos ya definidos. Se parte de un criterio de clasificación de sujetos en grupos y de una muestra en la que se han medido determinadas variables cuantitativas independientes, que son las que se utilizarán para tomar la decisión en cuanto al grupo en el que se clasifica cada sujeto, mediante el modelo matemático estimado a 
partir de los datos. Concretamente el análisis discriminante predictivo, trata de estimar a partir de los datos, unas ecuaciones, la utilización de éstas para un nuevo sujeto, del cuál se desconoce el grupo de pertenencia, permite clasificarlo en su grupo, proporcionando una regla de clasificación lo más precisa posible. Se trata pues de formular un algoritmo por el que se pueda determinar a qué grupo pertenece un sujeto. En el análisis discriminante predictivo es importante cuantificar con qué precisión se clasificará a un nuevo sujeto. 


\section{2.- Resultados Inferenciales}

\subsection{1.- Primera hipótesis}

\section{Los síntomas climatéricos producen una mayor vulnerabilidad hacia la alteración del estado de ánimo.}

Para comprobar esta hipótesis se realizan sucesivos análisis de varianza de un factor de efectos fijos, introduciendo como variable independiente los síntomas climatéricos y como dependiente las puntuaciones obtenidas en el Inventario de depresión de Beck (BDI). Al introducir los "sofocos", los resultados indican diferencias estadísticamente significativas $\left(\mathrm{F}_{(3,138)}=3.87 ; \mathrm{p}_{\mathrm{a}}=.01\right)$ (Figura 20):

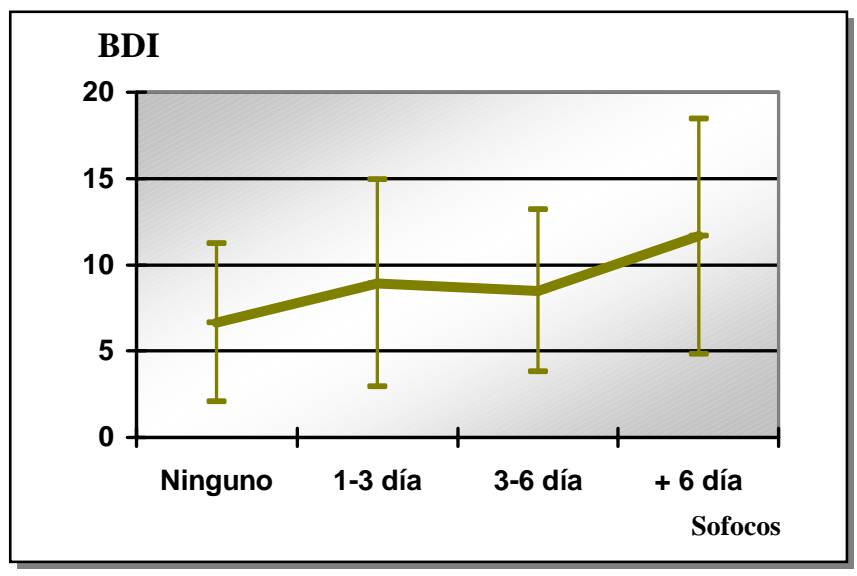

Fig. 20.: Efecto de los sofocos sobre estado de ánimo

Los análisis a posteriori con la $\mathrm{F}$ de Scheffé, indican que las diferencias se encuentran entre el grupo sin sofocos y aquél que tiene más de seis al día, no habiendo tales diferencias entre el resto de los grupos (tabla 9). Las mujeres que no evidencian tener sofocos no manifiestan alteración en su estado de ánimo, al igual que aquellas cuyo número de sofocos es relativamente bajo (hasta seis al día), sin embargo sí existe efecto de este factor cuando el número de sofocos al día es 
elevado, estas mujeres evidencian una puntuación en el BDI susceptible de ser clasificada como depresión leve.

Tabla 9:

Análisis a posteriori: sofocos-BDI (F de Scheffé)

\begin{tabular}{llcc}
\hline Categorías & & Dif. Medias & p \\
\hline \multirow{2}{*}{ Ninguno } & 1-3/día & $-2,28$ &, 21 \\
& 3-6/día & $-1,85$ &, 62 \\
\multirow{2}{*}{ 1-3/día } & Más 6/día & $-4,99$ &, $02^{* *}$ \\
& 3-6/día &, 43 &, 99 \\
\multirow{2}{*}{ 3-6/día } & Más 6/día & $-2,71$ &, 44 \\
& Más de 6/día & $-3,14$ &, 42 \\
\hline
\end{tabular}

Al introducir los trastornos del sueño como variable independiente los resultados no indican efecto del factor sobre la variable de medida $\left(F_{(3,138)}=2,95 ; p_{a}\right.$ $=.051$, no obteniéndose diferencias significativas que permitieran relacionar alteraciones del sueño con afectación del humor o del estado de ánimo en la mujer menopáusica.

Cuando se analiza la irritabilidad, los resultados son significativos $\left(\mathrm{F}_{(3,138)}=\right.$ $\left.13.55 ; \mathrm{p}_{\mathrm{a}}=.0001\right)($ Figura 21$)$ :

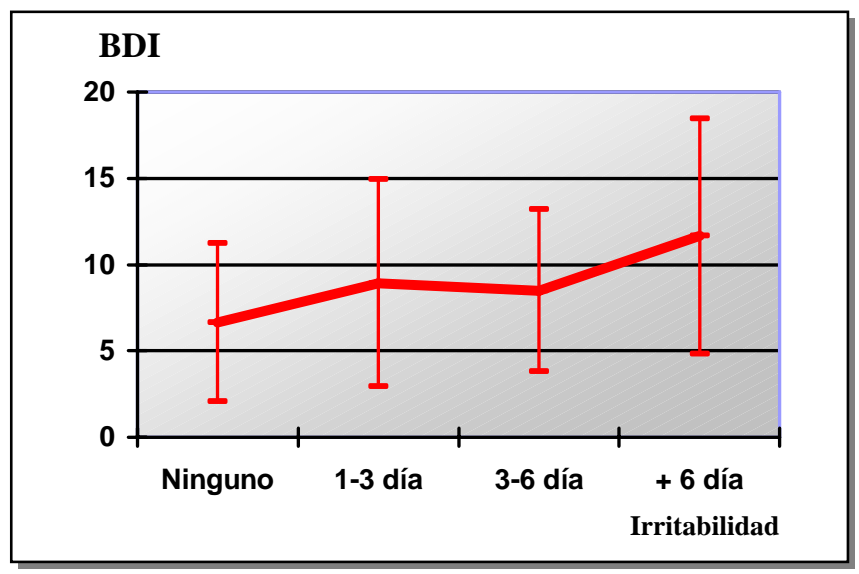

Fig. 21.: Efecto de la irritabilidad sobre estado de ánimo 
Los análisis posthoc indican que las diferencias se producen entre los dos primeros grupos con respecto a los otros, es decir no hay efecto del factor cuando la irritabilidad es nula o poca, pero cuando la mujer percibe bastante o mucha, se evidencian niveles de sintomatología depresiva en ascenso, alcanzando valores de depresión leve. (Tabla 10):

Tabla 10:

Análisis a posteriori: irritabilidad-BDI (F de Scheffé)

\begin{tabular}{llcl}
\hline Categorías & & Dif. Medias & \multicolumn{1}{l}{$\mathbf{p}$} \\
\hline \multirow{2}{*}{ Ausencia } & Algo & $-2,44$ &, 23 \\
& Bastante & $-7,45$ &, $0001^{* *}$ \\
\multirow{2}{*}{ Algo } & Mucho & $-10,29$ &, $001^{* *}$ \\
\multirow{2}{*}{ Bastante } & Bastante & $-5,01$ &, $0001^{* *}$ \\
& Mucho & $-7,85$ &, $009^{* *}$ \\
& Mucho & $-2,84$ &, 71 \\
\hline
\end{tabular}

El cuarto síntoma es el ánimo depresivo y lógicamente se identifica el factor con la variable de medida. Hemos tenido en cuenta esta variable porque el estado depresivo sería una percepción subjetiva de la mujer sobre su humor, mientras que las puntuaciones del Beck nos darían la medición objetiva del estado de ánimo. Los resultados indican diferencias significativas $\left(\mathrm{F}_{(2,138)}=28,72 ; \mathrm{p}_{\mathrm{a}}=.0001\right)$ (Figura 22):

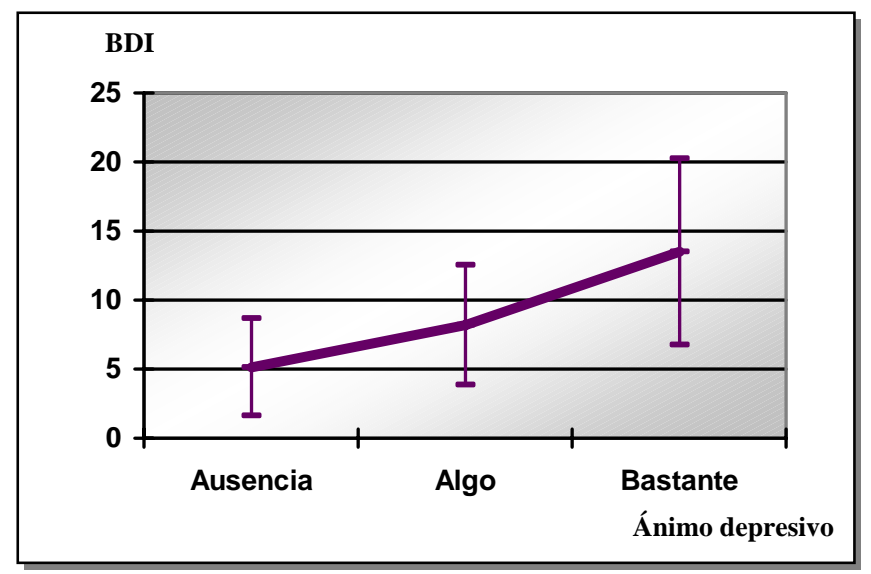

Fig. 22: Efecto del Ánimo depresivo sobre estado de ánimo 
Como podemos comprobar en la figura 22 , no existen mujeres que hayan elegido la categoría de "mucho", en concordancia con la objetivación del BDI en el que ninguna mujer obtuvo niveles de depresión grave y muy pocas alcanzan el nivel de moderado.

Los análisis a posteriori indican que existen diferencias entre las tres categorías, a medida que la percepción sobre su estado de ánimo es peor, la sintomatología evaluada por el Inventario de Depresión es mayor; de nuevo el salto a niveles moderados se produce cuando la mujer afirma que su estado es "bastante" depresivo (tabla 11).

Tabla 11:

Análisis a posteriori: ánimo depresivo-BDI (F de Scheffé)

\begin{tabular}{llcl}
\hline Categorías & & Dif. Medias & p \\
\hline \multirow{2}{*}{ Ausencia } & Algo & $-3,03$ &, $004^{* *}$ \\
\multirow{2}{*}{ Algo } & Bastante & $-8,36$ &, $0001^{* *}$ \\
& Bastante & $-5,33$ &, $0001^{* *}$ \\
\hline
\end{tabular}

La variable sequedad vaginal, también ejerce efecto sobre el estado de ánimo $\left(\mathrm{F}_{(3,138)}=7,23 ; \mathrm{p}_{\mathrm{a}}=.0001\right)($ Figura 23):

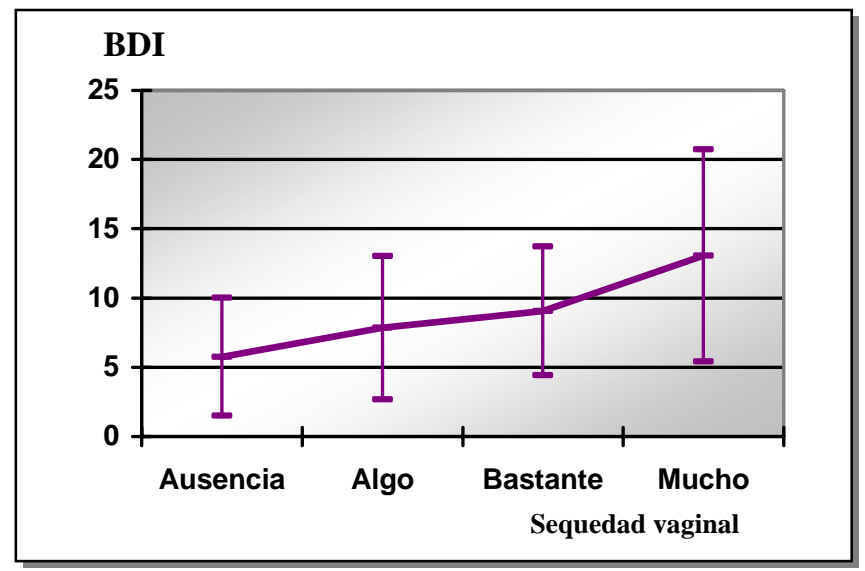

Fig. 23.: Efecto de la Sequedad vaginal sobre estado de ánimo 
Los análisis con la F de Scheffé se muestran en la tabla 12:

Tabla 12:

Análisis a posteriori: irritabilidad-BDI (F de Scheffé)

\begin{tabular}{llcl}
\hline Categorías & & Dif. Medias & p \\
\hline \multirow{2}{*}{ Ausencia } & Algo & $-2,09$ &, 32 \\
& Bastante & $-3,31$ &, 11 \\
\multirow{2}{*}{ Algo } & Mucho & $-7,30$ &, $0001^{* *}$ \\
\multirow{2}{*}{ Bastante } & Bastante & $-1,22$ &, 79 \\
& Mucho & $-5,21$ &, $01^{* *}$ \\
& Mucho & $-4,00$ &, 13 \\
\hline
\end{tabular}

Las diferencias se encuentran entre los dos primeros grupos y el último, pero no existe diferencia de la categoría "bastante" ni con la inferior, ni con la superior. De nuevo es el grupo que percibe mayor sintomatología el que alcanza peores puntuaciones en el estado de ánimo.

Cuando como variable independiente se introduce el interés sexual, los resultados sobre el estado de ánimo también son estadísticamente significativos ( $\mathrm{F}$ $\left.(3,138)=9,15 ; p_{a}=.0001\right)($ Figura 24):

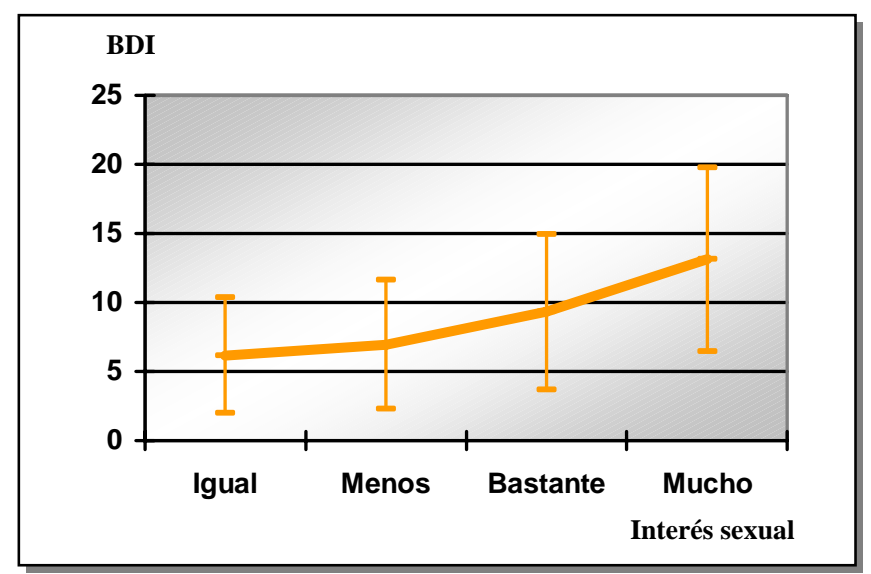

Fig. 24.: Efecto del interés sexual sobre estado de ánimo 
Los análisis con la F de Scheffé se muestran en la tabla 13:

Tabla 13:

Análisis a posteriori: Interés sexual-BDI (F de Scheffé)

\begin{tabular}{llll}
\hline Categorías & & Dif. Medias & p \\
\hline \multirow{2}{*}{ Igual } & Algo Menos & $-0,79$ &, 92 \\
& Bastante Menos & $-3,16$ &, 12 \\
\multirow{2}{*}{ Algo Menos } & Mucho Menos & $-6,94$ &, $0001^{* *}$ \\
& Bastante Menos & $-2,38$ &, 23 \\
Bastante & Mucho Menos & $-6,16$ &, $0001^{* *}$ \\
& Mucho Menos & $-3,78$ &, 09 \\
\hline
\end{tabular}

Los resultados indican que a medida que la mujer percibe menor deseo sexual su estado de ánimo empeora, no habiendo diferencia entre igual y algo menos y bastante menos. Es decir la categoría de bastante menos no discrimina entre los otros tres grupos.

Al analizar la sintomatología de dolor en articulaciones, los resultados sobre el estado de ánimo también son significativos $\left(\mathrm{F}_{(3,138)}=3,99 ; \mathrm{p}_{\mathrm{a}}=.009\right)$ (Figura 25):

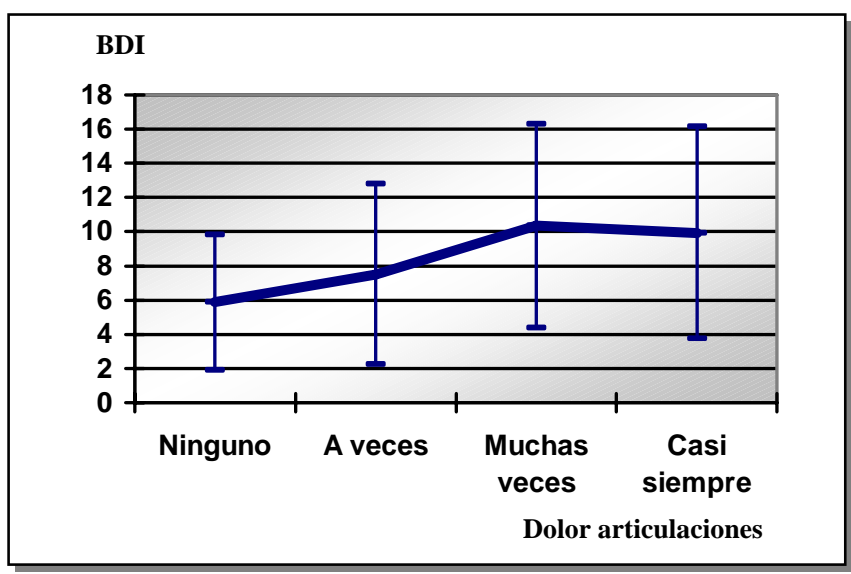

Fig. 25: Efecto de dolor en articulaciones sobre estado de ánimo 
Los análisis con la F de Scheffé se muestran en la tabla 14:

Tabla 14:

Análisis a posteriori: Dolor en articulaciones-BDI (F de Scheffé)

\begin{tabular}{llcl}
\hline Categorías & & Dif. Medias & p \\
\hline \multirow{2}{*}{ Ninguno } & A veces & $-1,65$ &, 66 \\
& Muchas veces & $-4,48$ &, $03^{* *}$ \\
\multirow{2}{*}{ A veces } & Casi siempre & $-4,07$ &, 13 \\
\multirow{2}{*}{ Muchas veces } & Muchas veces & $-2,83$ &, 14 \\
& Casi siempre & $-2,43$ &, 41 \\
& Casi siempre & $-0,40$ &, 99 \\
\hline
\end{tabular}

Los resultados indican las diferencias se establecen únicamente entre el grupo que no tiene ningún dolor articular y los otros, destacando que tanto las que tienen muchas veces dolores como las que tienen casi siempre alcanzan niveles de depresión leves.

Por último, al introducir la categorización de la variable relación de pareja, los resultados sobre el estado de ánimo también son estadísticamente significativos ( $\mathrm{F}$ $\left.(3,138)=17,28 ; p_{a}=.0001\right)($ Figura 26). Como podemos observar, tan sólo aquellas mujeres que no perciben cambio en la relación de pareja presentan ausencia de depresión, el resto se ubican en niveles leves. Parece que la variable relación de pareja es muy sensible y que al menor cambio produce efecto sobre el estado de ánimo.

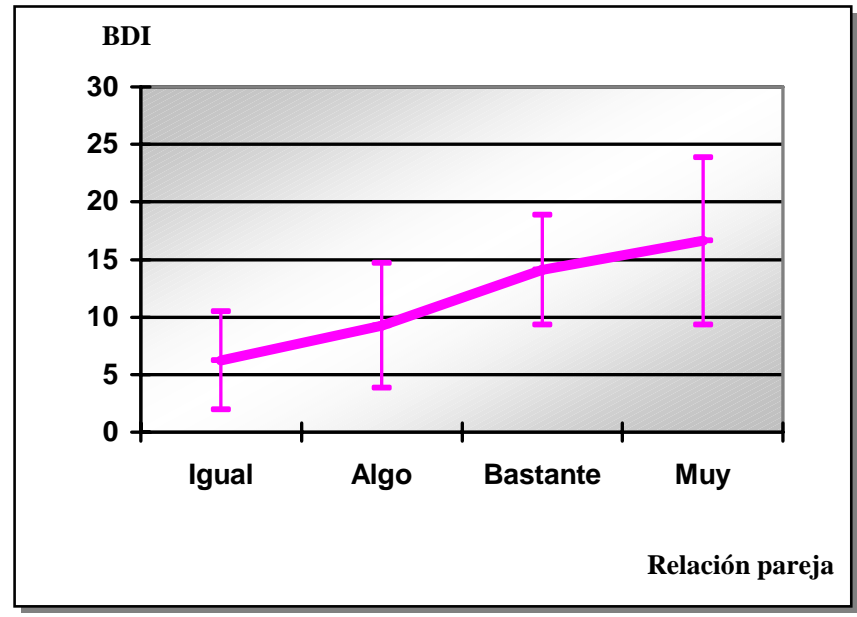


Los análisis con la F de Scheffé se muestran en la tabla 15:

Tabla 15:

Análisis a posteriori: Relación de pareja-BDI (F de Scheffé)

\begin{tabular}{llrl}
\hline \multirow{2}{*}{ Categorías } & & \multicolumn{1}{c}{ Dif. Medias } & p \\
\hline \multirow{2}{*}{ Igual } & Algo deteriorada & $-3,04$ &, $02^{* *}$ \\
& Bastante deteriorada & $-7,88$ &, $0001^{* *}$ \\
\multirow{2}{*}{ Algo deteriorada } & Muy deteriorada & $-10,40$ &, $0001^{* *}$ \\
\multirow{2}{*}{ Bastante deteriorada } & Bastante deteriorada & $-4,84$ &, $02^{* *}$ \\
& Muy deteriorada & $-7,36$ &, $02^{* *}$ \\
& Muy deteriorada & $-2,32$ &, 80 \\
\hline
\end{tabular}

Los resultados indican que todos los grupos se diferencian entre ellos, excepto los dos cuya relación de pareja está más deteriorada, alcanzando éstos puntuaciones subclínicas en depresión.

Como hemos descrito en los resultados comentados, todos los síntomas climatéricos ejercen efecto sobre la alteración del estado de ánimo excepto los trastornos del sueño. Los síntomas evaluados con la Escala de Sintomatología Climatérica de la Asociación Española ofrecen diferencias significativas sobre la sintomatología depresiva, confirmando así nuestra hipótesis.

Este hecho nos parece relevante y de gran importancia a la hora de generalizar los resultados, ya que en la literatura revisada respecto a la descripción de los síntomas más prevalentes, existen estudios congruentes con nuestra investigación respecto a la importancia de los sofocos en la vivencia de la menopausia y en la aparición de sintomatología depresiva, pero son escasas las investigaciones que reseñan una significación en la mayoría de los síntomas, como ocurre con los datos de nuestro estudio. Cabe reseñar que casi la totalidad de las investigaciones que parten del análisis de estas variables establecen relaciones teniendo en cuenta 
alteraciones leves del estado de ánimo, no sintomatología depresiva moderada o grave compatible con un trastorno depresivo mayor.

Sin embargo, existe concordancia en estudios como el de Daly et al. (1994), donde también se obtiene una significación en la mayoría de los síntomas climatéricos y en el mismo año, Brambilla y Vass (1994) evalúan todos los síntomas que nosotros hemos incluido en nuestro estudio, y concluyen que existe una relación entre menopausia y depresión y que esta relación es explicada por la intensidad de los síntomas climatéricos.

También Bosworth y cols., (2001) detectan un aumento significativo de los síntomas depresivos en la mujer menopáusica y consideran que es debido a la presencia generalizada de sintomatología climatérica, aunque rechazan la hipótesis de una asociación permanente entre menopausia y depresión. Un autor que realiza una propuesta similar, pero incluye un objetivo para la práctica clínica en función de los resultados obtenidos es Lindaker (2004) quien asegura que el disconfort que presentan las mujeres durante la menopausia es consecuencia de los síntomas climatéricos (generalizados, pero no especifica cuáles son más significativos) y propone programas de educación para la salud en la mujer menopáusica para que la mujer aprenda a manejar y minimizar los efectos de los síntomas.

Entre las escasas investigaciones recientes que ofrecen resultados $y$ conclusiones integrando prácticamente la totalidad de los síntomas climatéricos consensuados por la comunidad científica, destaca la diseñada por Magyar (2006) quien obtiene como síntomas con diferencias significativas en el estado de ánimo, principalmente los sofocos, dolor en las articulaciones, sequedad vaginal e interés 
sexual aunque considera que la totalidad de síntomas tienen influencia directa en las alteraciones anímicas.

Por último, dentro de las investigaciones con estas características, Budakoglu y Karacam (2007) también concluyen que la mayoría de los síntomas climatéricos (principalmente sofocos y dolor en articulaciones) tienen un efecto negativo sobre la vivencia subjetiva de la menopausia y sobre el estado de ánimo.

Por otro lado, existen investigaciones que hacen referencia a un número muy reducido de síntomas o incluso toman como variable independiente un síntoma climatérico aislado (en la mayoría de las ocasiones, los sofocos) para explicar la relación o asociación existente entre sintomatología depresiva y climatérica. Se semejan a nuestros resultados en el cuanto a la asunción de una relación significativa entre alteraciones del estado de ánimo e intensidad de los síntomas climatéricos, pero lo hacen desde síntomas individuales o por grupos reducidos de síntomas sin evaluar una escala general. Entre estas investigaciones, Bell (1995) concluye que la frecuencia e intensidad de los síntomas climatéricos no explicaban aspectos como las expectativas o creencias respecto a la menopausia, ni sobre el estado de ánimo.

Kaufert y cols. (1998) encontraron que sólo los síntomas de irritabilidad y el estado depresión estaban relacionados y tenían una influencia relevante en la percepción subjetiva de la menopausia. El mismo resultado obtuvieron Jiménez y Pérez (1999) que asumen que son los síntomas depresivos y la irritabilidad (también incluían la fatiga y la inestabilidad emocional) los que favorecen la aparición, intensidad y frecuencia de sintomatología depresiva.

Betti et al. (2001) afirman que los cambios propios de la transición menopáusica, tanto físicos como psicológicos, están integrados y asumidos por las 
mujeres de forma adecuada, mostrando en general una adaptación satisfactoria aunque presenten sintomatología climatérica relevante (sofocos y estado de ánimo principalmente). Estos autores apoyan estas conclusiones en el hecho de haber encontrado un número significativo de mujeres que asociaban síntomas climatéricos (sofocos) con experiencias positivas durante la menopausia.

Otro de los autores que defienden la relación existente entre estado de ánimo depresivo y síntomas climatéricos específicos, no el grupo de síntomas, es Chendraui (2007) quien en las conclusiones de su estudio asegura que el $75 \%$ de las mujeres menopáusicas presenta alteraciones del humor que puede explicarse por la presencia de sofocos y alteraciones del sueño, contrariamente a nuestras conclusiones según las cuales, todos los síntomas climatéricos, salvo las alteraciones del sueño, presentan diferencias significativas en su efecto sobre los síntomas depresivos durante la menopausia

Para finalizar este apartado, comparamos nuestros resultados con investigaciones que presentan resultados y conclusiones contrarias a las muestras, bien porque no establezcan una relación entre la intensidad de los síntomas climatéricos y alteraciones leves en el estado de ánimo de la mujer menopáusica, o bien porque incluyan el único síntomas climatérico que en nuestra investigación no consideramos significativo para explicar dicha relación (las alteraciones del sueño). Entre estos autores destaca Kahn y cols. (1994) quienes después de analizar los síntomas menopáusicos consideran que no se observa un aumento de los síntomas que debieran tener más relación con el estado de ánimo depresivo durante la menopausia, es decir, el ánimo depresivo y la irritabilidad. 
Hunter (1996) argumenta, después de analizar la influencia de los síntomas en el estado de ánimo durante la menopausia, que los factores que influyen en el estado de ánimo de la mujer menopáusica son los psicosociales, no los climatéricos. Avis y cols. (2001) manifiestan, de forma más específica en cuanto al análisis de los síntomas climatéricos, que la existencia de síntomas depresivos se explicaría por la presencia e intensidad de sofocos y alteraciones del sueño.

Por último, Yost y cols. (2005) sólo encuentran tres síntomas discriminantes (sofocos, ánimo depresivo y sequedad vaginal) y no obtienen una relación entre la intensidad de estos síntomas y el estado de ánimo en la mujer menopáusica ni tampoco en su calidad de vida mientras que, en otro estudio, Willbur (2006) llega a estas mismas conclusiones, al considerar que los síntomas climatéricos que aparecen con más intensidad son los sofocos, dolor en las articulaciones y sequedad vaginal, no estableciendo una relación entre estos síntomas y sintomatología depresiva. De Lorenzi (2006) es el único autor revisado que otorga un papel primordial al interés sexual en la percepción y satisfacción de la mujer acerca la transición menopáusica.

Respecto a esta primera hipótesis de nuestra investigación, consideramos que los resultados estadísticos confirman que los síntomas climatéricos, y la intensidad en que estos aparecen, son un factor de vulnerabilidad para la presencia de alteraciones del estado de ánimo en la mujer menopáusica. Esta vulnerabilidad aparece de forma significativa en la totalidad de los síntomas climatéricos (salvo en las alteraciones del sueño). Muchas de las investigaciones parten de hipótesis en las que no se plantea la evaluación de una escala climatérica general, si no síntomas aislados, por lo que consideramos que los resultados de nuestra investigación pueden generalizarse al 
establecer una relación significativa entre alteraciones leves del estado de ánimo y la totalidad de los síntomas climatéricos.

Conviene destacar que ninguno de los estudios revisados concluye que exista una relación positiva entre ambas variables, en el sentido de observar una profilaxis en cuanto al estado de ánimo debido a los sintomatología climatérica, sino que este efecto lo atribuyen a factores personales o psicosociales.

Otro aspecto que consideramos necesario destacar de nuestra investigación, es la relación tan firme que tiene la valoración del deterioro de la relación de pareja con la presencia de alteraciones anímicas en la mujer. Se trata de una relación significativa y de gran relevancia social, que consideramos sería necesario una investigación posterior, más precisa, centrada en la influencia de este aspecto durante la transición menopáusica 


\subsection{2.- Segunda hipótesis}

\section{Un nivel de expectativas positivo y la mayor calidad de vida percibida, ejercen un efecto protector en el humor.}

Para comprobarla, se realizan sucesivos análisis de diferencia de medias o $\mathrm{t}$ de Student, introduciendo como variable independiente las mediciones obtenidas en las cinco subescalas de la Batería de Expectativas Generalizadas de Control (BEEGC), previamente categorizadas en función del percentil 50. Como variable dependiente, las puntuaciones en el Inventario de Depresión de Beck (BDI).

Los resultados indican diferencias significativas únicamente en dos de ellas, la contingencia y la indefensión (Figuras 26 y 27):

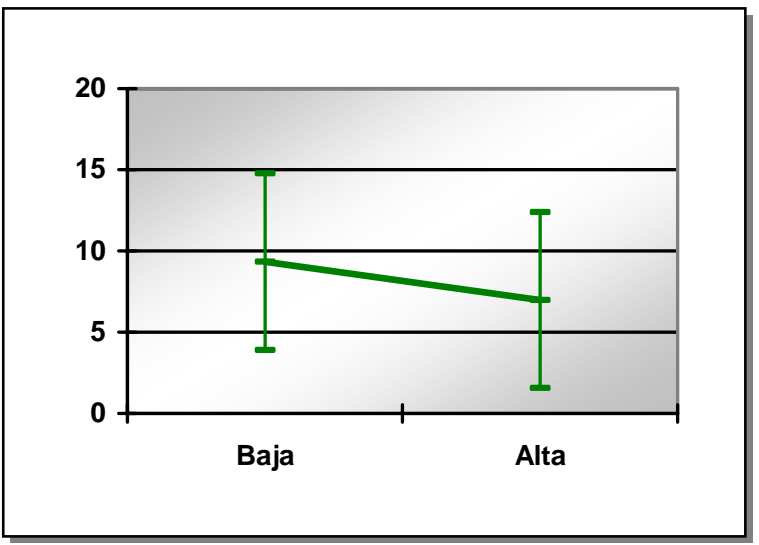

Fig. 26: Contingencia y estado de ánimo

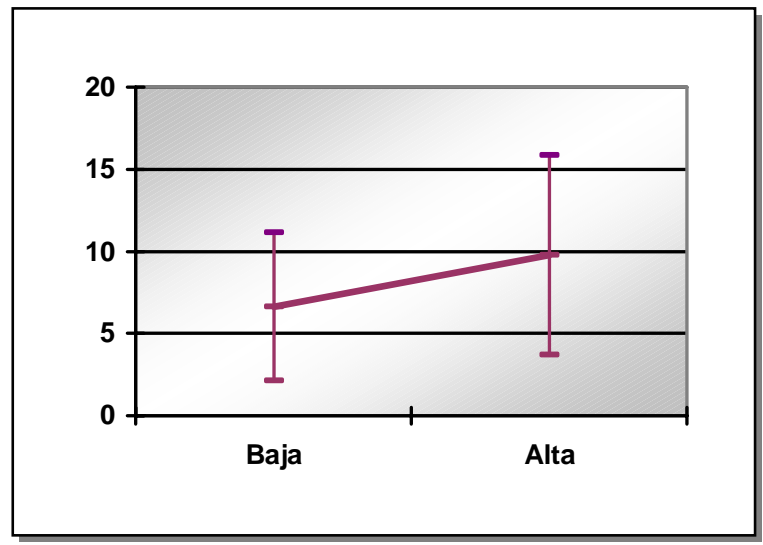

Fig.27: Indefensión y estado de ánimo

Como se puede observar, cuando la mujer tiene más seguridad en la contingencia de sus acciones, es decir, cuando cree que sus esfuerzos se adecuan a los resultados obtenidos en sus actos, mejor estado de ánimo. Sin embargo sucede lo contrario con la indefensión, cuanto más cree la persona que no puede hacer nada para modificar las circunstancias de su vida o que independientemente de los que haga nada en su vida se modificará, peor estado de ánimo. 
Los valores de todos los análisis efectuados se reflejan en la tabla 16:

Tabla 16:

Expectativas y Estado de Ánimo

\begin{tabular}{lrll}
\hline Variable & $\mathbf{t}$ & g.l. & p \\
\hline Contingencia & 2,56 & 136 &, $01^{* *}$ \\
Autoeficacia & $-0,86$ & 136 &, 39 \\
Indefensión & $-3,48$ & 136 &, $001^{* *}$ \\
Éxito & $-1,63$ & 136 &, 11 \\
Suerte & 0,12 & 136 &, 90 \\
& & & \\
\hline
\end{tabular}

Compararemos nuestros resultados con las investigaciones revisadas que utilizan de forma más general el término de expectativa e incluso, alguno de ellos, utilizan términos psicológicos diferentes, de forma sesgada, para referirse a lo mismo (creencia, actitud, percepción subjetiva, etc...). Entre las investigaciones que por su importancia, merecen ser contrastadas, cabe destacar la realizada por López y Fuertes (1989) quienes se apoyan en un término más general (expectativas sociales) para afirmar que las mujeres menopáusicas que sufrirán un proceso de desadaptacion a esta transición menopáusica serán aquellas que evidencian un desajuste entre sus expectativa y la realidad conseguida, llegando a considerar que no podrán cumplir determinadas metas y objetivos. Coincidente con los resultados obtenidos en este estudio, aunque los autores mencionados hacen referencia a la expectativa de resultado, en nuestro caso abordamos la teoría del control personal concretamente son las expectativas de indefensión y autoeficacia, las que explicarían las alteraciones del estado de ánimo y, la desadaptacion de la mujer menopáusica.

Otro estudio referente en la literatura especializada, determina una influencia directa entre las características personales y sintomatología depresiva es el realizado 
por Avis y McKinlay (1991) quienes afirman que las mujeres que refieren expectativas negativas respecto a la transición menopáusica mostraban mayor sintomatología depresiva, de forma significativa.

Una investigación que explica las alteraciones del humor en la menopausia mediante la expectativa de indefensión lo firman Liao y cols. (1994), indicando que las creencias negativas estereotipadas provocan expectativas y atribuciones falsas en cuanto a que ya no pueden hacer nada por cambiar lo que les ocurre en esta etapa. Consideran que una mayor información es primordial para modificar estas expectativas de indefensión que generan sentimientos de desesperanza y éstos, alteraciones del estado de ánimo.

Utilizando la misma batería de medición, Díez (1994), tras realizar un path análisis obtiene un efecto directo en la expectativa de contingencia sobre el estado de ánimo, afirmando que la depresión en la menopausia es un constructo multidimensional actuando el resto de las expectativas, excepto la de suerte, de forma indirecta sobre el proceso adaptativo en estas edades.

Existe un estudio de 1995, que presenta un diseño con el término expectativa en general utilizando diferente sistema de medición, pero con unas conclusiones que permiten una semejanza con nuestros resultados en las expectativas de control. El trabajo de Wilbur y cols. (1995), analiza las expectativas de las mujeres premenopáusicas y postmenopáusicas, observando que éstas últimas presentaban expectativas más realistas y positivas respecto a la transición menopáusica, mientras que las mujeres premenopáusicas presentaban bajas expectativas de contingencia (creencias de que su situación durante la menopausia, no dependía de su esfuerzo o su actuación) y altas expectativas de indefensión (hicieran lo que hicieran, "sufrirían" 
las consecuencias de la menopausia). Determinaron que las mujeres premenopáusicas, con las características detalladas presentaban mayores puntuaciones en la escala de depresión.

En general los autores afirman cómo la estigmatización social de la menopausia es una fuente generadora de expectativas negativas hacia la misma, en concreto Chen y Voda (1996), diseñan un estudio sobre mujeres chinas, encontrando que la mayoría de las mujeres describían la menopausia como un fenómeno natural y mostraban expectativas positivas hacia la misma (altas expectativas de contingencia y autoeficacia) y no se detectaban alteraciones del estado de ánimo. Los autores indican que este estudio debe suponer un ejemplo para conseguir un cambio de actitudes y expectativas hacia la menopausia en la cultura occidental. Coincidente con el realizado en Gran Bretaña sobre población de origen asiático por Seti y Pitkin (2000) quienes encontraban estas expectativas positivas en un $82 \%$ y $77 \%$, respectivamente.

La explicación a estos resultados la centra Stotland (2002) en las expectativas sociales, variable principal de su estudio. Afirma que las características históricas y sociales de cada cultura determinan qué tipo de expectativa tienen las mujeres respecto a la menopausia y considera que es la "presión social" la que provoca una generación de expectativas negativas (principalmente de baja autoeficacia) lo que conllevaría una percepción negativa de la menopausia y un aumento en la prevalencia de alteraciones del humor en estas mujeres.

La investigación que lideró Bertero desde Suecia (2003) es muy aclaratoria y está en consonancia con nuestras conclusiones, ya que afirma que son las expectativas de contingencia (conocimiento y actuación en función de los cambios 
propios que ocurren durante la menopausia) las que permiten una adecuación y adaptación a estos cambios.

La concordancia entre la investigación de Wu y cols. (2004) y la que nosotros hemos diseñado es muy alta pero con la diferencia que obtienen resultados significativos en las expectativas de contingencia y expectativas de autoeficacia. Sus resultados permiten confirmar que una alta expectativa de contingencia y de autoeficacia son predictores de un funcionamiento psicológico normalizado, ya que no detectan alteraciones del humor en las mujeres que presentan este tipo de expectativas en la menopausia.

Entre los escasos estudios de los últimos años que toman las expectativas como variable en sus investigaciones sobre menopausia, Hvas (2006) observa que las mujeres que presentan expectativas de autoeficacia bajas realizan estrategias de afrontamiento pasivo ante los cambios propios de la menopausia y considera adecuado que los profesionales orienten a estas mujeres hacia actividades, de dificultad progresiva, para ir consiguiendo éxitos que aporten mayor seguridad y expectativas más realistas. Legget (2007) considera que las mujeres que no presentan alteraciones del estado de ánimo son las que valoran la menopausia como una oportunidad de crecimiento personal.

Por tanto, consideramos que los resultados validan parcialmente la hipótesis indicando que una expectativa positiva de contingencia y baja de indefensión, tienen un efecto protector en el estado de ánimo de las mujeres menopáusicas. Conclusión que se observa en la mayoría de las investigaciones, a pesar de las divergencias en la conceptualización del término "expectativa" o en la falta de especificidad en la definición de las expectativas utilizadas y en la metodología estadística utilizada. 
Aludiendo, la mayoría de los estudios, a los condicionantes sociales y culturales en la generación de dichas expectativas. 
En segundo lugar, realizamos de nuevo análisis de diferencia de medias o $t$ de Student, pero en esta ocasión introduciendo como variable independiente las mediciones realizadas en el SF-36 (calidad de vida), previamente categorizadas en función del percentil 50. Como variable dependiente, las puntuaciones en el Inventario de Depresión de Beck (BDI).

Los resultados, (tabla 17) son todos significativos con excepción de la percepción del cambio de salud:

Tabla 17:

Calidad de vida y Estado de Ánimo

\begin{tabular}{lccl}
\hline Variable & $\mathbf{t}$ & g.l. & p \\
\hline Función Física & 2,05 & 136 &, $04^{* *}$ \\
Problemas Físicos & 3,70 & 136 &, $0001^{* *}$ \\
Dolor & 3,53 & 136 &, $001^{* *}$ \\
Función Social & 4,54 & 136 &, $0001^{* *}$ \\
Salud Mental & 7,41 & 136 &, $0001^{* *}$ \\
Problemas Emocionales & 4,01 & 136 &, $0001^{* *}$ \\
Vitalidad & 6,37 & 136 &, $0001^{* *}$ \\
Percepción Salud G. & 4,06 & 136 &, $0001^{* *}$ \\
Cambio Salud & $-1,06$ & 136 &, 29 \\
\hline
\end{tabular}

En la figura 28, se representan las medias obtenidas en el estado de ánimo:

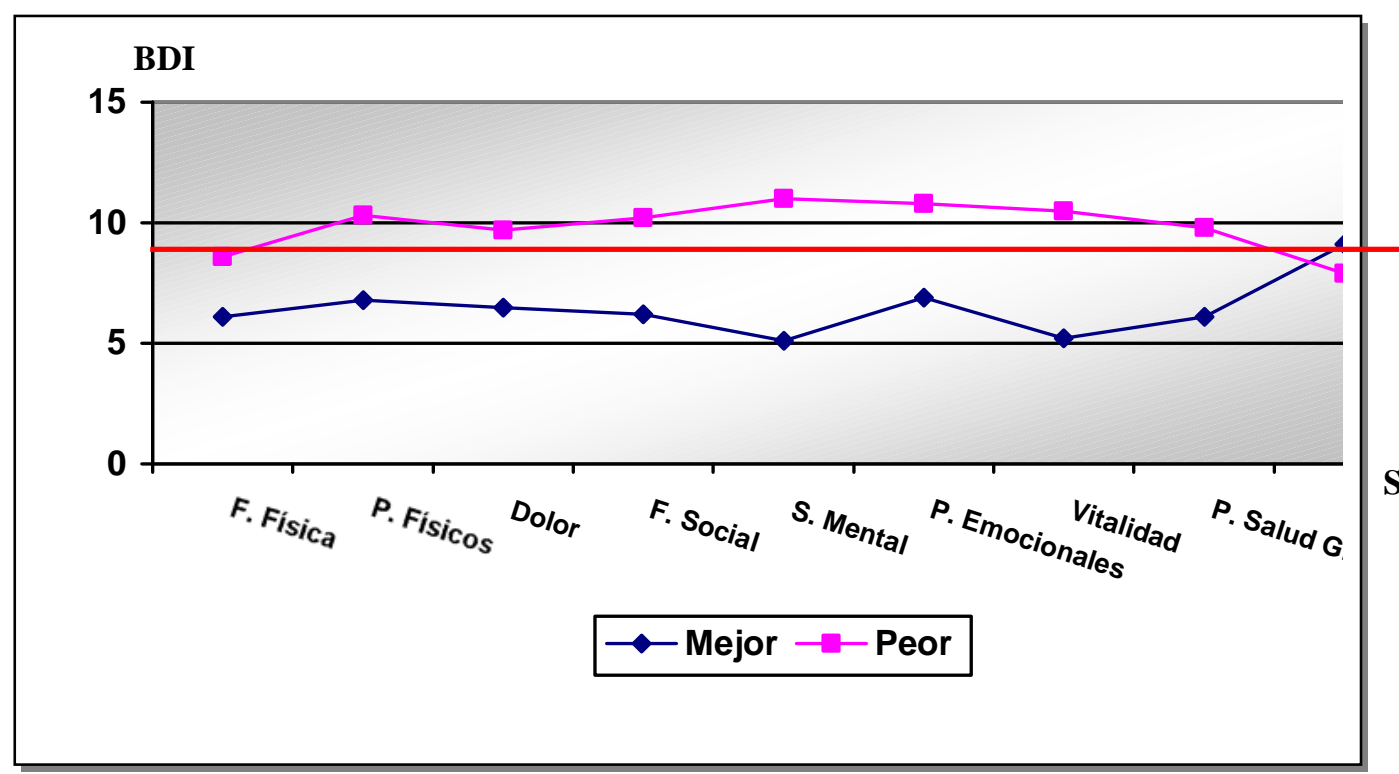

Fig. 28: Calidad de vida y estado de ánimo 
Como se puede observar en la figura 28, a medida que los valores percibidos en calidad de vida son mejores el estado anímico se ubica en puntuaciones por debajo de 9 (punto de corte del BDI para el nivel de depresión leve), sin embargo cuando la calidad de vida percibida es peor, todos los valores significativos, excepto la función física, se ubican por encima del mismo. Es decir existe un efecto de la calidad de vida percibida sobre el estado de ánimo, con suficiente poder cómo para poder intensificar la sintomatología depresiva a valores subclínicos.

Aunque son dos variables frecuentemente planteadas en los diseños de las investigaciones sobre menopausia, sorprende no encontrar apenas en la literatura estudios que analicen de forma aislada, la relación existente entre la calidad de vida y el estado de ánimo durante la menopausia. Entre ellas conviene destacar la realizada por Hunter (1993), que considera que la calidad de vida durante la menopausia depende del afrontamiento de las situaciones estresantes por las que pasa la mujer en la transición menopáusica, provocando un afrontamiento pasivo o negativo una sintomatología depresiva asociada. Ledesert (1994) evalúa el efecto de la calidad de vida sobre 1171 mujeres postmenopáusicas, observando una disminución en la calidad de vida en las mujeres que referían peor estado de ánimo y presentaban una sintomatología climatérica acentuada.

Schneider (2002), evalúa la calidad de vida de mujeres postmenopáusicas y considera que está influenciada por variables físicas y factores psicosociales. Entre estos factores, compara la presencia de ánimo depresivo con las dimensiones de calidad de vida del cuestionario SF-36 y concluye que la intensidad y severidad de los síntomas menopáusicos (entre ellos, el ánimo depresivo) condicionan la percepción subjetiva de la calidad de vida por parte de las mujeres. La diferencia con 
nuestra investigación es que en este estudio, las dimensiones de calidad de vida evaluadas con el mismo instrumento de medida (cuestionario SF-36), se considera la variable dependiente, a diferencia de nosotros que asumimos como variable dependiente el estado de ánimo e independiente la calidad de vida.

Un estudio que ofrece conclusiones contrarias a las nuestras lo proponen Mishra y cols. (2003) quienes diseñan una hipótesis semejante a la de este estudio en cuanto a la relación entre calidad de vida y estado de ánimo en la menopausia. Los resultados no permiten aceptar la hipótesis, es decir, no encuentra una influencia del estado de ánimo en la calidad de vida en la menopausia. En este mismo sentido, Avis (2004) analiza el estado de salud general, calidad de vida y variables psicosociales (considerando entre ellas el estado de ánimo). Observa una calidad de vida percibida menor en las mujeres postmenopáusicas pero no obtiene una relación significativa entre el ánimo depresivo y la calidad de vida. Ozkan (2005) tampoco encuentra una correlación significativa entre la calidad de vida percibida y el ánimo depresivo (entendido como un síntoma climatérico).

Más recientemente, Lain (2006) analiza el impacto que supone la menopausia en la calidad de vida de la mujer y su relación con diferentes variables, entre ellas el estado de ánimo. Obtiene que las puntuaciones más bajas en las dimensiones de calidad de vida se relacionan con la salud mental en general, no sólo con el estado de ánimo. Con un planteamiento y conclusiones muy semejantes, Bankowski (2006) no observa un declinar en la percepción de la calidad de vida de las mujeres menopáusicas, pero las puntuaciones más bajas se pueden explicar por dos factores muy concretos: bajas expectativas de autoeficacia y alteraciones del estado de ánimo. 
Conde (2006) también obtiene resultados congruentes con nuestro planteamiento y utiliza el cuestionario SF-36 para evaluar la calidad de vida de 81 mujeres menopáusicas. Los resultados tampoco muestran un descenso del nivel de calidad de vida durante la menopausia pero sí obtiene correlaciones significativas en cuanto al estado de ánimo.

Entre los estudios más recientes, Chen (2007) indica que no existe un descenso en la calidad de vida percibida por las mujeres menopáusicas ni obtiene una correlación con los principales síntomas climatéricos, como el estado de ánimo. En cambio, Budakoglu y Karacam (2007) consideran que la peor percepción de la calidad de vida está directamente relacionada con la intensidad de la sintomatología climatérica, entre los que destacan el ánimo depresivo.

En suma, es de resaltar que en la revisión de la literatura específica sobre el tema existe una gran controversia en la conceptualización de la calidad de vida percibida, considerándola algunos de los estudios como consecuencia de un peor estado de ánimo, sin embargo en otros es consecuencia del mismo. Con todo, los resultados obtenidos nos permiten aceptar la segunda hipótesis y afirmar que una mejor percepción de calidad de vida está relacionado con un mejor estado de ánimo, pudiendo afirmar que ejerce un efecto protector ante los síntomas depresivos. 


\subsection{3.- Tercera hipótesis}

\section{Las variables psicológicas estudiadas permiten clasificar psicopatológicamente a las mujeres menopáusicas}

El problema de la clasificación es uno de los primeros que aparecen en la actividad científica y constituye un proceso consustancial en casi toda actividad humana, de tal manera que en la resolución de problemas y en la toma de decisiones, la primera parte de la tarea consiste precisamente, en clasificar el problema o la situación, para después aplicar el tratamiento correspondiente y, en buena medida, su efectividad dependerá de esa clasificación.

Por supuesto, también es así tanto en Medicina como en Psicología, ciencias en las que el diagnóstico constituye una parte primordial, siendo una fase previa para la aplicación de la terapia. Diagnosticar es equivalente a clasificar a un sujeto en una patología concreta, en base a los datos correspondientes de su anamnesis y exploración.

Cuando hablamos de clasificar a un sujeto en un grupo determinado, a partir de los valores de una serie de parámetros medidos u observados, y esa clasificación tiene un cierto grado de incertidumbre, resulta razonable pensar en la utilización de una metodología probabilística, que nos permita cuantificar esa incertidumbre.

Uno de los problemas más sencillos en cuanto a la clasificación, es el de poder ubicar a un sujeto como enfermo o no por los resultados de una prueba diagnóstica. Lo usual en Medicina y Psicología es que las cosas no sean tan simples y que no se maneje una sola variable para tomar la decisión clasificadora; lo habitual será disponer de un grupo de variables, y al utilizarlas de forma conjunta nos conduce a un enfoque multivariante de la cuestión. 
Cuando los grupos están bien definidos, desde el punto de vista científico, se intenta determinar un criterio para etiquetar a cada individuo como perteneciente a alguno de los grupos a partir de una serie limitada de parámetros.

Uno de los instrumentos utilizados para ello es el análisis discriminante, ya que permite estimar un algoritmo por el que se pueda determinar a qué grupo pertenece un paciente. Concretamente, en el discriminante predictivo es importante cuantificar con qué precisión se clasificará a un nuevo sujeto.

Para comprobar la hipótesis planteada se considera oportuno aplicar este tipo de análisis. Las variables predictoras que se han introducido son las diez que en los análisis previos han indicado que tienen efecto sobre el estado de ánimo (contingencia, indefensión, función física, problemas físicos, dolor, función social, salud mental, problemas emocionales, vitalidad y percepción de la salud general). La variable clasificatoria se ha hecho en función de los puntos de corte del BDI, propuestos por los autores, para la clasificación psicopatológica.

Los resultados del análisis indican que ocho variables se introducen en la primera ecuación discriminante y dos en la segunda (tabla 18):

Tabla 18:

Variables introducidas en las funciones discriminantes

\begin{tabular}{lllll}
\hline Función & Lambda de Wilks & $\chi^{2}$ & g.l. & p \\
\hline $\mathbf{1}$ & .468 & 99,21 & 20 & .0001 \\
$\mathbf{2}$ & .871 & 18,02 & 9 & .035 \\
\hline
\end{tabular}

Estas variables conforman dos funciones discriminantes canónicas, en la primera función la correlación asciende a .468 y en la segunda función es de .871 . 
Los coeficientes para las variables discriminantes en cada ecuación figuran en la tabla 19

Tabla 19:

Coeficientes de las funciones discriminantes canónicas

\begin{tabular}{llc}
\hline & \multicolumn{2}{c}{ ECUACIÓN } \\
\hline & $\mathbf{1}$ & $\mathbf{2}$ \\
\hline Salud mental & .79 & \\
Vitalidad & .69 & \\
Problemas emocionales & .51 & \\
Dolor & .39 & \\
Percepción salud general & .39 & \\
Indefensión & -.34 & \\
Problemas físicos & .31 & \\
Contingencia & .21 & \\
Función física & & .63 \\
Función social & & .13 \\
\hline
\end{tabular}

Estas ecuaciones permiten clasificar correctamente al 74,6\% de las mujeres de la muestra, los resultados de la clasificación figuran en la tabla 20:

Tabla 20:

Resultado de la clasificación

\begin{tabular}{lcccc}
\hline \multicolumn{5}{c}{ Grupo de pertenencia pronosticado } \\
\hline Niveles depresión & Ausencia & Leve & Moderada-Grave & Total \\
\hline Ausencia & 74,7 & 11,5 & 13,8 & 100 \\
Leve & 11,9 & 73,8 & 14,3 & 100 \\
Moderada-Grave & 22,2 & 0,0 & 77,8 & 100 \\
\hline
\end{tabular}

Como se puede apreciar, aproximadamente un $75 \%$ de la muestra se clasifica correctamente en el grupo de ausente, y lo que es más importante el $73,8 \%$ con 
niveles leves y el 77,8\% de las mujeres con niveles clínicos de depresión se clasifican correctamente. En la figura 29, se representan los centroides de cada grupo y la clasificación de todas las mujeres de la muestra:

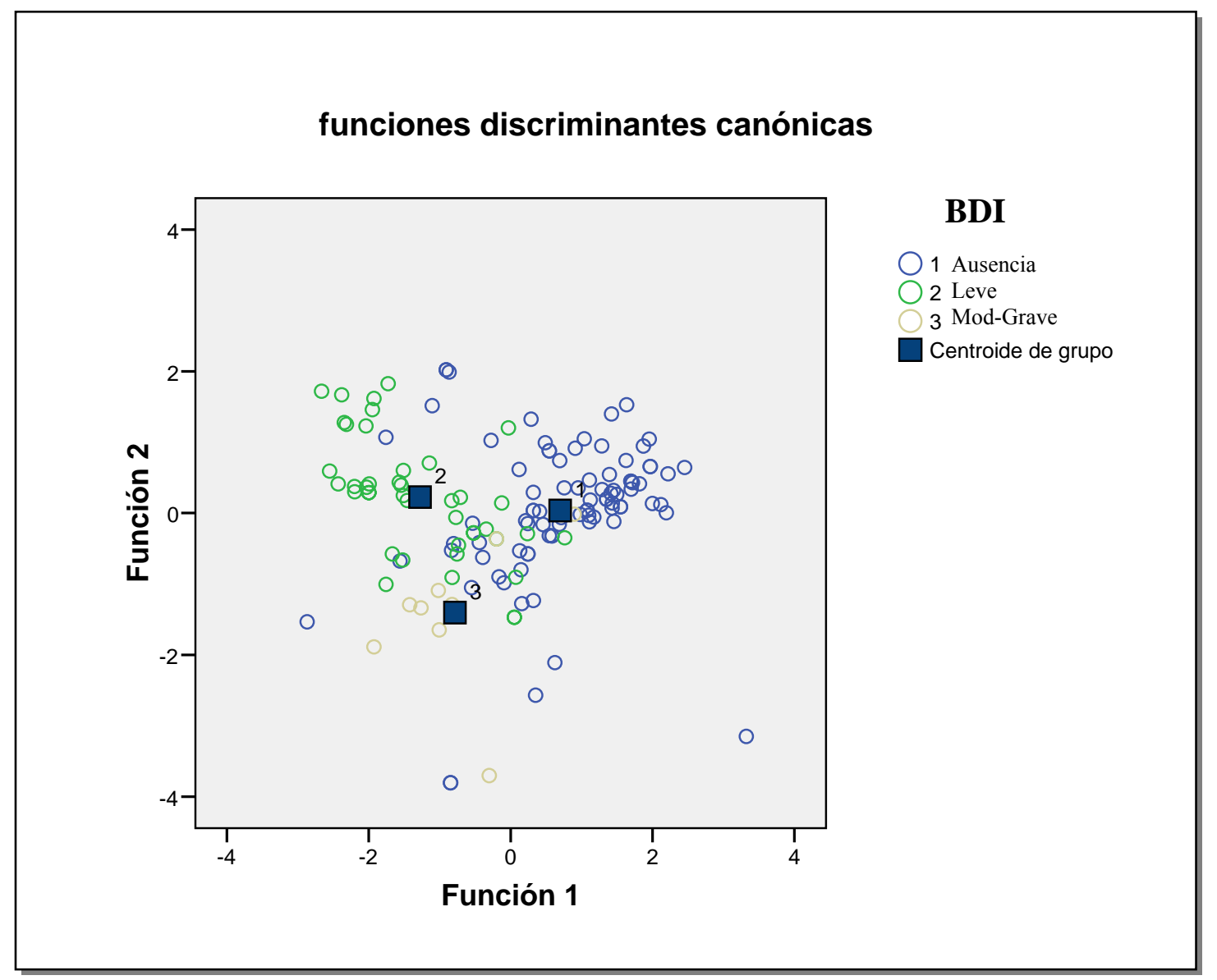

Fig. 29: Funciones discriminantes canónicas para el estado de ánimo

En conclusión, este tipo de análisis permite determinar algunos de los parámetros que actúan sobre el estado de ánimo. A nivel terapéutico se debería procurar que la mujer, cuando se encuentra en los años iniciales de la menopausia, debería mejorar a nivel de personalidad las expectativas de contingencia e indefensión, vigilar en especial los aspectos emocionales y el dolor, y por último no descuidar las funciones físicas y sociales. 
No ha sido posible realizar una comparativa de nuestras conclusiones respecto a esta hipótesis mediante otras investigaciones por dos motivos: en primero lugar, porque no hemos encontrado ningún estudio que utilice la técnica estadística del análisis discriminante, siendo una técnica específica y con unas características psicométricas concretas; y en segundo lugar, tampoco son frecuentes los análisis multivariantes que permitan realizar comparaciones con resultados que consideren el estado de ánimo en la menopausia de forma multidimensional .

Teniendo esto en cuenta, destacaremos algunas investigaciones que también refieren un conjunto de variables que muestran una influencia, bien protectora o bien desencadenante, sobre el estado de ánimo de la mujer menopáusica a pesar de no utilizar la misma metodología. Es de destacar en este sentido el estudio de Rohde (2007) quien considera que existe una génesis multicausal y multifactorial para explicar la presencia de alteraciones anímicas en la transición menopáusica y aunque no es preciso en la especificación de las variables implicadas, sí admite que la transición hormonal y determinados sucesos vitales son factores con influencia en la aparición de síntomas depresivos.

Uno de los primero estudios que facilitaron un grupo de variables como predictoras o explicativas de los síntomas depresivos en la menopausia fue el proyecto Manitoba (1992) que concluía que son los cambios hormonales, los estresores familiares y sociales los que explicaban las alteraciones anímicas.

Una publicación que ofrece una interpretación curiosa de la afectación del humor en la menopausia es la que realiza Bemesderfer (1996) quien aborda desde una perspectiva psicoanalítica los problemas asociados a la menopausia y considera que, en la menopausia se debe redefinir la identidad materna. Considera que el ánimo 
depresivo aparece, de manera inevitable, en la menopausia debido a la removilización del complejo de castración.

Dennerstein (2004) propone un complejo de variables a tener en cuenta por su significación en la aparición de sintomatología depresiva. Estas variables eran: antecedentes de alteraciones del estado de ánimo, complicaciones en la premenopausia, actitudes negativas, edad y problemas generalizados de salud.

Por último, Amore (2007) considera que la incidencia de los síntomas depresivos durante la menopausia se podrían predecir por la presencia de dos variables muy concretas, los antecedentes personales con una historia previa de episodios depresivos y acontecimientos vitales negativos. Como se observa, entre los estudios comparados que proponen un grupos de variables para predecir, explicar o precipitar la sintomatología depresiva en la menopausia, no encontramos ninguno que únicamente tenga un diseño con variables psicológicas y personales como en nuestro caso ( expectativas y calidad de vida ). 


\section{Conclusiones}




\section{7.- CONCLUSIONES}

$1^{\mathrm{a}}$.- Se puede afirmar que los cambios propios de la transición menopáusica, se evidencian en la mayoría de las mujeres, presentando más de la mitad de la muestra sintomatología climatérica relevante tales como sofocos, trastornos del sueño, irritabilidad, sequedad vaginal, dolor en articulaciones y disminución del interés sexual.

$2^{a}$.- El perfil general de personalidad de las participantes muestra que poseen sensación de control durante la transición menopáusica, con sensación de autoeficacia para afrontar y resolver las dificultades de esta etapa, consideran que lo que les ocurra tiene una relación directa con lo que ellas hagan y no se perciben indefensas ante el momento vital que atraviesan.

3a .- Su percepción de calidad de vida relacionada con la salud, está por debajo de la puntuación media para la población general española, sin embargo no muestran alteraciones en su vida sociofamiliar debido a problemas de salud; no se detecta una afectación en la ocupación y funcionalidad diaria de las mujeres debido a problemas emocionales y son los problemas físicos y la salud general, las dimensiones donde puede haber algunas interferencias en su autonomía personal diaria.

4a .- La mayoría de las mujeres ofrecen un estado anímico normalizado, el más adecuado para relacionarse con los demás y mantener una actitud positiva ante la vida, ahora bien, hay que reseñar que un tercio ofrece sintomatología subclínica y un 7\% alcanza valores psicopatológicos susceptibles de valoración clínica depresiva.

$5^{\text {a }}$.- Consideramos que los síntomas climatéricos, y la intensidad en que éstos se manifiestan son un factor de vulnerabilidad para la presencia de alteraciones del estado de ánimo en la mujer menopáusica. Esta vulnerabilidad aparece de forma 
significativa en la totalidad de los síntomas climatéricos, salvo en las alteraciones del sueño.

$6^{\text {a }}$ - La relación de pareja se ha evidenciado importante sobre el estado de ánimo, tan sólo aquellas mujeres que no perciben variación en la relación presentan un estado anímico normalizado, el resto evidencia la sensibilidad de esta variable, dado que los mínimos cambios producen diferencias en la sintomatología depresiva.

$7^{\mathrm{a}}$.- La creencia de la mujer en la contingencia de sus acciones, es decir, cuando cree que sus esfuerzos se adecuan a los resultados obtenidos en sus actos, ejerce un efecto protector de la depresión. Sin embargo, la indefensión o creencia de la persona en la imposibilidad de modificar las circunstancias de su vida produce mayor vulnerabilidad para sufrir una alteración del estado de ánimo.

8 a - El efecto en la transición menopáusica de la percepción de calidad de vida sobre el estado de ánimo es significativo, con suficiente intensidad como para poder acentuar la sintomatología depresiva hasta valores subclínicos.

9a.- Existen parámetros que van a permitir pronosticar si una mujer en la transición menopáusica es susceptible de padecer un trastorno depresivo. Los síntomas climatéricos, la calidad de vida percibida y las expectativas, son variables que discriminan perfectamente entre un estado de ánimo saludable y la depresión moderada y grave, sin embargo, para identificar la sintomatología leve sería deseable recurrir a otras pruebas no consideradas en este estudio.

$10^{\mathrm{a}}$.- A nivel terapéutico, con la intención de evitar alteraciones del estado de ánimo durante la transición menopáusica, se debería procurar que la mujer cuando se encuentra en los años iniciales de este momento evolutivo, mejore las expectativas de contingencia e indefensión, vigile en especial los aspectos emocionales, 
concretamente la relación con la pareja y, proponer programas de educación para la salud con el objetivo de que aprendan a manejar y minimizar los efectos de los síntomas climatéricos. 


\section{Referencias Bibliográficas}




\section{8.- REFERENCIAS BIBLIOGRÁFICAS}

ABRAHAM S et al. Changes in Australian women's perception of the menopause and menopausal symptoms before and after the climateric. Maturitas, 1994; 2-3: 121-128

ADLER EM, ROSS L. Impact of menopausal symptoms. Study perpetuates false impresion. Br Med J, 1993; 307: 1420: 1421

ALONSO J et al. La version española del SF-36 Health Survey (Cuestionario de Salud SF36):un instrumento para la medida de los resultados clínicos.Med Clin,1995;104:771-6

AMORE $M$ et al. Psychologial status at menopausal transition: an Italian epidemiological study.Maturitas, 2004; 48(2): 115-24

ANDERSON, E., HAMBURGER, S., LIU, JH. ET AL. Characterisitcs of menopausal women seeking assistance. Am J. Obstet Gynecol 1987; 82: 523-528

ARCHER JS. NAMS/ Solvay Resident Essay Award. Relationship between estrogen, serotonin and depression. Menopause 1999; 6 (1): 71-78

AROSTEGUI I. Evaluación de la calidad de vida en personas adultas con retraso mental en la comunidad autónoma del País Vasco. Universidad de Deusto. 1998

ASOCIACIÓN ESPAÑOLA PARA EL ESTUDIO DE LA MENOPAUSIA. Medicina basada en la evidencia en menopausia. 2002

AVIS NE et al. Longitudinal study of hormone levels and depresión among women transitioning through menopause. Climateric, 2001; 4 (3): 243-249

AVIS NE et al. A longitudinal analysis of the association between menopause and depression. Results from the Massachussets Women's Health Study. Ann Epidemiol, 1994; 4 (3): 214-220

AVIS, NE ; McKINLAY, S. A longitudinal analysis of women's attitudes towards the menopause: results from the Massachusetts women's Health study. Maturitas, 1991; 13: 65-79 
AVIS NE et al.Quality of life in diverse groups of midlife women:assessing the influence of menopause,health status and psychosocial and demographic factors. Qual Life Res,2004;13(5):933-46

AYUSO-MATEOS JL, LASA L et al. Measuring health status in psychiatric community surveys: internal and external validity of the Spanish version of the SF-36. Acta Psychiatr Scand, 1999; 99: 26-32

BACKE B, HUNSKAAR S. General practitioner's attitudes to oestrogen prescription in the menopause: a national survey in Norway. Scand J Prim Health Care 1992: 10 (3): 179-184

BACKSTROM T. Symptoms related to the menopause and sex sterorid treatments. Ciba Found Symp 1995; 191: 171-180

BALASCH, J. Síntomas y complicaciones de la postmenopausia en relación con la deficiencia estrogénica y con los años transcurridos. Medicina integral. 1991, 3

BALLINGER CB. et al. Factors associated with psychiatric morbidity in women. Acta Psychiat Scan, $1985 ; 71: 272-280$

BALLINGER CB. Psychiatric aspects of the menopause. Br J Psychiatr, 1990; 156: 773-787

BANCROFT J, RENNIE D, WARNER P. Vulnerability to perimenstrual mood change: the relevance of a past history of depressive disorder. Psychosom Med, 1994; 56 (3): 225-231

BANDURA A. Social Learning Theory. New York: General Learning Press, 1977

BANDURA A. Social foundations of thought and action: A social cognitive. Englewood Cliffs, NJ: Prentice Hall, 1986

BANGER M. Affective syndrome during perimenopause. Maturitas, 2002; 41 Suppl 1: 513-518 
BEATON D, BOMBARDIER C, HOGG- JOHNSON S. Choose your tool: a comparison of the psychometric properties of five generic health status instruments in workers with soft tissue injuries. Qual Life Re, 1994; 3: 50-60

BEBBINGTON PE Y COLS. The influence of age and sex on the prevalence of depressive conditions: report from the National Survey of Psychiatric Morbidity. Psychol Med, 1998; 28 (1): $9-19$

BECH P, MUNK- JENSEN N, OBEL EB et al. Combined versus sequential replacement therapy: a double blind, placebo-controled study on quality of life-related outcome measures. Psycother Psychosom, 1998; 67 ( 4-5 ): 259-265

BECH P. Quality of life Measurements in Chronic Disorders. Psychoter Psychosom, 1993; 59: $1-10$

BECH P. Rating Scales for Psychopatology, Health Status and Quality of Life. A Compendium on Documentation in Accordance with the DSM-III-R and Who Systems. Berlin: SpringerVerlag, 1993

BECK AT et al. Inventory for mesassuring depression. Arch Gen Psych 1961;4:561-571

BECKER D et al. Psychological distress around menopause. Psychosomatic, 2001; 42 ( 3): $252-257$

BECKER D et al. Depressed mood through women's reproductive cycle:correlation to mood at menopause. Climateric, 2007;10(1):46-50

BELL ML. Attitudes toward menopause among Mexican American women. Health Care Women Int 1995; 16 (5): 425-435

BELSKY J. Psicología del envejecimiento. Teoría, investigaciones e intervenciones. Barcelona: Masson,1996 
BEMESDERFER S. A revised psychoanalytic view of menopause. J Am Psychoanal Assoc, 1996; 44 Supple: $351-369$

BENAZZI F. Female depression before and after menopause. Psychother Psychosom, 2000; 69 (5): $280-283$

BERTERO C. What do women think about menopause? A qualitative study of women's expectations, aprrenhensions and knowledge about the climacteric period. Int Nurse Rev, 2003;50 ( 2): 109-18

BETTI S, ORSINI MR et al. Attitudes towards menopause in a group of women followed in a public service for menopause counseling. Aging (Milano) 2001 ;13(4):331-338

BEYENE Y. Cultural significance and physiological manifestations of menopause. A biocultural analysis. Culture Med Psychiatr, 1980; 10: 47-71

BINET L, BOURLIÈRE F. Gerontología y geriatría, 1982; París P.U.F.: nº 319.

BIRKHAUSER M. Depression, menopause and estrogens: is there a correlation? Maturitas 2002; 41 Suppl 1: 53-58

BLANCO ML et al. Estudio clínico-biológico de mujeres menopáusicas con síntomas afectivos. En: Trastornos afectivos en la menopausia. P.T.D. España, 1993

BLUMBERG G, KAPLAN B et al. Women's attitudes towards menopause and hormone replacement therapy. Int J Gynaecol Obstet 1996; 54 (3): 271-277

BOBES J, BOUSOÑO M, IGLESIAS C, GONZÁLEZ MP. Calidad de vida: concepto. En: Bobes J, González MP, Bousoño M ( eds ). Calidad de vida en las esquizofrenias. Barcelona: JR Prons, 1995

BOBES J, GONZÁLEZ MP, BOUSOÑO M, SUÁREZ E. Desarrollo histórico del concepto de calidad de vida. Monografías de Psiquiatría, 1993; 6: 5-9 
BORRULL J. Aspectos psicosociales bajo el punto de vista del ginecólogo. En P.T.D. ( Ed. ): Trastornos afectivos en la menopausia, 175-182; 1993

BOSWORTH HB, BASTIAN LA et al. Depressive symptoms, menopausal status and cliamateric symptoms in women midlife. Psychosom Med, 2001; 63 (4): 603-608

BOTELLA LLUISÀ, J. La edad crítica. Climaterio y Menopausia. Barcelona: Salvat,1990 BOUSOÑO M et al. Estrategias terapéuticas: Psicoterapéuticas y psicofarmacológicas en los trastornos mentales del climaterio. En: Ferrer J, Bobes J (eds). Climaterio: Aspectos ginecológicos, psicológicos y psiquiátricos. Oviedo, 1993

BOUSOÑO,M ET AL. Manifestaciones clínicas y neuroendocrinas de los trastornos afectivos en la menopausia. En P.T.D. ( Ed. ): Trastornos afectivos en la menopausia, 185-193; 1993

BRAZIER J, HARPER E et al . Validating the SF-36 Health Survey questionnarie: new outcome measure for primary care. Br Med , 1992; 305: 160-164.

BRZYSKI RG, MEDRANO MA et al. Quality of life in low-income menopausal women attending primary care clinics. Fertil Steril 2001; 76 (1): 44-50

BUCHANAN MC, VILLAGRAN MM et al. Women, menopause, and (Ms.) information: communication about the climateric. Health Commun 2002;14(1):99-119

BUDAKOGLU II et al. Quality of life and postmenopausal symptoms among women in a rural district of the capital city of Turkey.Gynecol Endocrinol,2007;23(7):404-9

BUENDÍA J.Envejecimiento y Psicología de la Salud. Madrid: Siglo XXI,1994

BUSCH H et al. Menopausal transition an psychological development. Menopause 2003; 10 (2):179:87

CABALlERO GORDO, A. La Menopausia.Revista JANO Medicina y Humanidades, 1985; 615 
CABALLERO, A. La menopausia y sus problemas. Grafimad Ed.Madrid 1985

CAGNACCI A, NERI I. Effect of long-term local or systemic hormone replacement therapy on post-menopausal mood disturbances. Influences of socio-economic and personality factors. Maturitas 1999; 31 (2): 111-116

CAIRNEY J, WADE TJ. The influence of age on gender difference in depression: further population-based evidence on the relationship between menopause and the sex difference in depression. Soc Psychiatr Epidemiol, 2002; 37 (9): 401-408

CALAF i ALSINA J. Benefits of hormone replacement therapy: overwiev and update. Int J Fertil Women Med 1997; 42 (2): 329-346

CALATRONI, CJ., RUIZ, V. Terapéutica Ginecológica. Editorial Panamericana, 1988; 5: $96-$ 113

CALLEGARI $\mathrm{C}$ et al. Female psychopathologic profile during menopausal transition: a preliminary study. Maturitas,2007;56(4):447-51

CAMPBELL S, WHITHEAD M. Oestrogen therapy and the menopause syndrome. Clin Obstet Gynecol, 1977; 4: 31-47

CARANDAG JM, FRANCO-BRONSON K, KAMAREI S. Recognizing and managing depresión in women throughout the stages of life. Cleve Clin J Med, 2000; 67 (5): 329-331, $335-338$

CARRANZA- LIRA S, VALETINO-FIGUEROA ML. Estrogen therapy for depression in postmenopausal women. Int J Gynaecol Obstet 1999; 65 (1): 35-38

CASTAÑO D., MARTÍNEZ I. Aspectos psicosociales en el envejecimiento de las mujeres. Anales de Psicología 1990; 6(2):159-168

CASTRO RA, MORENO MJ et al. El papel modificador de la menopausia en los valores y las creencias femeninas. Rev. Atenc Primar y Salud Mental 2002; 18-26 
CHEN YL, VODA AM et al. Chinese midlife women's perceptions and attitudes about menopause. Menopause 1998 ;5(1):28-34

CHEN YL et al. Menopause specific quality of life satisfaction in community dwelling menopausal women in China. Gynecol Endocrinol,2007;23(3):166-72

CHENG MH et al. Does menopausal transition affect the quality of life?A longitudinal study of middle aged women in Kimen. Menopause,2007;14(5):885-90

CHENDRAUI P. Assessing menopausal symptoms among healthy middle aged women with the Menopause Rating Scale.Maturitas 2007;57(3):271-8

CHINCHILLA A Y COLS. Depresión y menopausia: factores patogénicos y patoplásticos. En: Trastornos afectivos en la menopausia. P.T.D. 1993

CHOOMPOOTAWEEP S et al. Menopause survey in Thai women. Data presented at the $6^{\circ}$ International Congress of Menopause. Bangkok, 1990

COMINO, R. Aspectos epidemiológicos del climaterio. En: La menopausia. Ediciones CEA, S.A. 1990; 1: 1-9

COMINO, R., RODRÍGUEZ, J. La terapéutica bajo el punto de vista del ginecólogo. En: Trastornos afectivos en la menopausia.P.T.D. Barcelona, 1993

COMMISSION OF EUROPEAN COMMUNITIES. Age and attitudes: main results from a eurobarometer survey. Bruselas, The Commission, 1994

CONDE, V et al.: Aspectos psicosociales bajo el punto de vista del psiquiatra. En: Trastornos afectivos en la menopausia. P.T.D. España 1993

CONDE, V. et al.:Aspectos históricos y conceptos básicos relacionados con el climaterio y la menopausia. En: Trastornos afectivos en la menopausia. P.T.D. España, 1993 
CONDE DM et al. Factors associated with quality of life in a cohort of postmenopausal women.Gynecol Endocrinol,2006;22(8):441-6

CORALINA J. Breve diccionario etimológico de la lengua castellana. Madrid: Gredos, 1980

COOKE DJ. A psychosocial study of the climateric. En: Broome A, Wallance L,eds.Psychology and Gyneacological Problems. London: Tavistock Public, 1984; 243-265

DALY E, GRAY A, BARLOW D et al. Measuring the impact of menopausal symptoms on quality of life. Br Med J, 1993; 307: 836- 840

DE LA GÁNDARA J.J.Trastornos afectivos de la menopausia. En: Gutierrez M, Escurra S, Pichot P ( eds ). Avances en tratornos afectivos. Barcelona: Ediciones en Neurociencias, 1996; $329-345$

DE LA GÁNDARA, J.J. Menopausia y salud mental. ELA. 1994

DE LA GÁNDARA JJ, SANCHEZ J et al. Influencia de las actitudes, expectativas y creencias en la adaptación a la menopausia. An Psiquiat, 2003; 19(8):329-36

DE LORENZI DR et al. Factor related to quality of life in post-menopause. Rev Assoc Med Bras,2006;52(5):312-7

DE MUYLDER X. The place of androgen therapy in menopausal women. Acta Clin Belg 2002; 57 (4): 176-183

DEBRAY R. El Estado seductor. Buenos Aires: Manantial, 1995

DEEKS AA, McCABE MP.Well-being and menopause:an investigation of purpose in life, selfacceptance and social rol in premenopausal,perimenopausal and postmenopausal women.Qual Life Res,2004;13(2):389-98

DEL SOL FERNÁNDEZ, JR. Apuntes de la Cátedra de Ginecología y Obstetricia de Valladolid. 1976 
DELGADO A., SANCHEZ MC et al. Actitudes de las mujeres ante la menopausia y variables predoctoras. Atenc Primaria 2001;27:3-11

DENNERSTEIN L, ASTBURY J, MORSE C. Psychological and Mental Health Aspects of Women's Health. Geneva, OMS, 1993

DENNERSTEIN L. Well-being, symptoms and the menopausal transition. Maturitas, 1996; 23 (2): $147-157$

DENNERSTEIN L.Depression in the menopause. Obstet Gynecol Clin North Am, 1987; 14 ( 1): $33-48$

DENNERSTEIN L et al. A population based study of depressed mood in middle-aged, Australian born women. Maturitas, 2004; 11(5):563-8

DERMAN RJ, DAWOOD MY, STONE S. Quality of life during sequential hormone replacement therapy, a placebo-controlled study. Int J Fertil Menopausal Stud 1995 ; 40(2):7378

DEXEUS JM. Importancia sociocultural de la menopausia. Conferencia en el I Symposium Internacional sobre la menopausia. Clínica de la Concepción. Madrid, 1987

DI CORRADO D, DI NUOVO S et al. Quality of life in menopause. Experimental research. Clin Ter 2001; 152 (4): 235-240

DÍEZ MA, GLEZ-TABLAS M, LÓPEZ SOSA C et al. Incidencia y génesis multivariable de la depresión en la postmenopausia. Actas Luso-Esp Neurol Psiquiatr, 1995; 23 (4): 172-177

DÍEZ MA. Depresión climatérica y variables psicosociales. Tesis Doctoral. Universidad de Salamanca. 1994 
DOBS AS, NGUYEN $\mathrm{T}$ et al. Differential effects of oral estrogen versus oral estrogenandrogen replacement on body composition in postmenopausal women. J Clin Endocrinol Metab $2002 ; 87(4): 1509-1516$

DYCHTWALD K.Wellness and health promotion for the elderly. Rockville 1986; Aspen Publications

ECHEVERRI B., BUSTAMANTE C. La mujer ante la menopausia: acitudes, información y decisiones terapeúticas. Universidad Complutense de Madrid. Comunicación en VII Congreso de la ADEH. Granada, 2004

ERASMO. Elogio a la locura. Barcelona: Ediciones 29; 1993

ESTOK P., O'TOOLE R. The meanings of menopause. Health care for women international 1991; $12(15): 27-39$

ESPOSITO N. Agenda dissonance: inmigrant Hispanic women's and providers assumptions and expectations of menopause healthcare. Clin Nurs Res 2005;14(1):32-56

EWIES AA. A comprehensive approach to the menopause: so far, one size should fit all. Obstet Gynecol Surv $2001 ; 56(10): 642-649$

FELCE D, PERRY J. Quality of life: It's Definition and Measurement. Research in Developmental Disabilities, 1995; Vol. 16, № 1, pp. 51-74

FERNÁNDEZ VILLORIA Y COLS. Menopausia. Aspectos médicos y sociales. Schering España. Barcelona. 1989

FERRER, J., BOBES, J. Climaterio: Aspectos Ginecológicos, Psicológicos y Psiquiátricos. Oviedo, 1993; 31-39

FLINT M. The menopause: reward or punisment?. Psychosomatic, 1975; 15: 161-163 
FLUCK E et al. Cognitive effects of 10 years of hormone-replacement therapy with tibolone. J

Clin Psychopharmacol 2002; 22 (1): 62-67

FOTHERGILL J. On the management propper at the cessation of the menses. Medical Observations Inquiries, 1776; 5: 160-186

FREEMAN EW et al. Hormones and menopausal status as predictor of depression in women un transition to menopause. Arch Gen Psych,2004;61(1):62-70

FREEMAN EW et al. Symptoms associated with menopausal transition and reproductive hormones in midlife women. Obstet Gyncol, 2007;110(2):230-40

FREEMAN EW, SAMMEL MD et al. Symptoms in the menopausal transition: hormona and behavioral correlatos.Obstet Gynco, 2008; 111(1):127-36

FREIXA A. El impacto de la menopausia en la vida de la mujer. Reflexiones personales. Rev. Gerontol 1992; 4: 251-256

FREIXA A. La menopausia en el contexto de la mediana edad. Rev Gerontol. 1992; 4: 244-249

FUH JL, WANG SJ et al. Quality of life and menopausal transition for middle-aged women on Kinmen island. Qual Life Res 2003; 12 (1): 53-61

FUNDACIÓN JIMÉNEZ DÍAZ. El envejecimiento femenino saludable, un reto para el siglo XXI. Marzo, 2005.2 Disponible en http://www.fjd.es/Noticias/envejecimientofemenino.htm

GAFO J. La Iglesia Católica y la tradición cristiana ante al ancianidad. En: Ética y ancianidad. Madrid: Universidad Pontificia Comillas; 1995

GARCÍA RIAÑO D, IBAÑEZ E. Metodología de evaluación de la calidad de vida. En: Bobes J, Cervera S (eds). Psiquiatría: calidad de vida y calidad de asistencia. Barcelona: Menarini 1996; 79-109 
GARDANNE CPL. Sur les avis à donner aux femmer qui entrent dans l'àge critique.X: 11-42, $4^{\circ}$. París 1812, n 108, V, 90. Tomado de Index Catalogue of the Library of Surgeon-General's Office. U.S.A.: Armuy First Series Vol 5

GARDANNE CPL. Dissertation sur les avis a donner aux femmes qui entrent a l'Age Critique. (tesis Doctoral). París : Dodot Jeune, 1812

GATH D, ROSE N, BOND A, DAY A et al. Hysterectomy and psychiatric disorder: are the levels of psychiatric morbidity falling? Psychol Med, 1995; 25: 277-283

GEORGE SA. The menopause experience: a woman's perspective. J Obstet Gynecol Neonatal Nurs $2002 ; 31(1): 77-85$

GIRDLER SS, O'BRIANT C et al. A comparison of the effect of estrogen with or without progesterone on mood and physical symptoms in postmenopausal women. J Women Health Gend Based Med 1999; 8 (5): 637-646

GONZÁLEZ MERLO, J. Ginecología. Salvat, 1977

GRIGORIADIS S, KENNEDY SH. Role of estrogen in the treatment of depression. Am J Ther 2002; 9 (6): 503-509

GUILlET, JY., FENICHEL, P., GABAYDE, B., SOL, J.F.Menopause. París: Encycl Med Chir Gynecologiae. 1985; 38 A ( 10$): 6$

HALLSTROM T. Sexuality in the climateric. Clin Obstet Gynecol., 1977; 4: 227-239

HARLOW BL et al. Depression and its influence on reproductive endocrine and menstrual cycle marckers associated with perimenopause: the Harvard Study of Moods and Cycles. Arch Gen Psychiatry, 2003; 60 (1): 29-36

HELSON R., WINK P. Personality change in women from the eraly 40 s to the eraly 50 s. Psychol Aging, 1992; 7,1: 46-55 
HILDITCH JR, LEWIS J, ROSS AH et al. A comparison of the effects of oral conjugated equine and transdermal estradiol 17 - beta combined with an oral progestin on quality of life in postmenopausal women. Maturitas 1996; 24 (3): 177-184

HLATKY M, BOOTHROYD D et al. for the HERS Research Group. Quality of life and depresive symptoms in postmenopausal women after receiving hormone therapy. JAMA 2002; 287: $591-597$

HOLMES- ROVNER M, PADONU G et al. African-American women's attitudes and expectations of menopause. Am J Prev Med 1996 ;12(5):420-423

HOLTE A, MIKKELSEN A. Psychosocial determinants of climacteric complaints. Maturitas $1991 ; 13(3): 205-15$

HOLTE A. Longitudinal studies of the climateric-the South East England study. Data presented at the $6^{\circ}$ International Congress of Menopause. Bangkok, 1990

HUNTER MS. Mental changes: are they due to oestrogen deficiency?. En: Birkhäuser M, Rozenbaum H (eds). Menopause. París: Eska, 1996; 73-78

HUNTER MS. Predictors of menopausal symptoms: psychosocial aspects. Clin Endocrinol Metab 1993; 7 (1): 33-45

HUNTER, MS ET AL. Relationships between psychological symptoms, somatic complaints ans menopausal status. Maturitas, 1986; 8, 217-228

HUNTER, MS. Aspectos psicológicos del climaterio y la menopausia. En J.W. Studd y M.I. Whitehead. Menopausia, Ancora, Barcelona, 1990

HUNTER, MS.Psychological and somatic experience of the menopause:a prospective study. Psychosom. Med. 1990; 52, 357-367

HVAS L. Menopause women's positive experience of growing older. Maturitas, $2006 ; 54(3): 245-51$ 
JARKOVA NB, MARTENYI F et al. Mood effect of raloxifene in postmenopausal women. Maturitas 2002; 42 (1): 71-75

JASZMAN L. Epidemiology of the climateric complaints. Front Horm Res, 1973; 2: 220-234

JASZMANN L Y COLS. The perimenopausal symptoms. Med Gynaecol Sociol, 1969; 4: 268277

JEFFCOATE N. Ginecología. Editorial Inter-Médica.1971

JECKER NS. Envejecimiento social. La labor hospitalaria, 1997; 245 (3): 236-238

JIMENEZ J, PEREZ G. The attitude of the woman in menopause and its on the climateric. Ginecol Obstet Mex, 1999; 67: 319-322

KALACHE A., BARRETO SM., KELLER I. The demographic revolution in all cultures and societes. En: Age and Ageing. United Kingdom: Cambridge University Press; 2005: 30-46

KALACHE A., KELLER I. The greying world: a challenge for the $21^{\text {st }}$ century. Science Progress 2000; 83: 33-54

KALACHE A., KICKBUSCH I. A global strategy for healthy ageing. World Health 1997; 4-5

KALPAKJIAN CZ. Use of a standardized menopause symptom rating scale in a sample of women with physical disabilities.Menopause 2005; 12(1):78-87

KARACAM Z, SEKER SF. Factors associated with menopausal symptoms and their relationship with the quality of life among Turkish women. Maturitas, 2007;58(1):75-82

KARLBERG J, MATTSON LA, WIKLUND I. A qualitu of life perspective en who beneficits from estradiol replacement therapy. Acta Obstet Ginecol Scand 1995; 74 (5): 367-372

KAUfERT P, GIBERT P , TATE R. The Manitoba Project: a re-examination of the link between menopause and depression. Maturitas, 1992; 14 (2): 143-155 
KAUFERT,P. , SYROTUIK, J. : Symptom reporting at the menopause. Soc. Sci. Med., 1981; 15: $173-184$

KENDING H., HASHIMOTO A, COPPARD L. Family support for the elderly: the international experience. New York, Oxford University Press, 1992

KENEMAN P, van UNNIK GA et al. Perspective in hormone replacement therapy. Maturitas 2001 15;38 Suppl 1:S41-8

KHAN SA et al. Climateric symptoms in healthy middle-aged women. Br J Clin Pract, 1994; 48 (5): $240-242$

KINSEY Y COLS. Sexual Behavior in the Human Female. Londres: WB Saunders.1983

KITTEL LA, MASNFIELD PK. What perimenopausal women think about using hormones during menopause. Women Health 2000;30(4):77-91

KLAIBER EL et al. Estrogenic therapy for severe persistent depression in women. Arch Gen Psychiatr 1979; 36: 742-744

KORNAGA E. The effect of hormonal replacement therapy on symptoms of climateric syndrome and selected metabolic parameters. Ginekol Pol 2001; 72 (3): 113-120

KORNSTEIN SG et al. Self-reported premenstrual exacerbation of depressive symptoms in patients seeking treatment for major depression.Psychol Med,2005; 35(5):683-92

KRUSKEMPER G. Results of psychological testing ( MMPI ) in climateric women. En Van Keep y Lauritzen: Estrogens in the postmenopause,pp. 105-111. Basel Karger, 1975

KRYSTAL S, CHRIBOGA DA. The empty nest process in midlife men and women . Maturitas, 1979; 1, 215-228

KUKOPULOS A et al. Course of the manic depressive cycle and changes caused by treatments. Pharmacopsychiatry, 1980; 13: 1560-1567 
KUPPERMAN, HS., BLATT, MH., WIESBADE, H. Comparative clinical evaluation of estrogenic preparation by menopausal and amenorrheal indices. J Clin Endocr Metab. 1953; 13: 28-35

LAI JN et al. Quality of life and climateric complaints amongst women seeking medical advine in Taiwan:assessment using the WHOQOL-BREF questionnaire.Climacteric,2006;9(2):119-28

LAFOREST J. Introducción a la Gerontología. Barcelona: Herder, 1991

LANCHARES JL. Tratamiento Sustitutivo con estrógenos en la menopausia. An Med Intern $1991 ; 8(3): 35-42$

LANUSSA DG. Portal de las Organizaciones Geriátricas. Disponible en URL: www.geriatricas.com

LAURITZEN, C. El climaterio de la mujer. Monografía Laboratorio Schering. 1984

LEDESERT B, RINGA V, BREART G. Menopause and perceived health status among the women of the French GAZEL cohort. Maturitas 1994; 30: 113-120

LEGGETT D. The aging work force-helping employees navigate midlife. AAOHNJ,2007;55(4):169-75

LEWIN K. A dynamic theory of personality.McGraw Hill: New York. 1936

LIAO K, HUNTER MS et al. Beliefs about menopause of general practitioners and mid-aged women. Fam Pract $1994 ; 11(4): 408-412$

LIMOUTHIN- LAMOTE MA, MAIRON N, JOYCE CR, LE GAL M. Quality of life after the menopause: influence of homone replacement therapy. Am J Obstet Gynecol 1994 Feb;170(2):618-248

LINDH-ASTRAND L et al.Women's conception of the menopausal transition-a quality study. J Clin Nurs,2007; 16(3):509-17 
LLEDÓ E. El mundo homérico. En: Camps V. (ed). Historia de la Ética. Vol.1. Barcelona: Crítica, 1988

LOCK M. Hot flushes in cultural context: the Japanese case as a cautionary tale for the West. In Schömbaum E. (ed). Progress in Basic Clinical Pharmacology, vol.6. The climateric hot flush, $1991 ; 40-60$

LÓPEZ F, FUERTES A. Para comprender la sexualidad. Ed. Verbo Divino. Estella. Navarra 1989

LYNCH JW., SMITH GD., ET AL.Income inequality and mortality: importance to health of individual income, psychosocial environment and material conditions. British Med Journ 2000; 320: $1200-4$

LYNDAKER C, HULTON L. The influence of age on symptoms of perimenopause. J Obst Gynec Neonat Nurs, 2004;33(3):340-7

MAARTENS LW et al. Hormonal substitution during menopause: what are we treating? Maturitas 2000; 34 (2): 113-118

MACIAS FDEZ, JA: Trastornos psíquicos en la mujer. Universidad de Valladolid, 1996

MACÍAS JA. Trastornos psíquicos en la mujer. Universidad de Valladolid. 1996

MAGYAR Z. Treatment of menopausal symptoms-review of the current literatura. Orv Hetil,2006;147(19):879-85

MALLOL S. La exclusión globalizada, vejez divino tesoro. Disponible en URL: http:// www.agendadelasmujeres.com.sr/notadesplegada.php?id $=55$

MARAÑÓN, G. El climaterio de la mujer y el hombre. Madrid: Editorial Espasa Calpe. 1936

MARAÑÓN, G. La edad crítica. Estudio biológico y clínico. Madrid: Ed. Ruiz Hermanos. 1925, $2^{\mathrm{a}}$ ed., 1919 ( $1^{\mathrm{a}}$ ed. $)$ 
MARTIN- DU PAN RC, LUZUY F. What's new in hormone replacement for postmenopausal women? Advantages of hormone replacement therapy. Rev Med Suisse Romande 2000; 120 (6): $515-521$

McALLISTER M. Menopause: provinding comprehensive care for women in transition. Lippincotts Prim Care Pract 1998; 2 (3): 256-270

McCARTHY T. Menopause symptoms in Far Eastern countries-the Singapore segment. Data presented at the $6^{\circ}$ International Congress of Menopause. Bangkok, 1990

McKINLAY JB, McKINLAY SM, BRANBILLA D. The relative contributions of endocrine changes and social circunstances to depression in mild-aged women. J Health Soc Behav, 1987; 28: $345-363$

McKINLAY et al. The Masachussets Women's Health Study: a prospective investigation of the menopause. Data presented at the $6^{\circ}$ International Congress of Menopause. Bangkok, 1990

McKINNEY KA, SEVERINO M et al. Treatment-seeking women at menopause: a comparison between two university menopause clinics. Menopause 1998 ;5(3):174-177

MICHAEL CM. Further psychometric evaluation of older women. The effect of estrogen administration. J of Gerontology 1970; 25: 337

MILLER KJ, CONNEY JC et al. Mood symptoms and cognitive performance in women estrogen users and nonusers and men. J Am Geriatr Soc 2002; 50 (11): 1826-1830

MINOIS G. Historia de la vejez. De la Antigüedad al Renacimiento. Madrid, Nevea:2001

MISHRA GD et al. Physical and mental health:changes during menopause transition. Qual Life Res,2003;12(4):405-12

MONTERO I, RUIZ I. Depresión y menopausia. En: Leal C (coord). Trastornos depresivos en la mujer. Madrid. Masson: 1999 
MONTGOMERY JC et al. Effect of oestrogen and testosterone on psychological disorders in the climateric. Lancet, 1987; 297-299

MONTGOMERY JC, STUDD JW. Psychological and sexual aspects of the menopause. Br J Hosp Med, 1991; 45 (5): 300-302

MUÑOZ J. Psicología del Envejecimiento. Madrid: Pirámide, 2002

NAVARRO D. Factores relacionados con las características del syndrome climatérico en un grupo de mujeres cubana. Rev Cub Endocrinol 1999; 10(2):116-123

NELSON HD. Menopause. Lancet, 2008; 371:760-70

NELSON DB, SAMMEL DB et al. Effect of psysical activity on menopausal symptoms among urban women. Med Sci Sport Exercs, 2008; 40(1):50-8

NEUGARTEN BL et al. Womens attitudes toward the menopause. En: Neugarten BL ( Ed ). Middle age and aging. University Chicago Press, 1968

NICOL-SMITH L. Causality, menopause and depression: a critical review of literature. BMJ, $1996 ; 313(7067): 1229-1232$

NN.UU . United Nations Development Programme. Human Development Report 1994. Nueva York, Oxford University Press, 1994

NN.UU. World Population Prospects: The 2000 Revision; 2002

NORD E. Methods for quality adjustment of life years. Soc Sci Med 1992; 34:559-69

NORTH AMERICAN MENOPAUSE SOCIETY. A decision tree the use of estrogen replacement therapy or hormone replacement therapy in postmenopausal women: consensus opinion of the North American Menopause Society ( NAMS ). Menopause 2000 ;7(2):76-86 
O’CONNEL E. Mood,energy,cognition and physical complaints:a mind/body approach to symptoms management during the climateric. J Obst Gynec Neon Nur,2005;34(2):274-9

OVERMIER B.J, SELIGMAN M.E.P.Effects of inescapable shock and avoidance responding. Journ of Comp and Physyolog Psycholog 1967; 63:28-33

O.M.S. Global Commission on Women's Health. Women's Health: towards a better world. Geneva, World Healt Organization, 1994

O.M.S. Mujeres, envejecimiento y salud. O.M.S, 1998

OLAZÁBAL JC, PASTOR F et al. Adscripción a los diversos modelos de concebir la menopausia del personal sanitario de Salamanca. Cuadernos de Med Psicosom y Psiquiatr de enlace $2000 ; 53: 16-26$

OLAZÁBAL, JC., GARCÍA, R. La menopausia: una visión integral desde la Atención Primaria. Consejería de Sanidad y Bienestar Social. Junta de Castilla y León, 1994

OLDENHAVE A. Hot flushes and their relation to other symptoms: results from the third Ede study in the Netherlands. Data presented at the $6^{\circ}$ International Congress of Menopause. Bangkok, 1990

OMS. Envejecimiento activo: un marco político. Traducido por Dr.Regalado. Rev Esp Geriatr Gerontol 2002; 37: 74-105

OMS. Health Systems: Improving Performance.Ginebra: Organización Mundial de la Salud; $2000 \mathrm{a}$

OMS. Life in the $21^{\text {st }}$ Century: A vision for All. Ginebra: Organización Mundial de la Salud;1998

OMS. World Health Report, Database. Ginebra: Organizacion Mundial de la Salud; 1999 
OMS. Décima revisión de la Clasificación Internacional de las Enfermedades:descripciones clínicas y pautas para el diagnóstico. Madrid: Meditor, 1992

OMS. Investigación sobre la Menopausia. Informe del Grupo Científico de la Organización Mundial de la Salud, 1980; 7-25

OSBORN M. Depression at the menopause. Br J Hosp Med, 1984; 32 (3): 126, 128-129

OZKAN S. Women's quality of life in the premenopausal and postmenopausal periods.Qual Life Res,2005;14(8):1795-801

PALACIOS S, DE LA GÁNDARA J J. Depresión y menopausia: revisión de aspectos clínicos y terapéuticos. Monografía publicado por Juste, S.A.Q.F. 1998

PALACIOS S, MENÉNDEZ C. Tratamiento hormonal sustitutivo de las complicaciones psiquiátricas de la menopausia. Farmacología del SNC, 1988; 2 (4): 132-137

PALACIOS S. Coste / efectividad de la terapia hormonal sustitutiva en la menopausia. En: Palacios S. Menopausia y climaterio, Mirpal, Madrid, 1992

PALACIOS, S et al: Síntomas climatéricos en España. Comunicación personal, 1991

PALINKAS LA, BARRET-CONNOR E. Estrogen use and depressive symptoms in postmenopausal women. Obstet Gynecol 1992; 80: 30-36

PALENZUELA DL. Propiedades psicométricas de la Escala de Expectativas Generalizadas de Control Percibido. Comunicación presentada en el II Simposium de Metodología de las Ciencias Humanas, Sociales y de la Salud. Tenerife. 1991

PALENZUELA DL et al. Una versión española de una batería de escalas de expectativas generalizadas de control (BEEGC). Psicothema, 1997

PARRY B et al. Sleep,rhythms and women's mood. Part II.Menopause. Sllep Med Rev, 2006; 10(3):197-208 
PASINI W. Menopause et qualité de vie. Schweiz Rundsch Med Prax, 1997; 86 (33): 12641267

PATRICK DL, ERICKSON P. Assesing Health- Related Quality of Life for Clinical Decision Making. En: Walker S, Rosser R ( eds ). Quality of Life: Assesment and Aplication. Lancaster: MTP Press Limited, 1987

PAYER L. La menopausia en distintas culturas. En: Burger H y Boulet M. Perspectiva actual de la menopausia. Informe de expertos sobre estrategias médicas y terapéuticas para la década de los 90. Harofarma S.A. 1991

PEREZ J., BAYARRE H., NAVARRO D. El climaterio y la menopausia como expresión del envejecimiento femenino.Geroinfo 2007; vol.2 $\mathrm{n}^{\mathrm{o}} 1$

PERRONE G, CAPRI O. Attitudes toward estrogen replacement therapy. Study conducted on a sample population of women attending an ambulatory care center for the treatment of menopause. Minerva Ginecol 1993; 45 (12): 603- 608

PHAM KT, GRISSO JA et al. Ovarian aging and hormone replacement therapy. Hormonal levels, symptoms, and attitudes of African-American and white women. J Gen Intern Med $1997 ; 12(4): 230-236$

PLATÓN. La República. Santiago de Chile: Delfín; 1974

POPPER K. La responsabilidad de vivir: escritos sobre política, historia y conocimiento. Barcelona: Paidós, 1995

PRICES SL, STOREY S et al. Menopause experience of women in rural areas. J Adv Nurs, 2008; 61(5):503-11

RAERA J. Aproximación a la historia de la medicina. Cuba:Ediciones, 1982

RECASENS, J. Ginecología General. Madrid, 1913 
REED SD et al. Night sweats,sep disturbance and depression associated with disminshed libido in late menopausal transition and early menopause:baseline data from the Herbal Alternatives for Menopause Trial. Am J Obstet Gynecol,2007;196(6):593

RICHARDS $\mathrm{M}$ et al. Premenstrual symptoms and perimenopausal depression. Am Journ Psych,2006;163(1):133-7

RIBERA J C. El anciano desde el punto de vista biológico. Ética y ancianidad, 1995; 9: 29-40.

RIPLEY HS et al. The effect of treatment of depresion in the menopause with estrogenic hormone. Am J Psychiat 1940; 96: 905-915

ROHDE A. Importance of hormonal and psychosocial factors of depression in women. Forstchr Med,2007;149(24):25-8

ROTTER JB. Generalized expectancies for internal versus external control of reinforcement. Psycholog Monograph, 1966; 80:1-28

RYAN MM, DENNERSTEIN L, PEPPERELL R. Psychological aspects of hysterectomy: a prospective study. Br J Psychiatry, 1989; 154: 516-522

SAGSOZ N et al. Anxiety and depresión before and after the menopause. Arch Gynecol Obstet, 2001; 264 (4): 199-202

SANCHEZ J, DE LA GANDARA JJ et al. Utilidad de la terapia hormonal sustitutiva en los trastornos depresivos durante la menopausia :estado de la cuestión. An Psiquiat, 2003; 4

SATOH T,OHASHI K. Quality of life assessment in community dwelling, middle aged,healthy women in Japan.Climateric,2005;8(2):146-53

SCHOTTE CK et al. Construct validity of the Beck Depression Inventory in a depressive population. J Affect Disord 1997;46:115-125 
SCHNATZ PF et al. Pilot study of menopause symptoms in a clinic population. Menopause 2005;12(5):263-9

SCHEZ BORREGO, R. Perimenopausia: El climaterio desde su inicio. Schering España, 2001

SCHMIDT PJ, RUBINOW DR. Menopause-related affective disorders: a justification for further study. Am J Psychiatry, 1991; 148 (7):844-852

SCHMIDT J et al. A longitudinal evaluation of the relationship between reproductive status and mood in perimenopsual women. Am Journ Psych, 2004; 161(12):2238-44

SCHNEIDER HP. The quality of life in the post-menopausal woman. Best Pract Res Clin Obstet Gynaecol 2002; 16 (3): 395-409

SCHNEIDER MA. et al. The effect of exogenous oestrogens on depression in menopausal women. Med J Austr 1997; 2: 162-163

SELIGMAN M.P. Helplessness:on depression development and death. San Francisco: W.H.Freeman.1975

SETHI K, PITKIN J. British-Asian women's views on and attitudes towards menopause and hormone replacement therapy. Climacteric 2000;3(4):248-253

SHEPHERD M et al. Psychiatric illness in general practice. London, University Press, 1966

SOARES CN, ALMEIDA OP et al. Effciacy of estradiol for the treatment of depressive disorders in perimenopausal women: a double-blind, randomized, placebo-controlled trial. Arch Gen Psychiatry 2001; 58 (6): 529-534

SOARES CN, ALMEIDA OP. Depression during the perimenopause. Arch Gen Psychiatry, 2001; 58 (3): 306

SOMMER B, AVIS N et al. Attitudes toward menopause and aging across ethnic/racial groups. Psychosom Med $2000 ; 62(1): 96$ 
SPITZER WO. State of Science 1986. Quality of life and Functional Status as Target variable for Research. J Chron Dis, 1987; 40 (6): 465-471

STANDING TS, GLAZER G. Attitudes of low-incomes clinic patients toward menopause. Health Care Women Int 1992; 13 (3): 271-280

STEFFEN AM, THOMPSON LW. Physical and psychosocial correlates of hormone replacement therapy with chronically stressed postmenopausal women. J Aging Health 1999; $11(1): 3-26$

STEPHENS C, ROSS $\mathrm{N}$. The relationship between hormone replacement therapy for postmenopausal symptoms: no effects found in a New Zealand sample. Health Care Women Int $2002 ; 23(4)$

STOTLAND NL. Menopause: social expectations, women's realities. Arch Women Ment Health $2002 ; 5(1): 5-8$

STUDD, J., CHAKRAVARII, S., ORAM, D. El climaterio. Ginecología y Obstetricia. Temas actuales. 1977; 3

SYDOW R, REIMER C. Psychosomatic aspects of menopause. Review of literature 19881992. Psychoter Psychosom Med Psychol, 1995; 45 (7): 225-236

TATEBAYASHI Y. Perimenopausal and late life depression. Nippon Rinsho,2007;65(9):1694701

TAYLOR M. Psychological consuquences of surgical menopause. J Reprod Med, 2001; 46 ( 3 Suppl ): 317-324

TEJERIZO LC y COLS. Aspectos psicológicos y psiquiátricos del climaterio. Clin Invest Gin Obst, 1992; 7: 315-327 
THACKER HL. The case of hormone placement: new studies that should inform the debate. Cleve Clin J Med 2002; 69 (9): 672-673, 677-678

TILT, EJ: The change of life in health and disease. En: Churchill, J. Index Catalogue of the Library of Surgeon- Generalis Office. U.S. Army. First Series.Londres: 1857; $2^{\mathrm{a}}$ ed., vol 14, 307

TOLMAN EC. Purposive behaviour in animals and man. Century: New York. 1932

TREJO MATURANA C. El viejo en la historia. Acta Bioética, 2001; 7(1): 107-119

UNITED NATIONS. UNECE Ministerial Conference of Ageing. Council Economic and Social, 2008; United Nations

UNITED NATIONS. Second World Assembly on Ageing, Madrid 2002. Economic Comission for Europe,2002; United Nations

UTIAN WH. Menopause, hormone therapy and quality of life. En: Alan R, Liss (eds.) Menopause: evaluation, treatment and health concerns, 1989; 320: 193-209

UTIAN WH. The mental tonic effect of oestrogens administred to oophorectomized females. South Afr Med 1972; 46: 1079-1082

UTIAN, WH. The international Menopause Society menopause-related terminology definitions. Climateric 1999; 2: 284-286

VAN KEEP PA, PRILL HJ. Psychosociology of menopause and postmenopause. En: Van Keep PA y Lauritzen C. Estrogens in the postmenopause. From Hor Res, Kargel, 1975

VAN KEEP PA. The menopause. En: Dennerstein L. Y Burrows GD: Handbook of Psychosomatic Obstetrics and Ginecology. Elvesier, Amsterdam, 1983

VAZQUEZ C, SANZ J. Fiabilidad y validez factorial de la versión española del inventario de depresión de Beck.Barcelon:III Congreso de Evaluación Psicológica,1991 
VON GRUCHALLA B, HAHLWG-WIDMOSER B et al. Peri and postmenopausal changes: body awareness, sexuality and self-image of the middle age and older woman.Zentralb Gynekol $2003 ; 125(6): 202-8$

VON SYDOW K, REIMER C. Psychosomatic aspects of menopause: review of the literature 1988-1992. Psychother Psychosom Med Psychol 1995 ;45(7):225-36

WALASZEK P et al. Are the hormonal status or psychosocial conditions the major cause of female depressive disorders after menopause?. Ginekol Pol, 2006;76(10):788-98

WAGNER PJ, KUHN S et al. Age differences in attitudes toward menopause and estrogen replacement therapy. Women Health 1995; 23 (4): 1-16

WARE JE, SHERBOURNE CD. The MOS 36-item short form health survey (SF-36).Med Care, 1992;30:473-83

WARING M.Counting for nothing: what men value and what women are worth.United States of America: Allen and Unwin, 1988

WEINER B. Achivement motivation and attribution theory. General Learning Press, Morristown.NJ.1974

WEISMAN MM. The Mit. Of involution melancolia. JAMA 1979; 242: 742-744

WEISSMAN M, KLERMAN GL. Sex differences in the epidemiology of depression. Arch Gen Psichiatry, 1977 ; 34: 98-111

WHITEHEAD M, GODFREE V. Terapéutica hormonal sustitutiva. Ed. Española por CibaGeiby, 1992

WHOQOL Group. Study Protocol for the World Health Organization Project to Develop a Quality of Life Assesment Instrument ( WHOQOL ). Quality Life Res, 1994; 2: 153- 159 
WIKLUND I, BERG G, HAMAR M, KARLBERG J, LINDBERG R, SANDIN K. Long-term effect of transdermal hormonal therapy on aspects of quality of life in postmenopausal women. Maturitas 1992; 14: 225-236

WIKLUND I, KARLBERG J, MATTSON LA. Quality of life during transdermal oestradiol therapy in postmenopausal women. A double blind, placebo-controlled study. Am J Obstet Gynecol 1993; 168: 824-830

WIKLUND I. How to evaluate "quality of life" in the menopause. En: Birkhäuser M, Rozenbaum H (eds). Menopasue. Paris: Eska, 1996; 23-27

WIKLUND I. Methods of assesing the impact of climateric complaints on quality of life. Maturitas, 1998; 29 (1): 41-50

WILBUR J, MILLER A et al. The influence of demographic characteristics, menopausal status and symptoms on women's attitudes toward menopause. Women Health 1995; 23 (3): 19-39

WILBUR J et al. Menopausal transition symptoms in midlife women living with fibromyalgia and chronic fatigue. Health Care Women Int,2006;27(7):600-14

WILBUSH J. Surveys of climateric semeiology in non-Western populations: a critique. Maturitas, 1985; 7: 289-296

WILBUSH, J.: Trastornos climatéricos. Perspectivas históricas. En: Studd, J y Whitehead,M. Menopausia. Ancora, Barcelona, 1990

WILSON DH, TAYLOR AW, McLENNAN AH. Health status of hormone replacement therapy users and non-users as determined by the SF-36 quality of life dimension. Climateric $1998 ; 1: 50-54$

WINOKUR G. Depresión in the menopause. Am J Psychiatry, 1973; 130: 92-93 
WOODS NF, MARIELLA A, MITCHELL ES. Patterns of depressed mood across the menopausal transition: approaches to studying patterns in longitudinal data. Acta Obstet Gynecol Scan, 2002; 81 (7): 623-632

WOODS NF, MITCHELL ES. Anticipating menopause: observations from the Seattle Midlife Women's Health Study. Menopause 1999;6(2):167-173

WOODS NF, SAVER B et al . Attitudes toward menopause and hormone therapy among women with access to health care. Menopause 1998 ;5(3):178-188

WOODS NF et al. Depressed mood symptoms during the menopausal transition:observations from the Seattle Midlife Women's Health Study.Climateric,2006;9(3):195-203

WU, TANG, et al. Self-efficacy,health locus of control and psychological distress in elderly Chinese women with chronic illness. Aging and Mental Health, 2004

YOST, M. Psychology of climateric. Ed.Sciarra. 1990

YOST KJ et al. Comparing SF-36 scores across three groups of women with different health profiles.Qual Life Res,2005;14(5):1251-61

ZICHELLA L. The importance of life style after menopause. Int J Fertil Menopausal Stud 1995;40 Suppl 1:9-15 